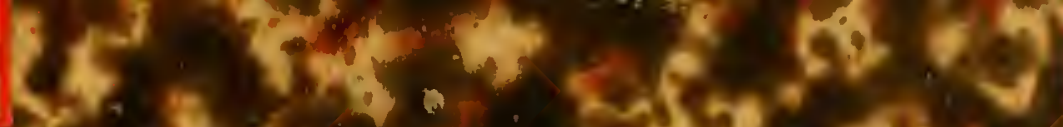

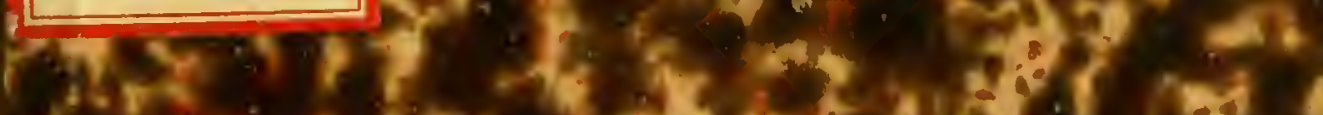

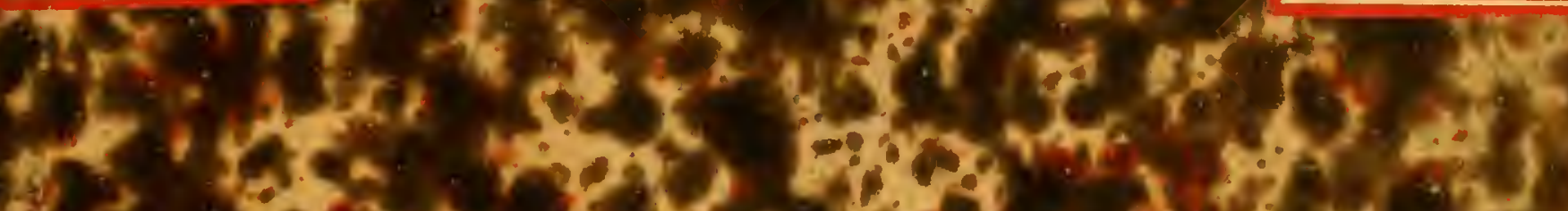

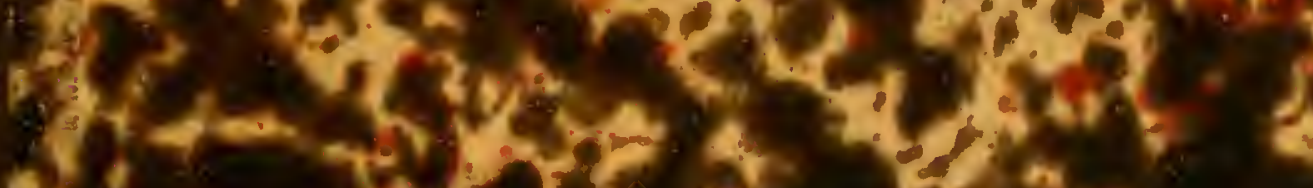

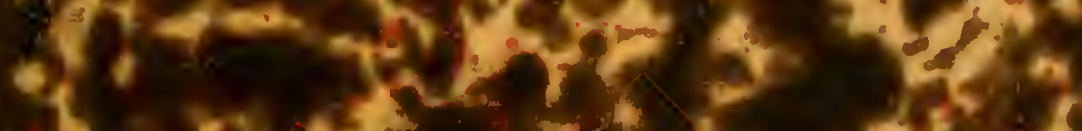

3. Wh

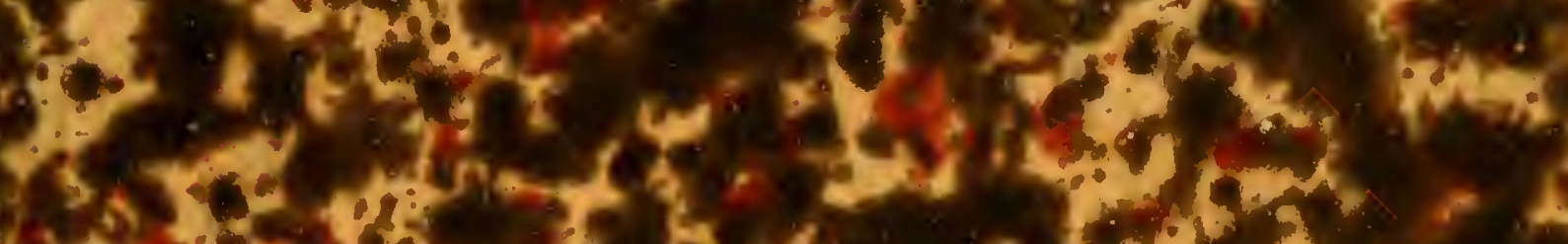

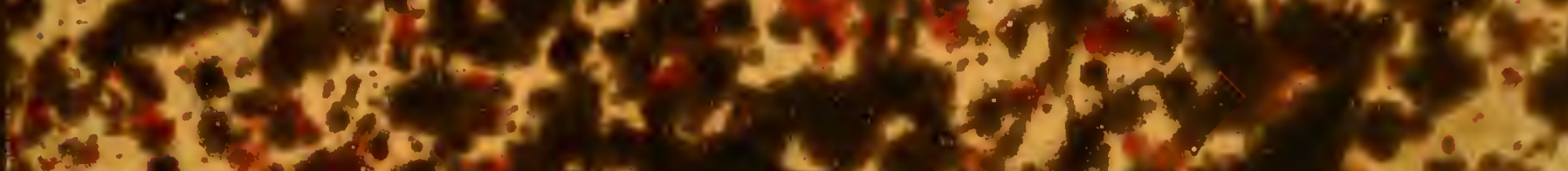

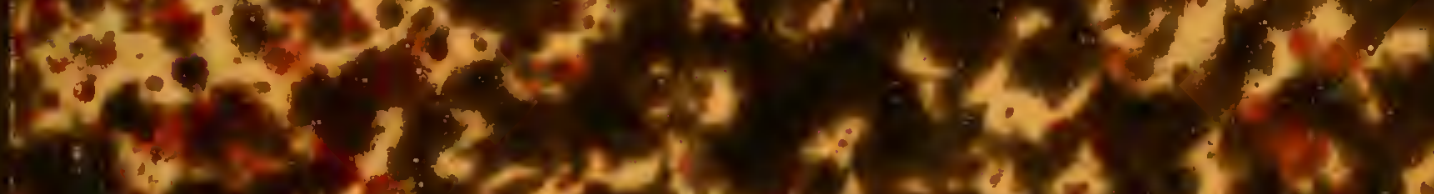

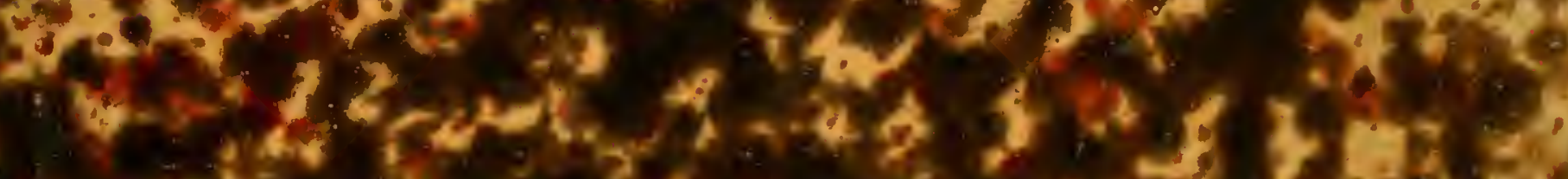

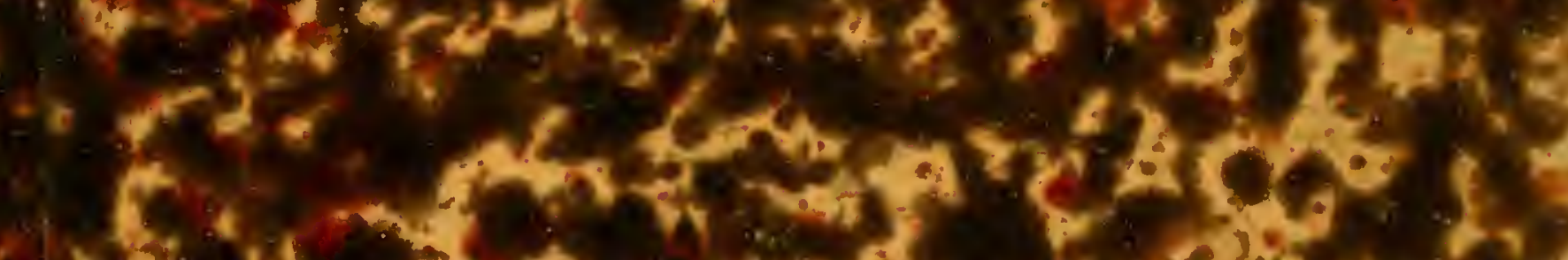

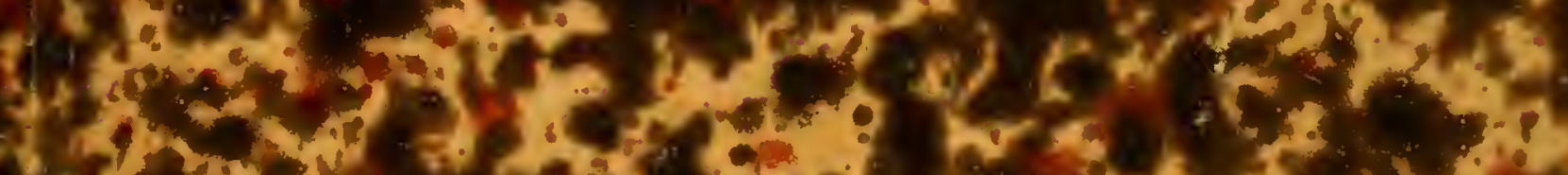

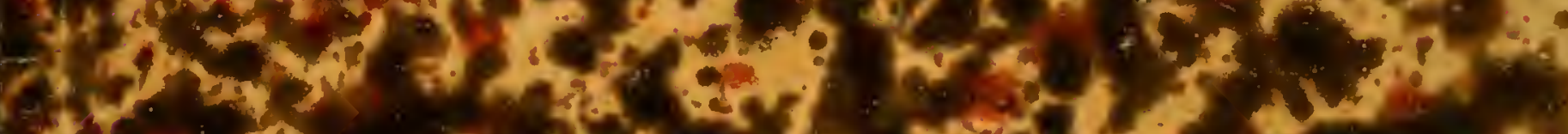

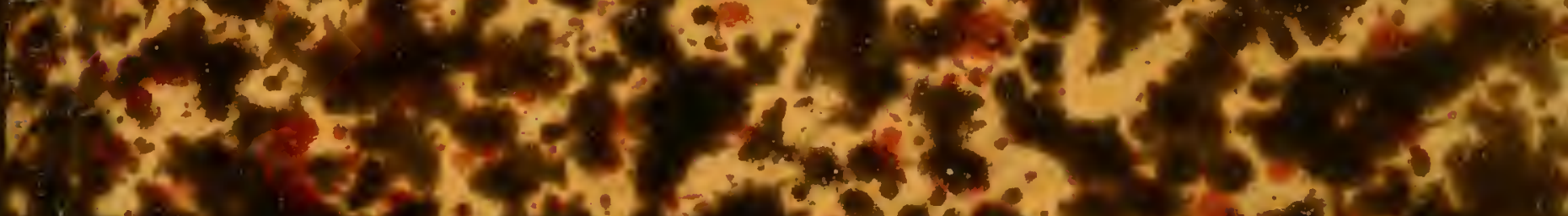

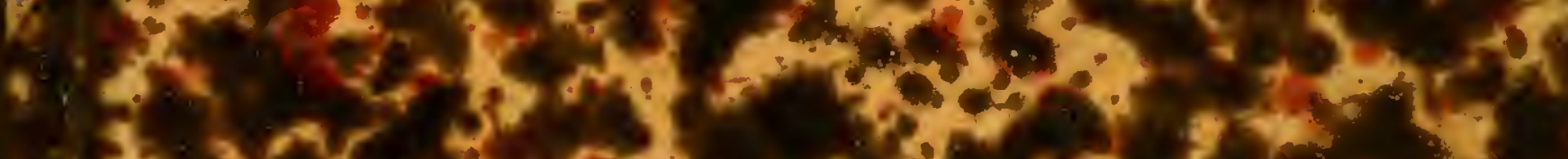

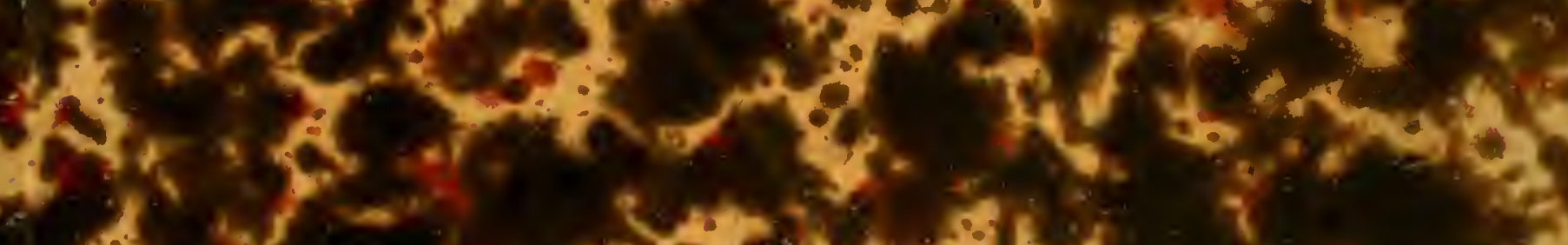
$42-7+2$ st 3

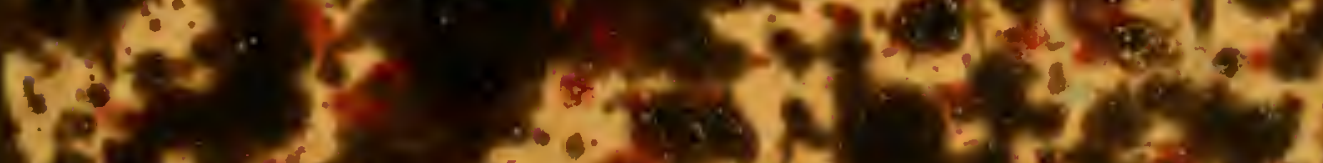

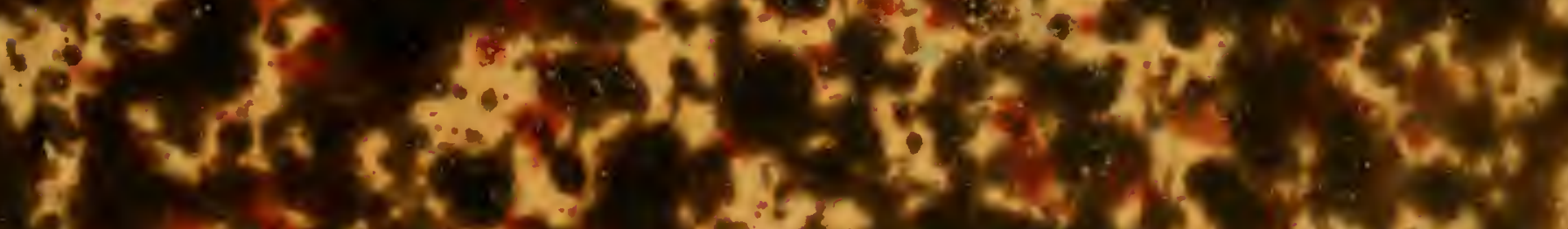




\title{
Soum Pasdine.
}

Marine Biological Laboratory WOODS HOLE, MASSACHUSETTS

\author{
IN MEMORY OF \\ Edward Gardiner Gardiner \\ $1854-1907$
}


Y̌rmon 


\title{
B e i träg e
}

7. II 1

\section{Naturgeschichte der 'Turbellarien}

In

\author{
Dr. Max Sigmund Schultze, \\ Proserter und l'rivatdorent \%n Greifswald.
}

Erste Abtheilung.

Mit siehen zmm Theil colorirten Kuplertatelu.

\section{Greifswald 1851.}

C. A. Koch's Verlagshandlutg.

(Theod. Kunike.) 


$$
3293
$$




\section{Vorwort.}

$\mathbf{N}$ gonnen, und bisher mit nur kurzen Unterbrechungen fortgesetzt worden. Besonders sind es die hleinen, den Rhabdocoelen angehörigen Formen gewesen, welchen ich meine Aufinerksamheit zuwandte, und ihnen ist der grösste 'Theil des F'olgenden gewidmet. Erst seit Kurzem hat man angefangen, gegründet auf mikroshopische Untersuchungen, den feineren Bau dieser hleinen, unsere Gewïsser in zahlreichen Arten bevölkernden Thiere darzılegen, die Species genau zu unterscheiden, und iibersichtliche Zusammenstellungen derselben zu versuchen. Nach dem Vorgange von Dugès und Elwenberg sind es $\ddot{O}_{\boldsymbol{r}}$ sled und besonders $\boldsymbol{O}$. Schmidt gewesen, welche hier Bahn gebrochen haben. Jeder dieser Forscher ist durch Auffindung interessanter anatomischer Thatsachen, nener Gesichtspunte für die systematische Uebersicht nnd vieler noeh unbeschriebener Arten reich belohnt worden. Auch mir hat, begïnstigi durch den Aufenthalt in einer sowohl an stehenden Gewïssern reichen, als auch der Ostsec benachbarten Gegend, ein bedeutendes Material vorgelegen, und ich überlasse es dem Urtheil der Sachverstiindigen, ob es mir gelungen, in Folgendem dasselbe zum Nutzen der Wissenschaft zu verwenden. Von den vielen von mir aufgefundenen neuen Species habe ich nur erst den kleineren Theil beschricben. Ich zog es zuniichst vor, wo ich honnte, die Lü̈chen in schon vorhandenen Beschreibungen zu ergïnzen, oder Uurichtigkeiten derselben zu verbessern. Line zweite Abtheilung wird als Fortsetzung der vorliegenden bald nachfolgen.

Der histologische Theil ist der jüngste der Albcit. Die rhabdocoelen Turbellarien besitzen die homogene Körpersuhstanz der Infusorien. Die Differenzirung von Haut, Muskel, Nerr etc, welche bei letzteren noch ganz zurïchsteht, hat hier zwar begonnen, ist aber auf niederer Stufe stehen geblieben. Bei den 
grossen Schwierigkeiten, welche die Untersuchungen derartiger Gewebe darbieten, muss ich für diesen 'Theil vor Allem um Nachsicht bitten.

Dass einzelne Untersuchungen über die che mis ch e Zusammensetzung der Gewebstheile nicht ohne Erfolg für die vergleichende Physiologie geblieben sind, wird unter Anderem der bestimmte Nachweis ron Chlorophyll im Parenchym einiger 'Turbellarien und anderer niederer Thiere zeigen.

Die Abbildungen, welche dieser Abtheilung beigegeben sind, sollen, denk' ich, einem Bedürfniss abhelfen. Durch die Liberalitït des Herrn Verlegers war ich in den Stand gesetzt, dieselben von anerkannten Künstlern in Kupferstich ausführen zu lassen. Wenn Einiges auf denselben nicht den gewünschten Grad der Vollkommenheit erreicht hat, so ist zum Theil meine Entfernung von dem Stichund Druck-Orte Schuld, welche die bei dergleichen Arbeiten so wünschenswerthe Beaufsichtigung unmöglich machte.

Schliesslich erfïlle ich die Pflicht, meinem Vater, welcher an allen Beobachtungen Theil genommen, für die Anregung, für seinen Rath und für die Erlaubniss, ein der hiesigen Küniglichen anatomischen Anstalt gehöriges, ausgezeichnetes, grosses Plössl'sches Mikroskop stets benutzen zu dürfen, den innigsten Dank abzustatten.

Greifswald im Nai 1851. 


\section{Inhaltsverzeichniss.}

Eimleitumg.

r. Ueber die Organisation der rhabsloeoelen Turbellarien im Algemeinen, besonders in histologischer Beziehung is

Allgemeine Körperlsedeckung . . . . . . . S S

Stäbchenfürmige Kürper . . . . . . . . . 11

Pigmente unter der Haut . . . . . . . Ji

Mnskeln und Parenchyn . . . . . . . . . . . I9!

Nervensystem . . . . . . . . . 21

Sinnesorgane . . . . . . . . . 23

Wassergefässystem . . . . . . . . 27

Verdaumgsapparat . . . . . . . . . . . .

Geschlechtsorgane . . . . . . . . . . . . . . . . . .

II. Gpecielle Beschreibung ler beobachteten Arten . . . :

Fam. Opistomea.

Monocelis Örst. . . . . . . . . . . 34

Monocelis agilis nov. spec. . . . . . . 37

Monocelis unipunctata Örst. . . . . . . . . . 38

Monocelis lineata Örst. . . . . . . . . . . . . 3!

Opistonum Schm.

Opistomum pallidum Schm. . . . . . . . 40

lim. Derostomea. . . . . . . . . . . . 43

Vortex lirlog.

Vortex viridis mihi . . . . . . . . 47

Vortex balticus noc. spec. . . . . . . . is

Vortex pellucidus nov. spec. . . . . . . . . . 4! 
berustomum ij,st.

Pag.

Derostumum Schmidtianum mili . . . . . . 50

lim. Mesostomea. . . . . . . . . . . . . . . . . .

Mesostonum ohtusum nor. spec. . . . . . . . . 5t

Mesostomum marmoratun mor. sprec. . . . . . . 54

Fum. Sclizostomea . . . . . . . . . . . . 5.5

Macrostommu Öjst.

Mlacrostomum hystrix Örsl. . . . . . . . . Hi

Macrostomnm auritum nor. spec. . . . . . . . 55

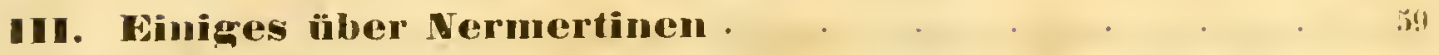

Prorhyuchus stagnalis nor. gen. nor. spec. . . . . (ill)

Tetrastemma olsscurmu noo. spec. . . . . . . . li.?

IV. Ueber Eutazoen in Turbellarien. . . . . . bi

Resultate .

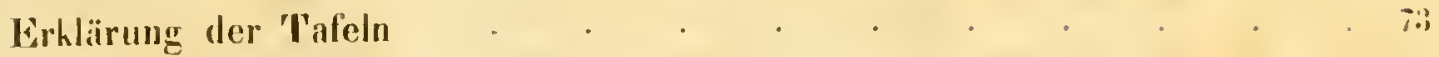




\section{Einle itung.}

() ie klasse der Tnrbellarien umfasst diejenigen ungegliederten, borstenlosen Würmer; welehe auf ihrer ganzen Oberlliche mit Wimpern bedeckt sind. Dieselben waren bei den Aelteren in der Gattung Planaria vereingt. Bei einer bald platten bald rundlichen Gestalt, einer weiclıen, jeder festen Stütze entbelırenden líörpersubstanz haben sie ein dentliches Nervensystem, welehes aus zwei in vorderen lï̈rpertheil gelegenen Ganglien besteht, die dureh eine oder zwei Brïcken mit cinamler verbunden sind, und Nervenfïden nach mehreren Richtungen aussenden ${ }^{1}$ ). Augen sind bei ihnen als dunkle

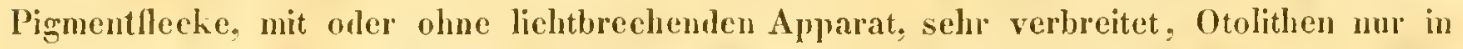
eimzelnen Fillen vorhanden. Ein mehr oder weuiges ausgebildetes IIuskelsystem dient zur liewegung des lïrpers. Ein Verdanmngskanal, häufig baumfürnig verzweigt, mit einer oder zwei Oeffunngen, nimmt cinen grossen Theil des Kürpers ein, der ausserdem noch bei Vielen vou $W$ assergefäss ver istelungen nach allen Richtungen Iurehzogen ist, welche mittelst einer oder mehrever Oeffuungen an ler Oberfliche des lï̈pers münden²). Geschlechtsorgane sind bei Allen vorhanden, mämbliche und weibliche entweder in einem lndividum vereinigt oder anf verschiedene vertheilt.

Sie leben mit wenigen Ausnahmen frei im Wasser.3).

Der Erste, weleher die hierhergehörigen Arten zusammenfasste, ist O. Fr. Müller. Er gründete in seiner Zoologia Danica ${ }^{4}$ ) dic Gattung Planaria, und hesehrieb eine seln bedeutende Menge von dänischen See- und Süsswasserformen. $v$. Bacr.5) und Dugìs6) waren die Ersten. Welche an den grösseren Arten den inneren Bau, soviel

1) Das Nervensystem ist ron mir in den Familien der Opistomeen, Derostomeen, Mesostomecu, Prostomeen und Schizostomeen beschrieben.

2) Ueber das Gefisssystem der Nemertinen siehe unten.

3) Ol die priichtigen tropischen Landplanaricn Darwin's (Magaz. of nat. hist. XIV. pag. 24-2 fi.), welche aul feuchter Erde unter Baumstimmen gefunden wurden, so wie die Planaria terrestris O. Fr. Mïller's (Verum. terr. et fluviat. hist. I. 2. pag. 68), welche auch Dugès salı (Ann. d. sc. nat. 1 Ser. XXI pag. S... Tah. II. IS), ebenfalls wimpern, ist, son ie dic gesammte imnere Organisation dieser merkwïrdigen Thiere, noch unbekannt.

4) Prodromus Zoologiae Hanicac 17\%6. pag. 221. Zoologia Danica 1755-1806.

5) Nora Acta Acat. Caes. Leop. 1827 Vol. 13 Abth. 2. pag. 690.

6) Annales d. scienc. nat. I Ser. 182S Tom. XV. pag. 139. 1830 Tom. XXI. pag. 72. 
sich mit blosssem Auge und mit schwachen Vergrösserungen ausrichten liess, mit Glück darlegten, letzterer lehrte auch die nit unermüılichem Eifer gesammelten kleinen Formen 1 ach der Lage des Mundes in Unterabtheilungen bringen. Seine Gattungen Prostoma, Derostoma, Mesostoma liegen den jetat noch gebrïuchlichen gleichnamigen zu Grunde. Das Mikroskop wurle jedoch erst von Khrenbery ${ }^{1}$ ) nit Erfolg zur Erkemung der sehr zusammengesetzten Organisationsverhälnisse der kleineren Arten angewandt, wïhrend bei unseren grüsseren Süsswasserplanarien Fr.Schuls $e^{2}$ ) die ersten gründlichen nikroskopischen Untersuchungen ïber den feineren Bau anstellte.

Elnenberg war es auch, welcher die Klasse der Turbellarien gründete. Er stellte in diesellye die Gattungen Planaria O. F. Miller, Neuertes Cuier, Nais und Goddius O.Fr. Müller, und theilte sie in zwei Orduungen, Dendrocoela nit verzweigtem Darm und Rhabdocoela mit unverzweigten, gralen Darm. Frstere Ordnung unfasste die eigenlichen Planarien, und ist bis auf die neuste Zeit in dem ihr damals beigelegten Sinne beibehalten. Von Oersted's ${ }^{3}$ Versuch, sie in Cryjtocoela und Dendrocoela zu zerfïllen, werde ich später handeln.

Die Rhabdocoelen Ehrenberg's waren ein Gemisch ron kleinen Planarien (den Dugès'schen Gattungen Derostoma, Prostoma u. n. A., den Rhabilococlen der Neueren), einigen Dendrocoelen (z. B. Leptoplana) und den Nemertiuen mit Naidinen und Gordieen. Letztere mussten die einen den Borstenwüımern, die andern den Nematoideen zugewiesen werlen. Die Nemertinen wurlen dann von Oersted unl den meisten späteren Zoologen als eigene Abtheilung den Dendrocoelen und Rhabdocoelen beigcorduet.

Somit funden wir jetzt die lílasse der Turbellarien 3 Ordnungen umfasseu: I) Dendrocoela; 2) Rhabdocoela; 3) Nemertina.

Der Darm derer, welche den ersten beiden Ordnungen nngehören, ist ohne After, bei den Dendrocoelen verzweigt, bei den Rhabdocoelen ein einfacher Blindsack. Die Nemertinen sind dagegen mit einem After versehen, und zeichuen sich dureh einen hïssel aus, weleher den anderen beirlen Ordnugen fehlt. Es fanden sich jedochzu den Rhabdocoelen einige kleine, ebenfalls nit einem After versehene Turbellarien ein. Es sint dies die Mikrostoneen Oerst. und Dinoplilus Schmidt. Dicselben den Nenertinen zuzurechnen, war, weil ilnen der für erstere charakteristische Rüssel fehlte, nicht möglich. Dendrocoelen und Rhabdocoelen sind hermapliroditiseh, die Mikrostonecn und Dinoplilus rlagegen getremnten Geschlechts, ebenso wie die Nemertinen. Dieses Verhalten der Geschlechtsorgane, sowie das eben erwähnte

1) Symbolae pliysicae. Decas I. Phytozoa Turbellaria.

Abliandl. d. Acal. d. Wiss zı Berliu. 1835. pag. 178. Tal. I. fig. 2. 3.

2) De Planariarum vivendi ratione et structura penitiori nonnulla. Diss. inaug. Berol. 1830.

3) Entwurf einer systematischen Eintheilumy und speciellen Beschreibung der Plattwürmer. Kopenhagen. 1844. pag. 38. 
des Darmes reranlasste mich in einem Aufsatze „Ucber die Mikrostomeen“ in dem Archiv für Naturgesehichte herausgeg. von 'Troschel 1S19 pag. 250 eine Trenumg der Turbellarien in 2 Unterklassen, der hermaphro a i tischen mul der eingeschlechtichen vorzusehlagen, und letzteren neben der Ordnung ter Nemertinen noch als bes ondere Ordmung die Mikrostomeen und Dinophilns unter ılem Namen der Arhynchia (Riissellose) im Gegensatze zu den Nemertinen, den Rhynchocoela, unterzuordnen. hulem ich jetzt bei dem gewiss rchtigen Prineip, die Tubellarien nach dem Verdaunngsapparat abzutheilen, für die Bezeiehnung der Unterklassen die nach der $\mathbf{A b}$ - oder Auwesenlıeit des Afters für passender halte, als die nach den Geschlechtstheilen; so nehme ieh die von Diesing ${ }^{1}$ ) für Unterabtheilungen der hluabdocoelen gebilıteten Namen der $\Lambda_{j}$ rocta und Proctucha, welche sich in der Diesing'schen Weise nicht festhalten lassen, zur Bezeichnung der Unterklassen der Turbellarien überhapt auf.

Somit würde sich jetzt die Eintheilıng folgendermaassen gestalten:

\section{Classis. Turbellaria.}

\section{Subclussis Aprocta.}

1. Ordo Dendiocoela.

2. - Rhabdocoela.

II. Subclassis Proctucha.

1. Orelo Arbyuchia.

2. - Rhynchocoela.

(Nemertina).

Was die Eintheilung dieser Ordnungen in Familicn betrifft, so sind solche bei den Dendrocoelen, anch Plan arien im engeren Sinne genannt, bisher nicht aufgestellt worden, Diesiug's Abtheilungen nach den 'Tentakeln ausgenommen, welche mir jeloch nicht röllig branchbar zn sein scheinen. da offenbar Planarien von sehr verschiedener Organisation umatïrlich vereinigt sind z. B. in sler Tribus der Ceridea, d. l. der mit Tentakeh versehenen, die Planaria torva, lactea mit den Seedendrocoelen Eurylepta und Thysanozoon.

Oersted hatte sich veranlasst geschen, den grössten Theil der marinen Planarien unter dem Namen der Crgptocoela einer anderen Ordnung, welche vorzugsweise Süsswasserformen enthielt. und denen der Name der Dendrocoela allein verblieb, ge. genüber zu stellen. Erstere, mit ebenfalls verzweigtem Darm, sollen durch eine eigenthümliche Mnndüffnung: welclıe in einzelnen grossen lappenartigen Tentakeln ausgestülpt werden kanı, ausgezeichnet sein. Aus den genauen Quatrefages'schen Beschreibungen und Abbildungen vieler in Mittelneere beobachteter planarien'2) geht jedoch hervor, dass diese Nlundlappen dureliaus nicht allgemein den marinen Formen zukommen, eine Abtheilung in Oersled scher Weise also nicht, auf dieselben gegrünlet werilen kanu.

Es scheinen mir aber andere bisher noch nicht lunrcichend gewürdigte Unter-

1) Systema helminthum. Wien 1550 Vol. I. pag. 181.

2) Mémoire sur quelques Planariées marines. Ann. d. sc. nat. 3 Ser. Tom. IV. pag. I54. 
schiede zwischen den Cryptocoelen und Dendrocoelen Oersted's obzuwalten. Diese liegen in der Auordum,g ler Geschlechtstheile uml in der Entwickelung. Unsere Sïsswasser-Planarien, Jenen die aus dem Meere stammenden Planaria affinis und Plan. ulvae Derst., welehe ich aus eigener Anschauung kenne, in Bezug auf ilure innere Organisation durchans gleichen ${ }^{1}$ ), lıaben cine cinfache Geschlechtsöfnung, in welche mämmliche und weibliche Organe eimuïnden, der verzweigte Dotterstock enthält keine Eikeime. Sie legen hartsehalige Eierkipseln, in welelıen sich I0-14 Embryonen entwickeln. welche las Ei in einer der der Erwehsenen gleichenden Gestalt verlassen. Die marinen Planarjen von Ruatrefuges haben dagegen doppelte Geschlechtsölfnungen: Dotterstock und Kieinstuck scheinen bei ihncn nicht getremt zu sein, da viele ans Dotterkügelchen und límblïschen bestchende Eier in Körper verbreitet gefunden wurden. Dic Jungen entwickeh sieh wahrscheinlich schon in den Eileitern zu beweglichen Embryonen, welehe später im Meere schwïmend in überraschender Weise cine Metamorphose durchmachen, welehe von $J$. Miiller kürzlich in Triest an den Jungen cincr noch mbekamiten Planarien-species verfolgt worden ist ${ }^{2}$ ).

Diese Untersehiede im Bereiche der Dendrocoelen scheinen mir wesentlich geung, um später eine Eintheilung auf dieselben gründen zu können, bei welcher die Beschaffenheit der Mundïffnung jerloch nicht vermachlässigt werdeı darf.

Die Rluabdocoelen Elrenberg's wurden von Oersted ${ }^{3}$ ), nachdem er die Naidinen, Gordieen unl Nemertinen ausgeschlossen lıtte, in 4 Fanilieu getheilt, welehe zum Theil deı oben genamten, von Dugès eingesetzten Abtheilungen entsprachen. Diese waren die Prostomea mit vorrerer, terminaler Mundöfnumg, die Derostomeae mit tomnenfïrmigem Munde in der Nïhe des vorderen Kürperendes, die Mesostomeae mit ringfürmigem Munde in der Mitte orler nahe der Mitte des Körpers, und die Microstomeac mit kleinem rumlen, (nicht ausstülpbarem) Mumde ebenfalls in der Nihe des vorderen lï̈rperendes. (). Schmidt hat in seiner schönen Monographie: ,Die rhabdocoelen Strudelwürmer les sïssen Wassers, Jena 18tS, durch welehe über die bis dahin nur obcrllïchlich untersuchten anatomischen Details zum Theil ein sehr helles Licht verbreitet wurle, und in weleher viele neue Species beschrieben sind, diese Eintheilung etwas verandert. Die Prostomeen und Derostomeen sind dieselben geblieben, aber von den Mesostomeen wurde die Gattung Macrostomum. mit schlitaförmigem, in rorderen Küpertheil gelegenen Munde abgezweigt, und einer eigenthïmlichen Familie, „en Schizostomeae, eingereilıt. Einc zweite neue Familie, die

1) Da die Gattung Mnnocelis zu den Rhabdocoelen gehürt, wie unten ausführlich gezeigt werden wird, und Telostoma Oerst. noch so gut wie ganz unbekannt ist, so bleihen deu Dendrocoelen Oersted's nur die Sïsswasserarten nd die beiden elsen genaunten Planarien aus der Ostsee.

2) Milller's Archiv. 1850 pag. 455.

3) Entwurl einer systemat. Einth. etc. 1844. pag. 60. 
Opistomeac, wude für eine bisher mbekannte Species mit folgender Charakteristik aufgestellt: , Mmml tommenfürnig im Ilintertheile des Köruers." Die Mikrostomeen verblieben als letzte Familie den lihabdoenelen, wie bei Ocrsled.

An dieser Eintheilung lube ich, mit Ausuahme dass die Mikrostomeeu, als den lihabdocoelen nieht angehürig, abzuzweigen sind, keine Verïnlerung zn treften. Die Reihenfolge Jer Familien möchte ich jedoch dahn abïnderu, dass die 0 pistomeen an die Spritze der lihabdococlen treten, weil sie sich in ler Form ihres Mundes (oder besser ihres Schlundes) den Demhoeoelen nähern'). Diesen lasse ich dic Derostomeen folgen, weil sie sich am leiehtesten ansehliessen, dam die Prostomeen, Mesostomeen und endlich die Sehizostomeen, welehe den Uebergang zu Jer folgenten Abtheilung, den Turbellariis Proetuehis, billen ${ }^{2}$ ).

Ich lasse die systematis ehe Uebersieht der lhabdocoelen mit der Characteristik der Familien naeh der Iage und Form des Mundes und Schlundes folgen.

\section{Rhabdocoela.}

1 Fan. Opistomea. Mnndöfnung im hiuteren Körpertheil gelegen, Schlund. sehlanchförnig wie bei den Dendrocoelen.

2 Fan. Derostomea. Mundöflunng etwas hinter dem vorderen Körperende, Sehlund tommenförmig.

3 Fan. Prostomea. Mundüfimng am rooderen Körperende. Schlum röhrenförmig, aus mehreren Abtheilnngen bestehend, einer vorderen, innen mit Papillen besetzten, einel zweiten musknlösen, dickwandigen, und einer dritten dünwwandigen. einem Oesophagus vergleichbaren.

4 Fam. Mesostomea: Mundöfliung in der Mitte oder nalı der Mitte des Kürpers. Schlund ringförmig, einem Sauguapf ähnlieh.

5 Fam. Schizostomea. Nund eine Lüngsspalte nahe dem vorderen Kïrperende. Ein muskulüser Sclılund fehlt.

Diesing ${ }^{3}$ ) reehnet, wie rordem Ehrenberg, die Nemertincu wieder zu den Rhabdocoelen, und theilt demgemäss letztere in die Gyratricinea, dic Rhablocoelen d. Neueren, und die Nemertinen. Erstere zerfällt er vieder in solehe ohne

1) Den Schlund des Opistomum pallidum Schmill finde ich nicht tonnenfïrmig, wic bei den Derostomeen, sondern schlauclifiormig; ebenso bei Mlonocelis, welche Gattung als den Rhabdocoelen angehürig keine bessere stelle als neben $O$ pistomum finden kann. Auch Pseadostomum faeroense Schm. wahrscheinlich identisch mit Vortex quadrioculatus Leuck. wïrde hier uuterkommen köunen.

2) Die Familie der Schizostomeen schliesst offenbar sehr verschiedene Thiere in sich. Schizostomum Schm. ist in Bezug auf die Geschlechtstheile ganz nach dem Mesostomeentypus gehaut, Macrostomu zeichnet sich vor allen übrigen Rhabdocoelen JaJurch aus, dass Keinstock und Dotterstock vereinigt sind wie bei den l'roctuchis.

3) Systema helmiuthum pag. 218. 
After und solche init After. Die Aprocta entsprechen meinen Rhabdocoela, die Proctucha umfissen die Microstomeen und Dinophilus nebst einigen zweifelhaften Gattungen. Eine lintheilung in Fanilien fiudet sich bei Diesing nicht, seine Gattungen Turbella, Gyrator, welche von Elvenberg entlehnt sind, umfassen jede für sich Species der verschiedensten Familien. -

Ieh komme jetzt zu den Turbellarja proctucha. Die erste Ordnung derselben, die Arlynchia, habe ich ausführlich in meinem Aufsatze über die Nlikrostomeen in dem Archiv für Naturgeschichte $18-19$ pag. 280 abgehandelt, und verweise ich desshalb auf denselben. Die dieser Ordnung angelı̈rigen Thiere sind ausgezeichnet durch den graden, mit einem After versebenen, rüssellosen Darm, weleher in der Nähe des vorderen Kürperendes mit einer sehr austehmbaren Mundöffnung beginnt, und sich bis zum hinteren Ende erstreckt. Sie sind getrennten Geschlechts, einzelne pllanzen sich auch rlurch Theilung fort. Ausser den Microstomeen enthält diese Ordnung nur noch die Gattung Dinophilus.

Die Nemertinen oder Rhynchocoela endlich sind zwar in Familien vertheilt worden, doch lassen sich dieselben nicht aufrecht erhalten. Die so verschiedene Deutung des als Rüssel aufzufassenden Organes, welcher bald als penis. bald als Darm, selbst als Eingeweidewurm (Voyage de l'Astrolabe. Zoologie. Zoophytes pag. 289. Cit. nach Oerstell) beschrieben wurde, sowie die noch fehlende genane Kenntniss einer hinreichenden Menge von Arten hinderte dieAufstellung durchgreifender Principien für die Classification. Oersted, so viel ich weiss der Erste, weleher eine übersiehtliche Zusam menstellung der Arten versuchte, trennt nach der Lage des Muntes die mit subterminaler Mundiofnung als Nemertina im engeren Sinne von den Amphiporina mit terminaler Numbiffnung (letztere Familie mit eimer einzigen Species). Seine Eintheilnng in Unterfamilien nach der deutlicheren oder weniger deutlichen Abgrenzung eines Kopfendes, dem Vorhandensein oder Fehlen der sogenannten Respirationsspalten, lässt leider nirgends selarfe Grenzen zu. So wenig wir Planaria gonocephala mit deutlich abgegrenztem Kopfe in eine andere Familie als Plan. torva, weleher diese Auszeichnung fehlt, bringen künnen, so unhaltbar scheint mir auch für die Eintheilung der Nemertinen ersteres Merkmal. Die Organe in dem Kopfende sind immer dieselben, mag aussen eine deutlichere oder weniger deutliehe $\Lambda$ hgrenzung vorhanden sein. Die zwei kleinen mit längeren Wimpern besetzten Grübchen. welche Oersted Respirationsspalten nennt, sind bei undurchsichtigen Arten sehr leieht zu übersehen, und eine Eintheilung nach dem Vorhandensein oder Mangel derselben scheint mir nieht eher durchführbar (wenn überhaupt passend), bis wir über das Vorkommen oder Felılen derselben genauere Angaben erhalten.

Qnatrefayes, der in einer ausgezeichneten Arbeit über einige Nemertinen des atlantischen und Mittelmeeres (Ann. d. se. nat. 3 Ser. Tom VI. pag. 173) die Organisation derselben theilweise sehr genau kennen lehrte, hat den Rïissel für den Darm gehalten. während er I’n Vordanmgskanal allgemeine Kïrperlı̈̈lle nennt. Mundöfnung 
ist bei ihm diejenige, aus weleher der Rüssel mit seinem ausstülpbaren vorteren Theile herrortritt, (bei Oersted, welcher den Rüssel für den penis hält, Geschlechtsüffunung) nnd da diese fast immer am Ende des Körpers liegt, so kommen alle die Gattungen, welche Ocrsted als mit subterminaler Mundöfmung versehen bezeichnete, bei Quattrefages in die Unterabtheilung der mit terminaler Mundöfnung. Was bei Oersted Nhund, ist bei Quatrefages Geschlechtsöffinung.

Diesing ${ }^{1}$ ) folgt der Quutrefuges'schen 1)eutung der Organe. Seine Unterabtheilungen, nach der l'orm des Kopfes gewählt, möchten so wenig wie die Oersted'schen beibehalten werden kümnen.

Meine Beobachtungen lebender Nemertinen sind noch zu vereinzelt, als dass ich eine naturgemässere Eiutheilung als die hisherigen vorzusehlagen im Stande wïre. Form und Bewallinmg des Rüssels, als des die Nemertinen am meisten anszeichnenden Organes, werden neben der Berüeksiehtigung der Körpergestalt vielleicht später ein gutes Eintheilungsprineip abgeben.

Dass wichtige Versehiedenlıeiten in der Entwickelung der Nemertinen vorkommen, welche bei einer Eintheilung benutzt werden müssten, ist nicht wahrscheinlich. Dass es aber sowohl Eier legende als lebendig gebärende Nemertinen giebt, ist dureh Beobachtungen festgestellt. Oersted ${ }^{2}$ ) und Desor ${ }^{3}$ ) sahen Nemertinen Eier legen, letzterer verfolgte auch die Entwickelung bis zum Auftreten eines wimpernden Embryo. lch beobachtete, dass ein an unserer Küste häufiges Tetrastemma, dem varicolor Oerst. an äbnliebsten, lebendige Junge gebärt, welehe bei einerLänge von $\frac{1}{4}$ “" schon den Rüssel mit seiner Bewaffnung, Nerven und Gefïsssystem ausgebildet enthalten, aber oft erst, naeldem sie eine Länge von $1_{\frac{1}{2}}{ }^{\prime \prime}$ erreielıt haben, geboren werden. Eine Metamorphose machen dieselben, nachdem sie las Ei verlassen haben, nicht durch. Biei einer Länge von $\frac{I}{8}$ Linie beginnen Nervensystem und Augen zu erscheinen. Darauf billet sich der Rüssel, in demselben zuerst jederseits die Reservespitzen-Tasehe unl danu das Stilet.

1) Systema helminthum pag. ํㅗ.

2) Entwurf etc. pas. 25.

3) Müllers Archiv 1818 pag. 51:?. 


\section{Ueber die organisation der rhabdocoelen Turbellarien im Allgemeinen besonters in histologischer Bezichung.}

\section{Allgemeine Körperbedeckung.}

Die Oberfäche der Rhablocoelen ist wie die sämmtlicher Turbellarien gleichmässig mit Cilien belleckt, leren Bewegung der Willkülır entzogen ist. Die Lüinge der äusserst feinen Wimperı ist in Allgemeinen bei den grösseren Rhablococlen etwas betrïchtlicher als bei den keinsten Arten. Sie variirt von 0,005“"-0.01 ".. Die Cilien stehen auf einer durchsichtigen Hautschicht, welche in einer feinkörnigen Grumbubstanz eine Mluge heller wasserklarer Bläschen zeigt md von lem Parenchym des Kä̈per: in den mcisten Fillen deutlich abgegrenzt crscheint. Bei farbigen Artcn ist dic Grenze au dentlichsten, imlem hier die Farbstoffe sich stets umittelbar mnter iler Haut, alıce nie in derselben abgelagert finden.

Zunächst ist die Frage von Wichtigkeit, ob die Haut aus Zellen bestehe. welcht: sich mit den Wimperepitheliumzellen höherer Thiere vergleichen lassen. oder ob die Cilien wie bei den lnfusorien auf einer nicht in Zellen zerlegbaren. gleichfïrmigen Substanz stehen.

Zar Untersuchung der Haut eignen sich an besten solche Rbabdocoelen, welche durch die später zı beschreibenden stäbchenförmiggen Körper nicht zu undurchsichtigr sind, z. B. Prostonum lineare, Vortex viridis, Nesostomum rostratmn. Bei maissigem Drucke mter einem Deckgläsclıen mit der $3-400$ maligen Linear-Vergrrüsserumg sielıt man in Aler durchsichtigen Haut. deren Dicke bei verschiedenen Arten zwischen 0.00:5" bis $0,009^{\prime \prime}$ variirt, in einer feinkömigen Grundsubstauz eine grosse Zahl wasserklarer. ovaler orler rundlicher Raume, welehe man leicht fïr mit besouleren Windungen versehene Zellen ouler Bläschen halten kïunte. Durch die eigenthümliche Lichtbrechumg

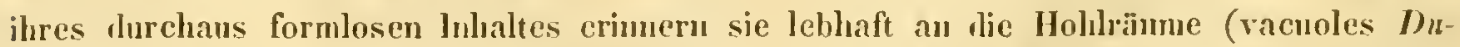
jurelin) ales Parenchyms der lufusorien mul Hỵdren. Sie erreichen mit ihrer Umgrenzmug 
nicht die Wimpern tragende Oberflïche der Ilaut, vielmehr stehen diese auf einer zusammenhängenden dïmnen Schicht der vorerwïhnten feinkörmigen Grundsubstanz. Vergl. Tab. I. Fig. 1. 4. 7.9. 15. Ili.

Wirkt Wasser lingere Zeit auf lie Haut eines solchen einem zienlich starken Drueke ausgesetzten Thieres ein, so nehmen die hellen Rïnme der Ilaut alhuihlig durch Imbibition an L'mfang zu, erheben sich ïber die Oberfliche, indem sie die Grundsubstanz vor sich her drängen, und die Cilien auf die Seite schielsen (lïg. 9 lei Prostomum lineare), werden immer blasser, und platzen eudlich um sofort ganz zu rerschwinden. An abgerissenen Stïcken der Ilant, welche sich aboumden, mol vermöge der ihnen aufsitzenden Wimpern kreisend im Wasser beriegen (Fig. 6) kann man gerade wie bei den Infusorien, wem das Spiel der Wimpern aufgehört hat, eine allmïllige Auflösung der ganzen Whasse beobachten, indem eins der eingeschlossenen hellen Rïumchen nach dem anderen beim Zutritt des Wassers platzt, und mur ein kleiner liest einer in Wasser nicht löslichen, feinkürnigen Masse ïbrig bleibt.

Nie grelingt es, durch Abreissen oder durch Druck regelmässige, an Wimperzellen erimnermde Brmehstiicke der Haut zu erhalten, weder bei jungen noeh bei ausgewachsenen Individuen.

Somit wirl es gerechtfertigt erseheinen, die Haut der Rhabilcoelen als nich? aus Wimpercpitheliumzellen, sondern aus der von Ecker ${ }^{1}$ ) kürzlich ausfïhrlich beschriebenen :: ungeformten contractilen Sulstanz der niedersten Thiere" bestehend zu betrachten, welche wir bei den Infusorien und bei Hlydra genauer kennen. Dass jedoch auch Untersehiede zwischen dieser Substanz und der Haut der Rhabdocoelen vorhanden sint, werten die folgenden Beobachtungen lehren.

Fügt man zu einem unter einem Deckglïschen in Wasser liegenden MesostoInum rostratum, tetraģoum, Opistommm pallidum, Derostomum Schmidt i a num ein wenig Aetzammoniak, so lïst sich die Haut in einzelnen sehuppenartigen Stïcken ab. welche alle die Dicke der ganzen Hantschicht haben nud. wie in Fig. 8 von Derost. Schmidtianum dargestellt ist, oft in grösseren Lappen gusammenhängen, durch stïrkeren Druck aber auseinanderweichen wie in Fig. 13 ron Opistomum.pallidum. Diese Bruchstïcke der Hant haben eine mmegelmässig vieleckige Gestalt. lhre Grösse ist hei einem und demselben Thiere ziemlich die gleiche, bei verschiedenen Arten ra-

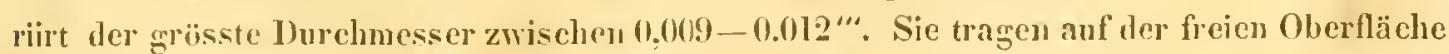
('ilien. welche siclı auch nach der Behandhung mit Ammoniak noch längere Zeit erkennen lassen, und schliessen in einer gleiehmuissig feinkörnigen Grumdsulstanz viele der mehr nder wenigur Mntlich gehlinbenen wasserhellen Hohlränme ein. Bei Mesostomm rostratnm ist in Fig. 10 dargestellt. wie die Hantschuppen sich ron dem unterliegenden Parenelym alozuliisen pllegen. In Fig. Il sieht man einzelne derselben mit den zahl-

1) Zur Lehre vom Bau und Leben der contractilen Substanz der niedersten Thiere. Zeit. schrift fïr "rissensch. Zoologie ron $r$. Siebold und Kö̈liker. Pad. I pag. "218. 
reielıen hellen Bläschen in Imnern. Einen liern komte ich in diesen Hautsehuppen nic crkeunen.

Wirkt Anmoniak in concentrirtem Zustande auf dieselben ein, so lüsen sie sich bald ganz auf, ebenso in lissigsïure, mit llülfe derer, wem sie verdünnt angewandt mird, die Isolirmg der Schüppchen jedoch anch gelingt. Stärkere Sïuren wirken sogrleich lüsend, ebenso Kalilange.

Sonit ergiebt sielı bei der sonst selır auffallenden Uebereinstimmung der Haut der Rhabdocoelen mit der Substanz der Infusorien und Hỵdren in dem durch Ammoniak hervorgebrachten Zerfallen in regrehnässige Stiicke eine nicht unerhebliche Verschiedenheit.

Wir werden zur Erklïrung dieser eigenthümlichen Erscheimugg eine Zusammensetzung der Jaut aus früher getrennt bestandenen Theilen amnehmen müssen, aus 'Zcllen, die Alle unter sich später zu der eigenthïmlichen Sulsstamz, welche der Sarcode gleicht. rerschmolzen sind. Nur dureh die Behandlung mit gewissen Reagentien kümnen wir nus noch Spuren der ehemaligen Trennung anschaulich machen. In der Kürpersubstanz der Hyilren lässt sich cine :ihnliche Bildung nicht nachweisen. Wir werden zwar auch hier auf eine Entstehung ans Zellen schliessen dürfen, müssen dabei aber vielleicht bis auf die Furchungskugehn im Fi zurückgehen (wie dies schon Kölliter und lieichert ansgesprochen haben). In der Haut der Rhabdocoelen zeigen sicb aber Spuren viel spiterer Zellengenerationen. welehe in dem durch Ammoniak hervorgerufenen Zerfallen in regelmässige Stïcke einen, wie mir scheint, sicheren Ausdruck finden.

Was die Haut der Dendrocoelen und Nemertinen betrift, so sprechen die Angaben von Quntrefuges ${ }^{1}$ ) sehr für eine Uebereinstimmung (lerselben mit der der lihabdococlen. Auch bei ilnen sollen die Cilien auf einer homogenen, feinkörnigen Masse anfsitzen. welche wie ein Firniss (assez semblable ì un rernis ì demi lhuile) die in tler Haut liegenden hellen Tï̈ume (ob Zellen oder einfache Hohlräume bleilut unentschieden) ïberzicht. Dei unseren Süsswasser-Dendrocoelen lässt die grosse Menge Iler stäbehenförmigen Körper eine genaue Einsicht in die feinere Struetur ler Haut kaum zu. Doch konute ich anch hier nie wirkliche Wimperepithelimmzellen durch Druck oder Reagentien isoliren. Aehmliche durchsichtige See-Dendrocoelen, wie die des Hittelmeeres, finden sich an unserer lïüste nicht. und hatte ich noch nicht Gelegenheit, llergleichen zu beobachten. Nach der Angabe von Mux Mitller, welcher die Haut der von J. Miiller beschniebenen Dendrocnelenlarve des Mittelmeeres mitersuchte ${ }^{2}$ ), ist jedoch die lsolirung von Wimperzellen hier müglich. Ueber die Nemertinen werle ich unten besonders handeln.

Es bleibt mir nun noch iibrig, einen eigenthümliehen Abschuppungsprocess zus mwilmen, welehen man an der Hant ciniger Rhlabdocoelen beobachten kam. Wem () pistomum pallidum einem mässigen Drucke unter einem Deckglïschen ausgesetzt liegt. so sielıt man bald cine Anzilıl leiner, turchsiehtiger Sehüppehen von mmegehmïs-

1) Ant. A. se. nat. II. 3 Ser. T'on. IV. 1. I45. Tom. VI. J. 229.

2) Müller's Archio 18.0 p. 492. Tab. XIII fig. 2... 27. 
sigg viereckiger Gestalt an den Rändern des Thieres erscheinen, welehe sich bei fortgesetzten leblaften Austrengungen des Thieres dem Drucke za entgehın, allmühligg zu einer bedlentenden Vlnge vermehren. Diese Schïppehen, deren zwei in l"ig. It abgebildet sind, gleichen in Bezugg anf ihre Grösse den rorhin als durch Ammoniak alogelöst beschriebenen, unterseheiden sich aher von denselben wesentlich sowohl ilurch ilıre aussiror dentliche Feinheit, als besonders dadureh, dass sich anl denselben durehaus keine Cilien finden. Sie bewegen sich nie wie alggelöste Wimperepithelinnschn̈ppchen selbststïnlig, sondern werden durch die selbst nacli bedeutender $\Lambda$ hschupjung vollstindigg unverändert scheinende Wimperbewegung auf der Oberlliche des Thieres, lin mud her geworfen. Ansser den Kíreise der Wimperwelle angekommen liegen sie gauz still. Diese Schüppehen zeigen keine andere Structur, als eine unendlich feine Punctirung. Sie haben grosse Neigung sich an den Rïndern eimzurollen. Durch Essigstüre werden sie blasser aber nur sehwer gelöst, Chromsäme maeht ilıre Contouren selır dentlich, líalilauge und stïrkere Sïuren lösen sie anf.

Fäulen sich anf der Oberflïche nnseres Opistomum im normalen Zustaude Stellen, welche keine Wimpern tragen, so würden wir die eloen beschriebenen Schüppehen als ron diesen Stellen herrïhnend ansehen kümnen. Da die Oberfläche jedoch, wie ich mich bei den rerschiedensten Lagen des Thieres überzeugte, ganz gleichmässig mit Wimpern belleckt ist, so bleibt fïr lieses merklärbar scheinende Factum Nichts übrig, als anzmelnmen, dass diese Schüppchen über dem Wimperüherzuge gelegen haben, und ron den Wimpern durelıbohrt wurden. Sic wïren dann als eine frühcre Geseration ilerjenigen aus Zellen entstandenen, wimperntragenden Hautstückehen anzısehen, welehe durch Anmoniak isolirt werden komnten. Wie aber die unbrauchbar gewordenen, bis zu einer versclıwindenden Dümulieit abgeplatteten Hautschüplıchen von den unter denselben neu gebildeten Cilien durchbohrt werden konnten, wage ich nicht zu erklären.

Ansser bei $O_{\text {p }}$ istomum pallidum konnte bei Vortex viridis und Macrostomum hystrix noch eine älmliche, wemngleich lange nicht so reichliche Abschuppung beobachtet werden. Hier fanlen sich in den Spuren von Schleim, weleher die Wege eines zwisehen zwei Glasplättehen sieh hindurchdrängenden Thieres bezeichnete. constant einzelne Schüppehen, Jenen von Opist. pallidum :ilmulich, welche von der Haut abgelüst sein mussten, aber keine Spur von Wimpern zeigten.

\section{Stäbchenförmige Körper.}

Als eine chararteristisehe Figenthümlichkeit rieler Bhabdocoelen und Dendrocoelen sind die stab-. spindel-oder pfriemenfürniggen körperelon zn erwïhıen. welche sieh in der Ilant derselben eingebettet finten. Dieselben sind an ihren 
scharfen Contouren leicht von den iibrigen Gewebstheilen zu unterscheiden. I. Schulze ) beohachtete sie zuerst bei unseren Süsswasser-Demirocoelen. Oersted ${ }^{2}$ ) sah sie auch bei Rhabulocoelen. Genaner beschrieb sie jerloch erst $O$. Schmilt $\left.{ }^{3}\right)$. Quatrefages ${ }^{7}$ ) erwiihnt ihrer bei den Planarien des Mittelmeeres nicht, doch fand sie $v$. Siebold ${ }^{5}$ ) bei Thysanozo on Diesingii aus dem Hafen von Triest, bei welcher Planarie sie J. u. $\boldsymbol{M}$. Mäller ${ }^{6}$ ) ebenfalls erkannten. Die Crösse dieser Körperehen bei den Rhabdocoelen variirt sehr. An kleinsten finle ieh sie bei Vortex viridis und II esostomum mar-

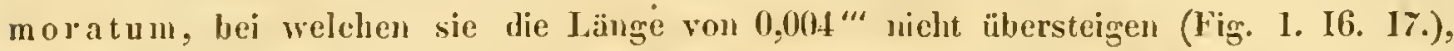
am crössten bei Mesostomum tetraģonm, bis 0:01S“" lang (Fig.4. IS.). Sie ragen nur in seltenen Füllen über die Oberlliche der Haut hervor ${ }^{\gamma}$ ), gewöhnlich liegen sie ganz in der Sulstanz derselben verborgen, gestreckt oder gebogen, einzeln oder bündelweise vereinigt. Bei einigen Rhablococlen fehlen sie ganz, so bei 0 pistomum pallidum, Prostomum lineare. Diese Stäbchen gehöreı jedoch nicht ausschliesslich der Haut an. Sie finden sirh bei einigen Arten in hedeutender Menge im Parenchym des Körpers zwischen rlen iihrigen Organen und zwar in sehr bemerkenswerther Anorilnung, welehe ich zumächst ausfülılich beschreiben werde. In dem vorderen Kürpertheil des sehönen, durchsichtigen Mesostomum rostratum sieht man zwei Strüıge dicht nebencinanderliegender Stibchen. deren jeder an der ïnsseren Seite einer der beiden Augen umnittelbar vorbeistreichend (Fig. 23) sich einerseits nach der schnabelartigen vorderen liörperspitze erstreekt, und hier mit dem der andern Seite zusammenlliesst, anderesseits sich nach hinten bis in die Mitte des Kürpers ausılehut. Hier zerfïllt jeder der Strïnge in vicle einzelne Reilıen von Stäbchen, welehe, zwischen den Eingeweiden hindurchlanfemt, theils frej zu endigen sclıcinem, theils in Zellen eintreten. Letztere sind ebenfalls mit

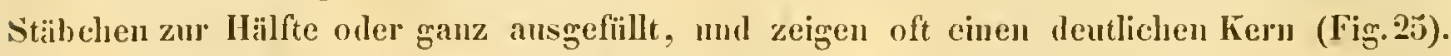

Diese Stibchen, welehe ganz den bei auderen Arten in der Haut liegenden gleichen, haben bei ausgewachsenen Thieren eine Lünge von $0,008-0,01$ “. Die Strünge in vorleren Körpertheil sind etwa $0,008^{\prime \prime}$ breit, an den Angen sowohl als nach der Mitte des Kärpers zu etwas licker, indem sie hier mehr Stäbchen enthalten. Eine besondere Membran umschliesst dieselben nicht, sie liegen fiei im Parenchym. In der Nähe der Augen liegen sie ummittelbar auf den Centralnervenganglien (Fig. 2:i), und wie sic sich nach vorn und nach hinten verbreiten, scheinen sie dem Verlauf der Ner-

1) De planariarum vivendi ratione etc. pag. 31.

2) Entwurf etc. pag. 72 bei Maerostomum hystrix.

3) Die rhablocoelen Strudelwiömer etc. pag: 6.

1) Anu. d. se. nat. 3 Ser. T. $1 V$.

5) Vergl. Anatomie pag. 163.

6) Miiller's Archiv 1850 jag. 492.

7) Nur bei Macrostomum hystrix habe iclı sie ijler, aber durchaus nicht regelmässig über die Oherllache der Hant hersorragen gesehen. Es liegen hier, wie schon Oersted und O. Schmidt angeben, gewöhnlich 3 der kleinen pfriemenfürnigen Kïperehen aneinandergeheftet (lig. 15.). 
veustrïnge zu folgen, welche bei anderen Rhabdocoelen wenigstens in ihnlicher Richtung verlaufend erkannt worden. An der vorderen sehr empfindlichen liöperspitze findet sich cine dichte Anltïufung ron Stïbchen, welche diesen Theil ganz undurchsichtig macht. Dieselhen liegen jedoch alle unter der Haut. Veberhanpt linden sich bei Mesostomum rostratnm nirgends Stibehen in der IIant. Die Zelten, in welele die Stibehenreihen in der Mitte des Kürpers eintreten, liegen vorzugsweise zu beiden seiten der Geschlechts - und Verdanungswerkzenge. Bei jungen Individuen fehlen dieselben; lier enden die Stibehenstrünge frei im Parenchym. Der hintere liürpertheil enthält keinerlei Ausläufer derselben.

Diese merkwürdigen Organisationsverhältnisse, welche zum Theil schon Oers/ed ") sah, jedoch als Muskeh deutete, ind die: $O$. Sehmidt. ${ }^{2}$ ) genauer, jedoch nicht vollstïndig erkanute, finden sich niclit allein bei Mesostomum rostratum. Bei Mesostomum tetragonum lindert die grosse Menge der Stibehen in der Inat und der braune Farbstoff unter derselben eine genaue Einsicht, doch konute ich bei durchsichtigeren Exemplaren nicht nur die allgemeine Anordnung wie bei Mes. rostratum erkennen, sonderu es gelang anch, in den Seitenlappen dieses interessanten Thieres die ïherall zwischen den Muskeh sich hindurclıziehenden Fäden vou aneinander gereihten St:̈bchen deutlich zu sehen. Wie in Fig. 24 a.b. abgebildet, liegen die St:ibchen bald grösser bahd kleiner oft zu mehreren nebeneinander, dann wieder einzehe lintereinander, oft ohne sich gegenseitig zu berïhren, in langen Reihen, deren Anfang oder Ende entweder iu cine ebenfalls mit Stiibchen erfüllte Zelle fïllt, oder im vorderen undurchsieltigen Kürpertheil sich der Beobachtung entzicht. Viele hören auch frei in Parenchym anf. Nicht selten begleiten die Stibchen ïnsserst zart contourirte Fäden, welehe von Zeit zu Zeit Anschwellungen zeigen (Fig. 24. c.). Bei Mesostomum Elırenbergii scheinen diese Verbialtnisse am leichtesten der beobachtung zugäuglich zu sein. wie ich aus den $A b$ bildungen von Focke $^{3}$ ) und O. Schmid/ ${ }^{+}$), sowie aus den Angaben des letzteren selıliesse. Leider habe ich diesen selı̈̈nen Strudelwurm in unserer Gegend noch nicht finden können.

Bei Rhabdocoelen aus anderen Familien habe ich diese Anbäufungen der Stäbchen um die Centralorgane des Nervensystens so wie die reihenweise Anordnung in Innerı des Körpers nicht beobachtet. Sehr hïufig sieht man dagegen die Haut der vorderen Kürperspitze so wie die zunïchst unter derselben liegenden Gewebstheile reichlich mit Stäbchen angefüllt, auch wenn die Haut des äbrigen Kürpers dieselben nur sparsan cuthilt, so bei Derostomum Schmidtianum, Mesostomum marmoratum, Mes. pratense.

Die Entwickelung dieser Stäbchen scheint immer in Zellen zu geschehen.

1) Entwurf etc. pag. 10. fig. 96 .

2) Die rhabdocoelen Strudelwürmer etc. pag. 44.

3) Annalen des Wiener Mluseums. Bd. I. Taf. XVII.

4) I. c. pas. 47. 
wie dies 0 . Srlmmidt angiebt. Man findet leicht bei den erwïlnten Turbellarien unter der Haut gekernte oft ziemlich grosse runde Zellen im Innern granz oder theilweise mit kleineren oder grösseren Stäbchen gefïllt, ebenso bei jungen Exemplaren von Mesostomum rostratum iu Verlauf der Stäbehenstringse. (Vergl. Fig. 19. 20.)

Von Bedeutung für die IIypothesen über die Funetion dieser eigenthünliehen Gebilde sind die chemischen Eigenschaften derselben. Zu diesen gehe ich jetzt ïber. F. Sclmulze giebt an, dass die Stäbchen der Dendrocoelen in Ammoniak mü̈̈slich seien, und sich desshalb sehr gut mit llïlfe dieser Flïssigkeit isoliren liessen. Die grosse Verbreitung, welchedas in Alealien unlösliche Chitin als wesentlicher Bestandtheil der Haut vieler niederer Thiere zeigt, regte bei mir die Vermuthung an, dass auch hier dieser eigenthümliche Stoff nachgewiesen werlen könnte. Dieselbe hat sich jedoch nicht bestätigt. Werden die Stïbchen der Dendrocoelen unt Rhablocoelen nach dem Zerstïckeln des Thieres in reines Wasser gebracht, so zerfliessen sie allmillig rollstïndig. bei den grossen Stïbchen erwachsener Thiere gelıt diese Aullösung langsamer als bei den kleineren jüngerer Thiere. Zuerst krïmmen und biegen sie sich unter dem Einfluss des Wassers, quellen anf und bekommen einen runden, durelssichtigen Hof, als ligen sie in einem Blïschen. Dann werden sie immer blasser, platzen auf, und verschwinden sofort g:ïnzlich. Essigsäure, so wie alle stïrkeren Sïuren lïsen auch im schr verdünnten Zustande die Stäbchen durchweg schnell auf. Clronsïure macht sie etwas zusammenselorumpfen, und giebt ilnen sehärfere Contouren. Nur die jüngsten und kleinsten werden von dieser Säure gelöst. Dagegen zeigen die Stäbchen gegen Ammoniak unl Kalilauge eine berleutende liesistenz. lei erwachsenen Dendrocoelen und einigen Pilabdocoelen z. B. Mesostomum tetragonun widerstehen sie selbst kochender concentrirter Kalilauge lingere Zeit. Doch gehen sie endlich eine Verinderung ein. Sie werlen kïrzer, gedrungener, helle Bläschen oder Iohlräune; welehe im Innern entstehen. erzengen Ausbuchtungen an der Oberlläche. (Die Stäbchen der Fig. 21 von P'lauaria lactea sind in Fig. 22 durch Kalilauge verändert abgebildet.) Endlich werden sie ganz blass und zerfliessen. Bei jungen Dendrocoelen und den kleineren Rhabdocoelen tritt liese Auflösung schneller ein, bei Vortex viridis und Macrostonmm hystrix sah ieh sie schon in kaltem Ammoniak und Kalilauge sich lösen. Die Stibchen aus dem Imeren von Jlesostomum rostratum verlalten sich chemiseh denen aus der Haut anderer Rhabdocoelen ganz gleich. Es erhellt aus dem Verlatten gegen Wasser und Siuren, dass die Substanz der Stäbchen sich mit dem Chitin nicht rergleichen lïsst. Dieselbe wird, da das Verhalten gegen Alealien die Annahme einer ciweissartigen Substanz, wie diw: der iibrigen Gewebstheile der Turbellarien ist. in denselben unü̈glich macht. vorläufigg als eine eigenthümliche gelten mïssen, ansgezeichet durch Schwerlöslickeit ja fast vollständige Unlïsliehkeit in Ammoniak und concentrirter Kalilange: leichte Zerlliesslichkeit in Wasser mul Säuren.

Ueber die Function dieser eigenthümlichen Gebilde kümnen nur Vernuthmigen aufgestellt werden. IIan hat die Stäbchen nit Nesselorganen verglichen und gerade zu 
für solche erklït. So Frey (Ueber die Bedeckungen wirbelloser Thiere pag. 93)

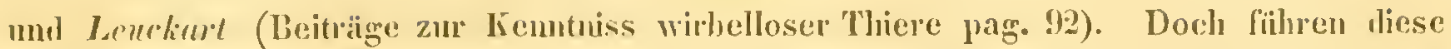
Forscher nicht an, dass sie einen Nesselfaden gesehen orler eine nesschule Kigenschaft wahıgenonmen hätten. Jok. I. Wax Miiller lıben kürzlieh von den Stibelien aus der Ilaut von Thysanozoon Diesingii, ciner Mendrococle fles Mittelmeeres, einen feinen Faden ausgehen schen. und diesen als Nesselfaden gedentet. Trotzdem dass diese Nesselstiblıch mit den beschrichenen der Süsswasserdendrocoelen mul Rihabdocoelen, wio ich aus der Ahbildung in Mïller's Archiv 1850 Tab. Xlll Fig. 22-2S selue, grosse Achulichkeit haben. möchte ich sie doeh für specifisch verschieden von letzteren erklären, ebenso wie die von Polycelis pallidus bei Quntrefages (Am. d. Se. nat. :3 Ser. Tom. IV. Tab. S fig. 9. 10. pag. 1.l6) abgebildeten Kö̋perchen mit Fadenanhang: welche letztere durch ihre Gestalt md Grösse sich anch von museren Stabchen schon hinreichend mterscheiden. Bei Rhahdocoelen und den von mir beobachteten Dendrocoelen bin ich trotz der grössten darauf verwantten Mïhle nie im Stande gewesen, eine Spur eines von den Stäbchen ansgehenden Farlens zu bencrken, während bei den analog greformten Nesselstibchen der Hydren und Acalephen sowie der Tergipeden der Nesselfaden auf das Leichteste zn erkemmen ist. Anch funde ich die Nesselstïbchen der letztgrnaniten Thiere chenisch sehr rerschieden von den Stabchen der Turbellarien. Erstere sind ebenso wie die krugfürmigen Nesseln, nit welchen sie meist zusammen vorkommen, und die sich anch bei einer Turbellarie Mierostomum lincare fudeu, vollkommen unlöslich in kochender Salpeter- und Schwefelsïure. Der Nesselfalen bleibt in diesen Säuren ebenfalls mversehrt und sehr deutlich sichtbar. Wasser, lissigsiure und Chronısänre üben ebenfalls keme Veränderung auf dieselben aus. Dagegen lösen sie sich leicht iu kochender concentrirter líalilauge. Anch diese bestehen also nicht aus Chitin, sind aber durch ihre bewundernswerthe Resistenz gegen die stïrksten Säuren und ilıre leichte Löslichkeit in líalilange von den Tubellarienstibchen schr ansgezeiehnet. Es wird interessant sein zu erfahren, wie sich die Stäbchen von Thysanozoon Diesingii mut die Nesselkörperchen von Polycelis pallidus gegen dic erwïhten Reagentien verhalten. Mlir ist es umwalnseheinlich, dass bei der Verbreitung, welche die in concentrirten mineralischen Sïuren nulösliehen Nesseln in Ier Klasse der Polypen. Acalephen. Turbellarien (Microstomum lineare) und Mollusken (Tergipeden) gefunlen hahen, anch noch andere gleichberlentende Organe nit lurchaus abweichender chenischer Zusanmensetzung in denselben Kilassen vorkommen sollten.

Somit kann ich schon aus den argeführten Gründen dic Vermuthung, die Stäb ehen der Rhahdocoelen und Süsswasserilendencoelen müchten Nesselorgane sein, nicht theilen. Vnabweislich spricht alıer gegen dieselbe das Vorkommen und die cigenthümliche Verbreitung der Stäbchen in In nern von Mesostomum rostratum, tetra gonum und anderen Tubellarien. Wir selen dieselben hier in einer dentlichen Bezielung zum Nervensystem: unmittelbar un die Centralnervennassen finden sic sirl angelı̈̈nft, in strahlenförmiger lichtung verbreiten sie sich in Körper, die offeubar zun 
Tasten eingeriehtete und sehr empfindliehe vorlere Spitze ist hesonders reiehlich mit ihnen ausgestattet. Ceher den Grund der reihenweisen Lagerung im Imnern des Kürpers rermagg ich keine hestimnte Vermuthung zu äussern. Dass die Stäbchen Bahnen für die Nerrenthïtigkeit seien. ist seh" unahrseheinlich, denn es finden sich neben denselben und selır hä̈ufigg olne dieselhen wirkliche Nervenfasern (Vergl, unten das Kippitel über das Nervensystem). Vielleicht beschräukt sich der Nutzen der in und unmittelbar unter ler Ilaut liegenden Stäbehen darauf, dass dieselben, indem sie den äusseren Drucke einen Wirlerstand entgrgensetzen, in ïhnlicher Weise befördern! anf das feinere Gefühl der Haut einwirken. wie der Nagel auf das Tastrermögen der Fingerspitze.

\section{Pigmente unter der Haut.}

Die Stoffe, welehe Trïger Jer verschiedenen Fürbung der Rhabdoeoelen sind, treten unter folgender versehiedener Form auf: 1) Regehuässige. runde Farbestofflulisschen von $0,003^{\prime \prime}$ mittlerem Durchnesser, welehe sich dlurch Aneinanderlegen auch zu Sechsecken gestalten. Diese kommen nur bei den grünen Arten Vortex viridis und Il esostomum virillatum ('Typhloplana Sclm.) vor (Fïg. 1. 2.). 2) Unregelniassige. bald rumle, bald ovale, oft verzogene Bläschen von 0,0003 " - 0,02 " Durehmesser, in welehen eine gefürbte Flïssigkeit neben Fettröpfehen, farblosen Blïsehen und molekulären Kürnchen entialten ist. So bei dem brannen Mesostomum tetragonum (Fig. 4). 3) Glejelınässig im ganzen Kürper verbreiteter, nielıt in Blïschen eingeschlossener oder an bestinumte Gewebstheile gehumlener Farbtoff, bei dem blassröthlichen M es ostomu rostratum (Fig. 10). 4) Molekuläre Pignenthörnchen, cinzelı orler in Klümpchen vereinigt im Küpper zerstrent, nicht in Bläsehen cingesehlossen, meist lunkelbraun oder schwarz. So bei Jerostomum Schmidtianum, Nonocelis rutilins. Eine besondere Albart bildet der zu Mlarmoradern ähnliehen Figuren gestaltete, den sternförmigen l'igmentzellen höherer Thiere nieht unilmliche Farbstolf ron Mesostomum marmoratum (Fig. 16.). Ueberall ist die Ilaut farblos.

An meisten luteresse bietet der grüne Farbstofl dar. Ich werde nachweisen, dass derselbe in listologiseher wie chemischer Beziehnng vollstindig mit dem Chlornphyll griner Pllanzentheile ïbereinstimmt.

bei Vortex viridis haben die in ungeheurer Menge im ganzen körper verbreiteten J'arbstoflblïsehen eine Grösse von 0,0003-0,00. “", gewöhnliche J'orm 0,003 ". Sie liegen entweder ainzeln, ouler zu klümpehen vereinigt. Dass die homogene, saftgrïne Substanz derselben won einer besonderen Jembran umgeben sei. wie es Nuegeli für die Chlorophyllulïsehen der Pllanzen nachgewiesen hat (Zcitschuift für wissenschaftl. Lotanik rou sicheiden u. Nuegeli 3. u. 4. Heft. 1816 pag. 110. Tab. III. fig. 10-13.), 
lässt sich da, wo die Blïschen dureh Aneinanderliegen eckig geworden sind (parenchymatisch werden Naegeli) leicht erkenuen. Line sehr dentliche farblose Zwischensubstanz grenzt die einzelnen 6 eckigen, grünen Felderchen von einander ab(Fig. 2). In lnnern der grösseren griünen Bliischen liegt ein farbloses, rundes Körperchen von $0,0003-0,0005^{\prime \prime \prime}$ bald genan in der Mitte bald an Rande.

Der grüne luhalt grleicht in seiner Farbe volkstindig dem Chlorophyll. Durch verdïnnte Alealien und Sïnren wird er nieht verändert. Dadurch unterscheidet er sieh von dem sprangrünen Farbstoff mencher einzelliger Algen, der Chroococcaceen und Nostochaceen, welcher nach Niugeli (Gattungen einzelliger Algen 1849 pag. (i) durch die genanuten Agentien in orange, gelb orler roth verwandelt wird. Concentrirte Schwefelund Salzsäure lösen den Farbstoft von Vortex viridis mit schı̈n grüner Farbe, welehe durch Kochen nicht verïmdert wird. Ebenso concentrirte Kalilange und Ammoniak. Alcohol und Aether nehmen den Farbstoff ebenfalls in einer der Chlorophyllïsung ganz gleichen Farbe auf. Die alcoholische Lüsung entfärbt sich in wenigen Stmuden an Sonnenlicht vollstïndig. Durch essigsaures Bleioxyd lïsst sich ans derselhen der Farbstoft niederschlagen. Chromsämre bleicht die Farbstoflblïschen.

Diese ehemischen Eigenschaften stimmen genau mit denen des Chloropliylls überein.

Sowie ferner die Entwickelung des Chlorophylls der Pllanzen von dem Lichte ablängt, und grüne Pllanzentheile in Dnukehn bleich werden, so verlieren auch unsere Turbellarien, längere Zeit dem Ënfluss des Lichtes entzogen, ilıre grüne Farbe vollständig. Vier Wochen Aufenthalt in einem dunkeln Raume genïgten, das intensive Grïn von Vortex virilis in ein helles Gelb zu rerwandeln. Die grünen Farbstollblïschen waren dabei auf ein Viertel ilıres früheren Volumens zusanmengeschrumpft, und schienen unter dem Mikroskop fast gauz farblos. Dieser Versuch wurde mit noch nielt ganz ansgewaelisenen Exemplaren angestellt. Dass aber die Bildung der grïnen Farbe nicht all e in von Lichte abhängt, beweist der Umstand, dass unter den intensiv grünen Thieren nicht ganz selten einige gefunden wurden, die des grünen Farbestoffes fast ganz ermangelten, ja hie mul da nieht ein eiuziges kö̈rnchen desselben enthielten. Besonders häufig fand ich diese weisse Varietät in den Nonaten December und Januar ehe die Gesellechtstheile sich ausbildeten.

An einer dunkleren Stelle des Zinmmers aufbewahrt, halten sich die grünen Thiere stets an der Lichtseite des Glases auf. Den directen Sonnenlichte ausgesetzt sterben sie jedoch binuen einer Stunde olne dass eine Gasentwiekelung eintritt.

Soweit der Beweis der Identitit des Farbstofles von Vortex viridis mit dem Chlorophyll der Pllanzen ohue Elementaranalyse geliefert werden kounte, glaube ich ihn in Obigem gegeben zn haben. Line solche Analyse würde aber, selbst wem das dazu notlwendige Jlaterial hätte beschaff werden können, auch vou keiner unbediugten Benciskraft gewesen sein. da die Vugewissleit über die elementare Zusanmensetzung des ('hlorophylls der Pllauzen anch nach der neusten ausfïhlichen Arbeit ïber dasselbe 
vou Morot (Recherches sur la coloration des plantes. Ann. d. sc. nat. 1850. Tom. XIII. pag. 160.) noch nicht ganz gehoben ist.

Was die chemische Zusanmensetzung der Membran und des Kerns der Cllorophyllbläschen von Vortex viridlis betrifft, so beschränkt sich meine Kemntniss derselben auf die folgender Eigenschaften: Kalilauge, Ammoniak und Schwefelsäure machen nach dem Ausziehen des Farbstof’es das zurückbleibende Bläschen, in welchem der Kern nicht mehr erkanut werden kann, auffuellen. Es wird blasser, und rerschwindet endlich, doch erst nach lüngerem Kochen ģanz. Essigsäure, Chromsäure, Salzsäure und Alcohol verïndern Membran und Kern nicht, ausser dass ein geringes Zusammenschrumpfen eintritt. Joultinctur lässt, nachlem das Bläschen braun gefärbt ist, den Kern heller erscheinen, doch olne Farbenveränderung desselben. Nit dem meist aus Amylum bestehenden Kern der Chlorophyllbläschen der Pllanzen lässt sich jener daher nicht vergleichen.

Die Vermehrung der Farbstoffbläschen beim Waschen des Thieres geschieht durch Theilung. Der Kern verschwiudet, und 1-4 Abschnürungen tremen jedes Bläschen in ebenso viel einzche, welche, nachdem sie die Grösse des Mutterbläschıens erreicht haben, sich von Neuen theilen.

Unter den Turbellarien ist nur noch eine grüne Art bekamnt, Mes os tomum viridatum. Ich konnte dieselbe gleichfalls untersuchen, und habe den Farbstoff, der hier auch in runden Bläschen erscheint, die jedoch im Durchschnitt etwas kleiner als bei Vortex viridis sint, ebenfalls aus Chlorophyll bestehend gefunden ${ }^{1}$ ).

In mehreren anderen KKlassen niederer Thiere kommen grüne Arten vor, deren Farbe der der griinen Blitter gleicht. Aus der Klasse der Polypen ist mir derart nur Hylra viridis bekamt. Der Forbstoff gुleicht, wie ich mich überzeugt habe, in histologischer wie in chemischer Beziehung dem von Vortex viridis vollkommen. Von grünen Infusorien, deren es mehrere giebt, habe ich Stentor polymorphus untersucht. Auch hier ist Chlorophyll die Ursache der Färbung. Es wirl keincm Zweifel unterworfen sein, dass die grünen Eikürnchen Ehrenberg's bei Vorticella chlorostigma, Ophrydiumversatile, Holophrya ovum, bursariavernalis, Spirostomum vireus und melıreren anderen lufusorien gleichfalls aus Chlorophyll bestehend gefunden werilen. Unter den Mlollusken giebt es einen schönen grasgrünen Acteon; dem $\operatorname{Vogt}^{2}$ ) in St. Malo scinc Aufmerksamkeit schenkte, die Entwickelung desselben zu studiren. Die Jungen, so lange sie in der Schale sitzen, laben ausser einem grünen Flecke in der Nähe der Augen nichts Grüncs an sich. Wie bei älteren Thieren der Farbstofi

1) Es verdient hier angeführt zu werden, diss sehon $c$. Siebold in seinem schönen Aufsatze ,Ueber cinzellige Pllanzen und Thiere" Zeitselır. f. wiss. Zoologie Hu. 1. pag. 274 die Vermuthung ausgesprochen, dass der grü̈e Farbstoff der erwähnten Turbellarien, Ilydra md lnlusorien mit dem Chloroplyll identisch sein müehte.

2) Ann. I. se. uatur. 3 Ser. Tom. Vi. pag. 5.

Ocean und Mittelneer. Reisehriefe pag. 62 ff. 
gestaltet ist, Ind ob sich auch hier Chlorophyll wird nachweisen lassen, bleibt einer späteren Untersuchung vorbehalten.

\section{Muskeln und Parenchym.}

Nach O. Sclmidl ${ }^{1}$ ) konmen den Rhabdocoelen nur zur Bewegung einzelner innerer Organe Muskeln zu, so am Schlunde, an gewissen Abtheilungen der Geschlechtsorgane. Haut - und Parenchymmuskeln, welche die allgemeinen Bewegungen und Körperstellungen vermitteh, sollen ihnen durchaus fehlen. Ich finde fast bei allen Rhabdocoelen ein gesondertes, schrdichtes Hautmuskelnetz und bei vielen Parenchymmuskeln in sehr ausgebildeten Grade. Die Fäden, welche den letzteren angehüren, hat auch $O$. Schmidt ${ }^{1}$ ) bei einigen Arten gesehen, jedoch nicht für Mluskeln bilten zu dürfen geglaubt. Da ich diese jedoch in chemischer wie histologischer Beziehmug ganz gleich den zur Bewegung innerer Organe dienenden!Muskelfüden finde, so bin ichı über ihre Bedentung nicht in Zweifel.

Unter der oben beschriebenen Hautschicht findet sich bei vielen Rlıabdocoelen ein dichtes Netz von Lüngs- und Querfasern, welche parallel und unnittelbar an einander liegend, ohne Verïstelungen, bei einer Breite ron 0,0005-0,002"' oft eine selır bedeutende Länge haben. Die Quermuskeln sind wahıscheinlich vollständig ringfürmig. Dieses Hautnuskelnetz wurde sehr deutlich bei Opistomum pallidum, Vortex balticus, Vortex viridis (var. alba) (Fig. 30), Derostomum Schmidtianum, Prostomum lineare, Mesostomum rostratum, tetragonum, pratense, viridatum, Macrostomum lystrix beobachtet. Die blassen Fasern desselben werden scharf begrenzt und leicht erkenubar durch Behandeln des Thieres nit Chromsäurelüsung (etwa von der Farbe des Madeira-Weines), ein Mittel, welches ich zum Deutlichmachen der blassen Muskelfasern niederer Thiere ausserordentlich passend fand. Sehr verdüunte Essigsäure macht dieselben ebenfalls leichter erkeunbar, concentrirte Essigstiure, stärkere Säuren und Alcalien lösen sie ganz auf.

Das meist farblose, durchsichtige Parenchyn der Rlabdocoelen, wclches auf diese Hautmuskelschicht folgt, und untermischt mit zallreichen Muskelfasern, sawie mit Gefüssen, Nerven und Farbstoffen den Theil des Thieres ausmacht, welcher nicht von den Verdauungs - und Geschlechtswerkzengen eingenommen ist, besteht aus einer weichen, eiweissartigen, Körnchen und Bläschen (Hohlräume) enthaltenden Substanz, welche sich mit der ...contractilen Substanz niederer Thiere" vergleichen lïsst, obgleieh die sellıst-

1) Die rhabdocoelen Strudelwürmer etc. pag. 5. 
stïndige Contractionsfilligkeit đerselhen ebenso wie bei der Hant niclıt direet erwiesen werden komnte. Die Muskelı, welche dies l'arenchym oft in grosser Zahl durelısetzen, lassen sich eintheilen in solclıe, welche zur Gestaltverïnderung unl Bewegung des Kürpers in Allgemeinen dienen, diese möchte ieh Parenchymmuskelı neınen, und solche, welche sieh an imere Organe zn deren Bewegung ansetzen. Dei den grüsseren Mesostomeen, Mes. tetıgonum mud rostratmm ist dieses Parenclımmuskelsystem am ausgebildetsten, um] lässt sich an durchsichtigen Exemplaren leicht im lehenden Zustande beobachten. Die l'asern sud

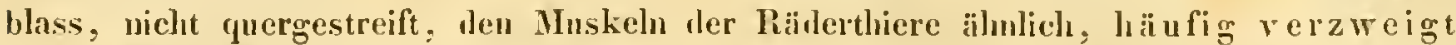
und 0,0005-0,002 "' breit. Sie entspringen nit feinen Anfingen von der inneren Oberlläche der Ilaut, verbinlen sich motereinander zu breiteren Fasern, um siel, wieder an der imeren Oberllïche der Hant an einer dem Ursprunge entfernten Stelle anzusetzen. lu Fig. 33 sind solche Muskeln aus dem Innern von Mesostomum tetragonum abgebildet. In den Seitenlappen dieses Thieres biegen die Fasern an dem Rande um, und gelangen wieder zurïck zur Mitte des Kärpers. Eine solelıe Stelle mit Umbiegungen der Muskelfasern ist in Fig. 31 dargestellt. Einzehe derselben siud an Farbstoffblischen befestigt, andere gehen in feinkönige Fasern ïlıer, welche den homogenen, ganz durchsichtigen Fïden ofters untermischt vorkonmen, um sich als unmittelbare Fortsetzungen dev letzteren naclwweisen lassen.

Diesen Muskeln ganz gleich greformt sind diejenigen, welche sich an imnere Organe wic Schlund oder Geschlechtswerkzenge befestigen, und ganz angenscheinlich zu deren bewegung dienen. Auch sic entspringen immer von der inmeren Oberflïhe der IIant, vereinigen sich zu breiteren Faseru, und setzen sich oft erst uach einem sehr laugen Verlauf an einem der genannten Organe an. Sie funden sich fast in allen Familien der Rhabdocoelen. Tiei Prostomum lineare beginnen sie im hinteren Körpereule. $n$ sich an deu vorne liegenden muskulösen Schlmud anzusetzen, bei Op is tomu pallidum und len Derostomeen sind sie kürzer (Vergl. Tab. III. fig. 1. 2. 4). liei den Mesostomeen sind sie ebenfalls leicht zu erkemen. Tiei den Gattungen Monocelis und Macrostomum scheinen sie dagegen ganz zu felilen. Hier habe ich ausser len unter der Haut liegenlen überhaupt keine deutlichen Muskelfasern im Inmern entlecken können.

Durch Chromsïure werden diese Muskeln selır dentlich, selırumpfen aber dabei etwas zusimmen. Ebenso durch verdinute Essigsäure und dureh Zuckerlösung. Anfgelïst werden sie vou stärkeren Sïuren und Alcalien. Schwefelsäure färbt die vorlier in Zuckerlösung getrinkten intensiv roth, löst aber gleichzeitig alle Theile auf.

Zcrreisst man eine der genamten Rhabdocoelen in möglielıst kleine Stïcke, so lassen sich in den cinzeluen meist alggemuleten Theilen die Muskelfasern nicht melur erkennen. Sie versehme!zen dureh die Einwirkung des Wassers mit dem Parenclyım, und hilden Klïmpehen, an welchen man ofters die eigenthïmliche Erseheimung der selhst. stïnligen Contractilitït wahruehmen kamn, wie wir sie an den Parenchymhruchstïcken der Hyilren kemen. Aher gerale desshalb, weil die Muskelsubstanz selbst mit in 
diesen Bruchstücken enthalten ist, die Faserform jedoch verloren hat, und nicht mehr als solehe getrennt ron dem l'arenchym mtersehieden werden kam, ist man richt im Stande zn entscheiden, ob in letzterer oder in der Mluskelsubstanz der Grund der selbstständigen (iestaltverïinderung der einzelnen abgerissenen Tlieile liegt. Diese Verinderung der Muskelsubstanz durch den Eintluss des Wassers kommt bei den Mluskeln der Riddertliere und Makrobioten ehenfalls vor. Der Grund derselthen liegt wohl in der noch mrollkommenen Differenzirung. der Muskelfäden ron dem nugebenden Gewebe.

Beim Zerreissen von II esostomum tetragoum in selrr verdümtem Eiweiss gelang es mir einige Male die Muskelfasem zu isoliren. Dieselben zeigten dann gleich abgerissenen elastisehen Fïrlen vielfache Windungen und Biegungen. Fig. 32.

\section{Nervensystem.}

(). Sirhmill hat mur bei einem einzigen Rhabdocoelum die Form des Centraluervensystems genau erkamt, nïmlich bei seinem Pseudostomum faeroense ${ }^{1}$ ). Hier liegen die 4 Augenllecke einer viereckigen Nerremmasse auf, von welcher 2 Fäden längs des Magens herabgehen. Frey und Leuckart ${ }^{2}$ ) sahen bei Vortex vittatus ron Helgoland unter den Augen einen ,:queroblongen, zweilappigen Gelirnknoten:" Weitere genauce Augahen ïber das Nervensystem der Rhabdococlen fehlen. Der bestimmte Nachweis der Anwesenheit und Form des Nervensystems in allen Familien dieser Ordnung der Turbellarien, den ich in Nachfolgendem geben werde, möchte ein nicht unresentlicher Fortschritt in der Kemutniss des feineren Banes dieser Thicre genannt werden.

Die überall sich wiederholende Grondforn des Centraluervensystems ist diejenige, welehe wir auch in den übrigen Ordnungen der Turbellarien finden. Zwei mit einander verbundene Ganglien liegen im vorderen Körpertheil und senden nach melıeren Richtungen Nervenfäden aus. Während sich bei den Nemertinen die Ganglien durch zwei Brücken verbunden zeigen, zwiselıen welchen ein Theil des Verdanungseanals hindurch länft (der zum Verlaumngsapparat wem auch mur indirect gehöremde Rïssel), siml bei den Dendrocoelen beide Centralganglien durch eine einfache Brïcke mit cinander in Verbindung gesetzt. Diese schwindet oft, so dass eine vollstindige Verwachsmng der Ganglien zu einem Doppelganglion eintritt. So anch bei den Rhabdocoelen. Eine Ringbildung un den Anfang des Verdaumngseanales könnte allein bei den Pro-

1) Neue Beiträge zur Naturgeschichte der Würmer. I848. pag. 9. II.

2) Beiträge etc. pag. 149 . 
stomeen vorkommen. Lier streicht nämlich der Oesophagus unmittelbar an Centralnerrensystem vorbei. Bei der grossen Blässe der Contouren des letzteren ist eine sichere Entscheidung nicht möglich geresen.

Bei Opistomum pallidum liegt las Nervensystem selır deutlich ror. Beim ertwachsenen Thiere ist die Zusammensetzung der Centralnerrenmasse aus zwei Ganglien kanm noch zu erkenuen. Tab. 1. Fig. 26. Tab. Ill. Fig.1.a. Von demselben gehen jederseits 3 Nervenfaserbiindel aus, eins an die vordere Körperspitze (Augen fehlen diesem Thiere), ein zweites seitwärts in die Gegend des Hoden und das dritte abwärts zum Verdauungscanal. Ebenso ist die Anordung des Nervensystems bei Vortex riridis Tab. 111. fig. 4. a, mit ılem Unterschiede, dass hier die nach rorn gehenden Nerven jellerseits ein Auge tragen. Bei jungen hodividuen fehlen diese Augennerven, das Pigment rulit hier unmittelbar anf den Ganglien. Ebenso bei Derostomum Schmidtianum, dessen grosse Ganglien an durchsichtigen jungen Individuen leicht erkennbar sind, und bei Vortex balticus Tab. IV. fig. 1. An dem Nerrensystem ron Prostomum lineare habe ich Spuren einer Zusammensetzung aus zwei Ganglien nicht erkennen künnen. Tab. I. fig. 2\%. Ein Nerr zu jedem Auge und einer abwärts zu den Eingeweilen wurden gesehen. Eigenthümliche, kernlose aber viele Kürnchen enthaltende, scharf contourirte, ovale Zellen von $0,00-1$ " Durchmesser bedecken das Nervensystem, und gehen mit den Nervenfäden eine Strecke aufwärts und abwärts. Sie finden sich an dieser Stelle in keiner anderen Familic wieder. Unter den Mesostomeen sind die beiden Centralganglien bei jüngeren Individuen von Mesostomum rostratum Tab. I. fig. 23 und M. tetragonum erkannt worden. Hier findet auch die eigenthümliche Anhäıfung stäbchenförmiger Körper um die Centralganglien und die von ihnen ausgehenden Nervenfïden statt, welehe oben pag. 12. beschrieben wurde. Bei dem blinden Mesostomum pratense ist das Nervensystem ähnlich wie bei Opistomum pallidum. Unter den Schizostomeen konnte ich nur Macrostomum hystrix auf das Nervensystem untersuchen. Hier liegt es ähnlich wie bei Vortex balticus unter rleu Augen ${ }^{1}$ ).

Was die sehr schwierig zn ermittelnden histologischen Verhäiltnisse des Nervensrstems der Rhabdocoelen betriff, so liessen sich einzig bei Opistomuln pallifl III mit einiger Sicherheit die Elementartheile unterscheiden. Ganglienzellen, ähnlich denen der Annulaten, finden sich hier ebensowenig wie nach Frey und Leuchart bei den Nemertinen 2). Die Nervenstrïnge sind aus feinen, blassen Fasern zusammengesetzt rou höchstens 0,0003 " Breite. Die Centraltheile scheinen ebenfalls aus diesen Fasern gebildet. bei genaner Untersuchung zeigen sich jedoch hier geschwänzte Körperchen ron 0,001 "' lireite und $0.005^{\prime \prime \prime}$ Lünge, welehe sich an beillen Enden in eine feine Faser fort-

1) In der Zeicbnung dieses Thieres Tab. Y. fig. 3. konnte dasselbe nicht mehr ausgeführt werden, da es erst nach dem Stich der Tafel erkannt wurde.

2) Beiträge etc. pag. 7?. 
zusetzen scheinen. Im Innern enthalten dieselben nur feine Kïrnehen. Vergl. Tab. J. Fig. 26. Dieselben Kürperehen fand ich auch da, wo die zur vorderen Spitze streichenden Nervenfasern in der Nälıe der Haut aufhörten. Fïg. 26. a. Dieselben siml offenbar als analog den Ganglienkörperchen höherer Thiere zu betrachten, wiewohl ihr Vorkommen an den letztgenamten Orte sehr befremden muss. Die zu den Eingeweiden geheulen Nerven kounten wegen nicht genügender Durchsichtigkeit tles Thieres nur eine kurze Strecke verfolgt werden. In dem Parenchym von Mesostomum tetragoun findet man zwischen den Muskelfasern nicht selten Füden wie die Fig. 24. c. d. algebilıleten. Dieselben sind aus einer lieilı hinter einander liegender geschwänzter, feinkürniger Körperehen zusammengesetzt, die mutereinander durch sehr feine, kürnige Fasern in Verbindung stehen unt bald in Begleitung von stäbchenförmigen Körpern bald olne dieselben verlaufen. Anfeng oder Ende derselben habe ich wegen der Undurchsichtigkeit des Thieres nicht auffinden können. Einzelne der Ansehwellungen lassen sich anch in ihrer Gestalt niit multipolaren Ganglienkörperehen vergleichen, indem mehrere Fasern von denselben ausgehen. Ob diese Gebilde für Nerven gehalten werden müssen, bleibt vor der Iland noch zweifelhaft, da der Zusammenhang derselben mit den Centralganglien nicht nachgewiesen werlen konnte. Mesostomum Ehrenbergit wirl offenbar an passendsten zur Entscheidung dieser Frage sein.

\section{Sinnesorgane.}

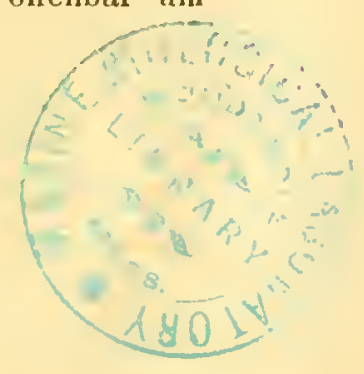

Die schwarzen Pigmentflecke, welehe gewöhnlich zu zweien bei den Rhabdocoelen wie in den übrigen Ordnungen der Turbellarien in der Nühe des rorderen Körperendes selır verbreitet vorkommen, sind als Gesichtsorgane auzusehen. Immer stehen dieselben in unmittelbarem Zusammenhange mit dem Centralnervensystem, inden entweder ein kurzer, dicker Nerv zu ihnen hinlïuft, oder sie den Centralganglien unmittelbar anlliegen. Auch wenn stark lichtbrechende, bilderzeugende Apparate, welehe nur ill seltenen Fällen bei den Rhabdocoelen nachgewiesen sind, imnerlalb des Pigmentes fehlen, wird letzteres allein in Verbindung mit der Nervenmasse zweifelsohne genügen, gewisse Lichteindrücke zum Bewusstsein zu bringen.

Nur bei wenigen Arten findet sich keine Spur dieser Augen. So bei Opistn. mum pallidum, Monocelis unipunctata, Vortex pellucidus, Mesostomm (Typhloplanil Örst. Schm.) viridatum, pratense und sulphureum (nach Sclmillt) Nacrostomum auritum. Conroluta und einigen anderen minder genau gekantern. Doch scheint dieser Mangel auf Lebensweise und Bewegungsart obne allell Finlfuss.

Dic Farbe des Pigmentes ist meist ein dunkles Schwarz. Nur bei Nosostomum 
rostratum fand ich wie Örsted stets rothe Angen, wïhrend O. Schmidt anch hier nur schwarzes Pigment sah.

Die Form der Augenllecke ist entweder eine scharf begrenzte, regelmässig wiederkehrende, oder eine unregelmisssig verïstelte. sehr mannigfaltige. Bei den weniggn Arten, welche deutlich lichtbrechende Medien in Ange besitzen. haben die Pigmentllecke eine nierenfürmige Gestalt, und in der nach aussen sehenden Concavitit findet sich die zum Theil von Pigment verdeckte, stark lichtbrechende kugel, einer Linse vergleichbar. So bei Mesostomum marmoratum Tab. I Fig. 2S. a. Tab. V. Fig. 2, und bei Vortex minutus; der kleinsten aller bekannten Rhabdocoelen, beides neue Species aus der Ostsee. Eine ïlnliche Bildnng sah $O$. Sclthidt ${ }^{1}$ ) bei einem neuen jedoch nicht näher bezeichneten Färöischen Nlesostomum. Nierenförmige l'igmentllecke ohne deutliche lichtbrechende Theile finden sich allgemein in der Gattung Vortex, so bei V. viridis, truncatus, balticus, pictus, doch sind sie bei eben diesen Thieren auch oft oval wie bei vielen anderen Rhabrlocoelen constant, so bei Prostomum lineare, Macrostomun hystrix. Die nierenförnigen zerfallen nicht selten in zwei getremite runde Pigmentlecke. So bei Vortex truncatus von Clivenberg ${ }^{2}$ ) und (). Schmidl ${ }^{3}$ ) beobachtet. Ersterer hailt diese Trennung der beiden Augen in vier eimzehe für das normale Verhättniss. Dies Zerfallen eines Auges in melırere ist anch in anderen Ordnungen der Turbellarien nicht selten.

Ganz abweichend von diesen scharf begrenzten Augenflecken sind die diffusen oder verzweigten bei Derostomum Schmidtianum, Mesostomum obtusum und tetragounm. Bei den beiden ersten liegt un die grösseren mregelnüissig rundlichen Augenlfecke noch eine Menge l'igment zerstrent, welches oft brückenartige Verbindungen zwischen beiden Augen erzeugt, auch wohl ein urittes Auge in der Mitte zu bilden scheint (bei Mesostonum obtusum Tab. V. Fig. 1.) oder die ganze vordere Körperspitze so gleichmässig färbt, dass die beiden ursprünglichen Augenllecke sich gar nicht mehr auszeichnen (bei Derostomum Schmidtianum Tab. IV. Fig.6). Bei llesostomum tetragonum liegt dlas Pigment in sternförmigen Verzweigungen, welche oft eine bedeutende Ansdehnung gewimnen (Tab. I. Fig. 29), auch ein Verschmelzen beider Augen bedingen. Letzteres ist bei den rothen Augen von Mesostomnm rostratum selir gewöhnlich.

Die Pigmentmoleküle. aus welchen die Angen gebildet sind, haben nicht immer gleiche Form und Grösse. Dieselben sind numessbar klein, bei den mit einer Linse versehenen Augen und den diffusen Pigmentllecken von Derostonum Schmidtianum, oder sind theiheise zu einer diaphanen Masse verschmolzen, bei 11 es os to mu un

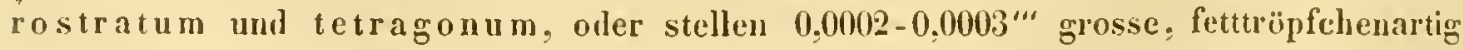

1) Neuc Beiträge etc. pag. 11.

2) Abhandl. d. Acad. d. Wiss. zu Berlin 1835. pag. 178.

3) Die rhabdocoelen Strudelıürmer etc. pag. 28. 
anssehende kïgelchen dar, welche sich von letateren nu durch eine noch stirkere

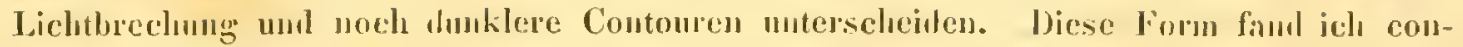
stant bei den nierenlörnigen mul ovalen Augen von Vortex balticus, wo sie \%u 20-30 mit selı weng ganz leinem P'igment vermisclıt je ein Auge zusammensetzen (Tab. I. Fign. 2S. b.), bei Vortex viridis, Macrostomum lystrix. J)i diesen dugen bestimnt eine linse felılt. so halte ich es nicht für umwalıscheinlich. dass die grö̈sseren, jerleufills selı stark lichtbrechenden lïigelehen als bilder\%eugende Theile dienen, in welelıem Falle diese Augen deu zusammengesetzten höherer Thiere vergleichbar wairen.

Bej eingen namentich hei angenlosen Rhabdocoelen funden sich Organe, welche den Otolithen vicler Mollusken ghleichen, und wegen ihner anatomischen liezielıung zum Nervensystem auch hiep als Simnesorgane zu deuten siml. Eime ans líalksal\%en (walı-

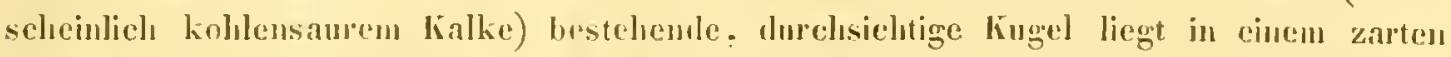

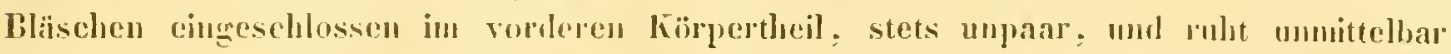
aul' dem ('entrahervensystem. C̈)rsted ${ }^{1}$ ) salı diese Organe zuerst bei der Gattmug Monocelis. und dentete sie als aus Glaskörper und Linse zusammengesetzte Augen, zu weleber Amalnue er namentlich dadureln gefïlut wurle, dass bei melueren species regeluaissig cin sebwamer Pigmentleck ïber denselben liegt. Frey un Leuckar(2) gebülırt das Verdieust, die lıleutitït dieser Theile mit den Gehörorgancu mancher nimerer Thieve zuerst ausgesprochen zu haben. Sie fanden diesclben ausser bei Monocelis auch bei Convoluta paradoxa. O. Srhmill ${ }^{3}$ ), welcher diese Organe anf seiner lieise nach len fïrï ebenfalls beobachtete, und anch noch bej einer nenen Art, Proporus Cyclops, aufianl, hat sich mit Jer Frey-Lencliarl'schen Deutung niclut einverstandeu erklärt. Olne die anatomische Tebereinstimunng dieser Organe mit den Otolithen vicler Mollusken lengnen zu künuen, ausgenommen dass ilunen die oscilliende Beweguug fehlt. glaubto er die Bedingungen zur Anualume, dass man es lier mit ejuem zur brechung von lichtwellen bestimuten Apparate zu thun luabe cbenfalls wirderufmlen. Vurl in der 'That melır geneigt diese Organe fïr Angen als für Ohren zu lıalten. stellte or als Mittelweg die Vermuthumg auf, lass in densclben die Gehörsund Gesichtsfunction rereingt sci.

lch habe das fragliche Organ bei : Species der Gattung Mnnocelis, bei Convoluta mul einem neuru Macrostomu aus der Ostsec, welches jelı a ritum nenne, beobaclutet. Tab. Il. Fig. 1. S. a. Tab. V. Jig. 4. a. Nur hei zwei MnnocelisArten agilis mml lincata liegt rin dumkler pigmentleck in der Nïhe dieses Orgaues, bei den ïbrigen genanten Thicen mul auch bei proporns Cyelops (nach Nrhmilt) fehlt ein solcher gäizlich.

Abgeselies davon: dass Angen ohne durkles l'igment noch nie beobachtet sind,

1) Entwurf etc. pag. 7. 5..

!) licitrige etc. biag. $\$ 2$.

3) Neuc beitrage elc. pag. 11 
Albino-Bildungen und einige in unterirdischen IIöhlen lebende Thiere ausgenonmen, welchen letzteren jedoch, bei zwar vorhandenen nervns opticus, auch lichtbrechende Medien gänzlich zu fehlen scheinen, würde auch die Annahme, dass ein aus kohlensaurem Kalk bestehender hörper als Linse fungire, eine ilureh keine Analogie unterstützte sein. Fassen wir ferner lie Lage des Pigmentfleckes zu dem als lichitbrechendes Organ angesehenen Körper bei Monocelis ins Auge, so spricht anch liese gegen die Deutung von Örsted und O. Schmidl. Wiilurend sonst überall das Angenpigment die lichtbrechenden Theile so umgiebt, dass seitlich einfallende Strahlen ahgehalten oder eingesangt werlen, wïrle der Pigmentlfeck bei Monocelis im gralen Gegensatze lierzu bewirken, dass nur seitliche Strahlen zur vermeintlielıen Linse gelaugen. läne pupillenartige Durchbohrung des l'igmentes fiudet niclit statt.

Ist es auch sonst richtig: dass, wie $O$. Schmirlt sagt, ,bei allen Thieren, welche nicht mchr die volle Zahl der Simnesorgane haben, immer eher Augen als Olnen zu erwarten sim]": so stehe ich doeh in diesem Falle nicht an, gestützt auf die anitomi sehen Thatsachen, das fragliche Organ einen Otolithen zu nennen, und eine Theilnalne desselben an der Vernittehng von Gesichtseindrücken für selır unwalıselıeinlich zu erklïren. Den in einzelnen Fällen über diesem Gehörorgan liegenden selwarzen P'igmentlleck halte ich für ein von ersterem ganz getrenutes, bestinmter brechender Medien ermangehndes, dem Ange vieler anderer Rlıabdocoelen analoges Gesichtsorgan.

Von ren mit einem einzigen runden Otolithen versehenen Gehörorgan bei Convoluta, Macrostomum auritum mol Proporus unterscheidet sich dasselbe bei Monocelis dadurch, Jass neben Jem kngligen noch 2 kleinere, unregelmïssige Gehörsteine liegen: welche ersterem an der nach vorn sehenton Flïche aufsitzen. Sehon Orstcd hat dieselben gesehen, und zwar bei seiner Auflassung dieses Apprarates als Auge, sie für 2 Linsen erklïrt, wälırend der grössere Otolith dem Glaskürper entsprechen sollte. Frey und Leucliart billeten diese kleineren Otolithen ganz richtig ab (Reitriige etc. Tab. I. Fig. 1\$), doch ist ihre Beschreibung der Natur nicht ganz entsprechend. Ich kann in denselben keine ,, solide, gekrümmte liogen erblicken. welehe mit ihrer Convexitit der Gehörkapsel aufsitzen, und mit beiden Selsenkeln sich der Oberläthe des Otolithen anlegen.: Mir erseheinen dieselhen als Körper ron unre gelmässig pyramidaler Gestalt, die mit der breiten Basis anf dem runden Gelı̈rstein liegen, aber mit lıenkelartig gestalteten Bägen nichts gemein haben. In Sänren behalten sic lïnger als der runde Otolith ihre scharfen Contonren, werden jedoch auch endlich gelöst, wobei eine organische Grundlage zurïekbleibt, welche ebenso wie bei dem grös seren Otolithen naeh den Verselwinden der anorganischen Bestandtheile der aullösenden líraft schwächerer Sïuren widerstrlat.

Als Sitz des sehr entwickelten Tastsinnes der Turbellarien ist lie Haut anzuschen. Hhe anatomischen Verhältnisse bei den Rhabdocoelen sind oben genan 
dnrchgenommen worlen. In vie Weit die stäbchenfürmigen Kö̈rper bei dieser Funktion der Haut mitwirken möchten, rurde pag 16. angedeutet.

\section{Wassergefässsystem.}

Die Kenntmiss der Wasscrgefïssveristelungen im Körper der Rhabdocoelen sowie der freien Mündungen diescr. Gefüsse nach anssen verulanken wir $O$. Srkmidt. leh labe seiner Beschreibung dieser Theile (die rhabdocoel. Strulelwimner etc. pag. 11) kaum etwas hinznzıfügen. Die Bewegung der Flüssigkeit in diesen Gefïssen, deren Verzweigungen in günstigen Fällen sich bis zur unmessbaren Feinlıeit verfolgen lassen, und deren Wandung auch ich nie contractil sah, geschieht durch eigenthinmliche Winperïppelien, welche an einer Stelle der Gefïsswand festgewachsen, frei in das Gefüss hinein ragen. und in umunterbrochen schlängelnder Bewegung begritlen sind. Sie liegen oft recht dicht nebeneinander, wie die Abbildung eines Theiles des Gefisssystems von Mesostomm tetragonm auf Tab. I. fig. 31 zeigt. In den grössten Gefässstümmen in der Nähe der nach anssen führenten Oeffunng fehlen sie, ebenso sind sie in den feinsten Verzweigungen nicht zu entdecken. Fine sehr sleutliche 0,001"' breite Wand sale ich constant an lem Hauptgefüssstamm vou Mesostomum tetragonum.

\section{Verdaungs a p a rat.}

Als einzelne Theile des stets afterlosen Nahrungscanales der Rhabdocoelen sind zu unterscheiden die Mundäffnung, lel muskulöse Schlund, von den bisherigen Schriftstellern meist Mund genamt, wnd der einen einfachen lilindsack darstellende Darm. Nur in der Familie der Schizostomeen fehlt der Schlund.

Der Mund ist eine einfache Oeffunng in der Haut, an welcher die oben beschriebenen blassen Hautmuskelfasern eine solehe Richtung und Lage annelımen; dass eine Frweiterung und Terengerung derselbrn leicht ausfiilmbar vird. Wegen Mangels anderer auszeichnender Bildungen an der Jlundöffumg ist dieselhe leicht zu übersehen. Nur bei Macrostomum lystrix funde ich die Muskulatur des Mundes so stark entwickelt, dass uerselbe schurll in die Augen fïllt Tab. V. Fig. 3. a. Viel schwerer ist r bei Macrostomun a urum zu erkennen. Bei Mesostomum tetragoun 
und rostratum lirgen um lie Mumdïftumg hermu eine Menge diclst gedringter rumler kemloser Bläschen in der Ilaut. Vielleicht sind es gan\% niedrige P’apillen.

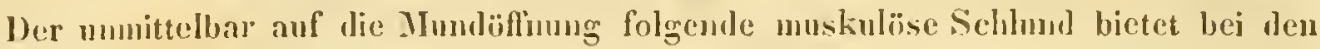
einzehen Fanilien: Wrelche allein nach dessen Form und Lage abgetheilt wurlen: grosse Verschiedenheiten dar. Bei den Opistomeen ghloblat er ainer cylindrischen Röhre, bei den Derostomeen ist a tomenförmig, wie ein Sangnapf gestaltet bei den Me sostomeen, bei den Prostome en strilt er einen aus melureren Abtheilungen hestehenden Canal dar: bei den Schizostomeen felılt er ginzlich. Die muskulasen, schr derben und leiclit aufallenden Ẅ̈̈nde dieses Organes sind aus dicken Lagen vou Längsund Ringfistru gebildet. Ibi den Mesostomeen mo Opistomum jallidum liegen zwischen den tieferen Lïngafnsem Canïle nit. eincr feinköruigen Flüssigkeit gefüllt, welehe bej den Contractiones hin und her gretrieben wird, an der verengten Stelle ausweicht. und bei لler Erweiterung vieder zuströmt. Diese Bildung ist lıei Mesostomum

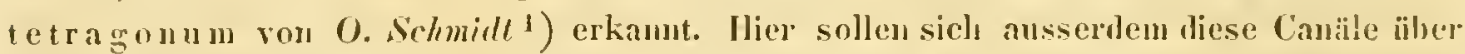
Jen Scluluud hinaus in lïngere, radienartig im Kïrper verbreitete nit eine blasigen Anschwellung emlende Röhren fortsetzen, welche ebenfalls nit der feinkïrniggen Fliissigkeit erfüllt sinal. Ich knmute in diesen R̈̈̈ıеn mu Büılel feinkürniger Fasern erkennen, nie abel die Bewegumg ciner Flüssiggkeit ähulich wie zwischen den Muskelı des Schlundes. Blasige Auschwellumgen au Eude habe ich auch bei vollständig erwachsenen Thicen nicht grefunlen. Die feiukürnigen Fasern, welche in der Nïhe des Schlundes zu dichten Bündeln vereinight waren, salı ich an ller Stelle, wo Nchnirlt die Endlılasen abbildet, sich ron einander tremnen. und einzehe divergirend im kïrper verbreiten. Die Bedeutung derselben ist mir noch unklar geblicben, loch kann iels die Vermuthmg richt unterdrïcken, lass, ta ich Parenchymmuskelfiseru manchnal deutlich in ilmuliche feinkörnige Fasem übergehen sah, wir es auch hier mit einer beson. deren Form ron Muskel zu thun laben möchten.

Des Schlund wirı nus durel seine Verbindung mit dem linter jlum berginneudeu 1)arm. und dusch die sich an iln ansetzenden Nuskeln in seiner Lage erhalten. Nach lem Zerreissen diesej V'erbindungen kann er leicht isolirt werden, und zeigt dam oft noch längere Zeit selbststïndige Contractionen, ailunlich wie sie an der Schlundrïlıre des Dendrocoelen in so ausgezeichuetem Grade vorkommen.

Der I) an Jej Rhabdocoelen ist constant mit eigenthünlichen Zellon ausige kleidet. Fine faserige ouler structurlose IIant besitzt Jerselbe nielt. Die Zellen siml ruml, vou 0,015-0,006" Jurchnesser, farblos mu durelssichtign, unl haben ciueu dun-

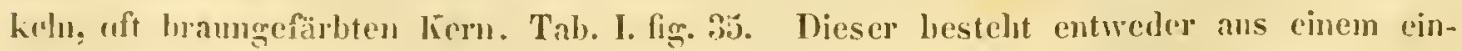
rigen scharf coutourirten, cincm Fetttröpfuhen ganz gleichenden lï̈rperchen, oder aus meluesen diclut verbundenen Mlolekiilen. und hat in letzterem Falle wlt eine unregel-

1) Die rlabilocuelen Strudelwiimter etc. plag. 45. Tab. III. fig. 86. 
mässige Gestalt. (). Schmirlt ${ }^{1}$ ) hat dieselben Zellen bei Vortex (IIypostomun) viridis als eine zusammenhäugende Sehicht isoliren kïmen. Lei den meisten ührigen Rhabdocoelen liegen sie nicht in der Weise dicht aneinander.

Wimperbewegung im lumern des Darms, wie sie bei den mit emen After versehenen Turbellarien vorkommt, habe ich sehr deutlich und constant bei Ma $\mathbf{c}^{\circ}$ stomum hystrix beohachtet. Die Speisereste waren hier in Grumde ver Verdaumgshöhle in steter Rotatiou begriften. Bei den ïbrigen Rhabdocoelen scheint dieselbe zu fehlen.

D) rüscuartigr Gebilde, welche zun Verdaungsapparat zu rechuen, liabe ich nu bei den loerostomeen geschen. Es sind dies 3 oder 4 jederseits nehen dem Schlunde liegende, nit einem Ausfïlurungsgang versehene Zellen, in welehen hei jungen Individuen deutlich eiu Kern, später ein feinkörnigger Inhalt unterschieden werden kann. Mit ihren Ausfïhrungsgängen liegen sie alle der Stelle zu, wo Śchlund und Darm einander berihrem ${ }^{2}$ ). Dieselben lassen sich den von Leydig beschrichenen einfachen Drüsen von Pisciegla und Argulus vergleichen ${ }^{3}$ ). Vergl. Tab. III. Fig. 4. e bei Vortex viridis, Tab. IV. fig. 1.5.6. I bei Vortex balticus, pellucidus, Derostomum Schuidtiannm.

\section{Geschlechtsorgane.}

Nachleu die eingeschlechtlichen Mikrostomeen vou den Rhabdocoelen entferut sind, funden sicls jetzt in dieser Orduung der Turbellarien mur hermaplooditische Thiere vor. Dic männliclıcn Orgame bestehen aus Hoden, Sameublase und Begattuugsorgau. die weiblichen aus Keimstöcke». Dotterstïcken, Eiertasche url Samentasche. Durch eine Oeffunng miunden die Organe beiderlei Geschlechts.

In allen Familien der Bhabdocoelen mit Ausuahme der Prostomeen kommen doppelte Hoden vor. Bei zwei Arten der Gattung Mesostomum, den anf Tab. V. fig. 1. 2. abgebildeten nenen .I. obtusum und marmoratum, habe jeh jedoch nur einen Ilorlen selıen können, während zwei andere neue Species derselben (iattung aus der Ostsee, deren specielle beschreibung ich nir für die ote Abtheilung anfspare, deutlich doppelte Hoden besitzen. Lei den Opistomeen, Derostomeen und bei Macrostomum sind constant 2 Hoden vorlanden.

I) I. c. pag. 31. Tal. II. fig. 4. b.

2) O. Solmidt erwälnt bei Fortex viridis auch eincr drisigen Masse an her hezeichneten Stelle, oline dieselbe jedoch näher zu lieschreilien oder ahzubilden.

3) Zeitscbrift für wissensch. Zoolngie von r. Siebold uod Külliker. Bd. I. pag. 109. Bd. II. 
Die Iloden sind Schläuche mit einem engen Ausfülırungsgang, weleher in die Samenblase führt. Sie reichen oft von einem Ende des lï̈ppers bis zum anderen, sind aber nie gewumlen. Die Bildung der im reifen Zustande stets sehr langen, fadenfïrmigen Spermato\%oiden geht in denselben auf zweierlci Weise vor sicl. liei einigen Arten finden sich die aus den Spermatozoiden-Mutterzellen entstandenen Kéeimzellen zu 20-30 nm eine homogene, durehsiehtige língel gruppirt, un in dieser Lage die Samenfiden aus sich zu entwiekeln, sei es durch Metamorjhose des lierns oder Ausdehmung der Zellenwand selbst. Die strahlenfüruig an der unverüindert gebliebenen mittleren Kungel anhängenden Spermatozoiden lüsen sich später einzeln ab, verlieren die kopfartige Anschwellung, welche sie im Anfang besassen, und werden fadenfürmig. Diese Art der Entwickelung, welehe bei Anneliden unt anderen wirbellosen Thieren schon rielfach beobachtet ist, findet sich bei Monocelis und II a crostomum hystrix. Siehe Tab.ll. fig. 2-7. Bei Opistomum, den Derostomeen und Mesostomeen dagegen liegen die aus den Mutterzellen hervorgegangenen Spermatozoiden-kémzellen stets einzeln. Von den homogenen kingeln oder einer Gruppirung zn besonderen Zellenhaufen ist nie eine Spur da. In ihnen bildet sich wahrscheinlich Jurch Umwandlung des Kernes je ein Samenfaden, weleher die Wand der Zelle erst vor sich hertreibend, dann durehbrechend endlich frei wird. Tah. I. fig. 3r u. 35 . Eine eigenthümliche Form der Spermatozniden hat $O$. Schmidt ${ }^{1}$ ) von $O$ pistomum pallidum beschrieben. Hier soll die Mitte des Samenfadens mit einer Anschwellung versehen sein. wihlend eine solehe sonst nur an einem Ende vorzukommen pflegt. Tab. I. fig. 39. a. Iclı kann in dieser Form, welche ich ebenfalls häufigg beobachtete, nur eine eigenthümliche Entwickelungsstufe sehen. Die Spermatozoiden aus der Samenblase zeigen die Anschwellung nicht, lagegen meist eine korkzieherartig gewundene Stelle da, wo vorher die Ansehwellung war (Fig. 39. b). Bei den Samenfïden aus der weiblichen Samentasehe ist jedoch anch diese rersehnunden, und die Bildung eine wie bei den übrigen Rhabrlocoelen. (Fig. 39. c.).

Die Samenblase stelt eine orale oder runde, melir oder weniger dickwandige Höhle dar, in welche einerseits die vasa deferentia einmünden, während von ihr andrerseits ein Canal nach dem penis fülırt.

Ein Begattungsglied fehlt den Rhabdocoelen mur in den seltensten Fällen. so bei Mesostomum obtusum Tab.V. fig. 1. Meist ist dasselhe durch harte, Widerhaken bildende Theile selur ausgezeichnet, zu deren Entfaltung eine Art ron Erection nothrendig wird. So bei Monocelis unipunctata Tab. Il. fig. 10. Opistomum pallidum Tab. III. fig. :3, Vortex viridis Tab. III. fig. 5. Bei anderen Arten stellt dasselbe eine einfache Rïlire dar: so hei Vortex balticus Tab. J.fig.1. Derostomun Schmidtianum Tal. W. fig. 6. und bei llen meisten Mesnstomeen. Sehr lang ist dieselbe bei V. pellucidus Tal, IV.fig. S.. bei Mesostomum marmoratum

1) Die rbabdocoelen Strudelwïrmer pag. 16. Tah. V. fig. 14. I. 
Tab. V. fig. 2. Hakenfürmig gekrümmt ist ler penis bei Macrostomum hystrix. Aus einer weichen Papille besteht er bei Monocelis agilis Tab. Il. fig. I.d., Nonocelis lineata fig. 12. M., Macrostomum auritum Tab. V. fig. 4. e.

Die Sulstanz, ans welcher die harten Theile iles penis gebildet sint, ist eine eigenthümliche, durch folgende ehemische lïgenschaften ansgezeichuet: Von kalter concentriter Kalilange wirl sie nicht verändert, ebensowenig ron kilten mud kochendem Ammoniak; kochende Kalilauge liist sie schnell auf. Darlurch untersclueidet sie sich vou dem Chitin. Coneentrirte Sümen lüsen sie bei gewöhnlicher 'Temperatm' nicht auf, Essigsänre und Salzsäure anch nach lïngeren Kochen nicht, wïhreul sie von kochender Salpeter- und Schwefelsänre allmählig grelïst wird. Gleiche chemische Eigenschaften bietet das von $O$. Schmidl als Giftorgan gedeutete Stilet ron Prostomum lineare dar. Andere aus dieser gegen starke Sïuren uml Alcalien so resistenten Sulstanz gebildete Körpertheile finden sich bei deu Rhabılococlen nicht.

Die weiblichen Geschlechtstheile sämmtlicher Rhabdocoelen nit Ansuahme der Gattung Mincrostomum zeichnen sich dadurch aus, dass Eikeime mod Dotterunase in verschiedenen Organen gebildet werden, und erst zur Zeitigung des lies in einen besonderen Eiersack zusammentreten. Diese auffallenle Anordnung, welche O. Schmill zuerst bei den Rhabdocoelen kemen lehrte ${ }^{1}$ ), koum bei den Trematoden unter den Eingeweidewïmern nach r. Siebold's ${ }^{2}$ ) Entdcckung elsenfalls vor. Bei den übrigen Ordunngen der Turbellarien findet sie sich nicht, sie müsste Jem bei den Süsswasserdendrocoelen (der Gattung l'lanaria (̈̈rs..), deren Geschlechtstheile noch nicht himlänglich bekannt sint, noch nachgewiesen werden.

Die lieimstïcke siud entweder doppelt vorhanden, bei II onocelis und einem grossen Theil aler Derostomeen: oder eiufach. Sie stellen kurze unl wegen ihrer Bliisse oft sehr schwer zu fundende Blindschliuche dar, welche 10-80 Zellen enthalten. unit einem durchsichtigen feinkörnigen Inhalt, Keimbläschen und Keimlleck. Die dem Ausführmıgsgang des Keimstockes zmuïclıst liegenden sind die grössten und kugelrund, am blinden Ende sind die Eikeine klein und abgeplattet.

Die Dotterstöcke sind stets doppelt vorhanden. Sie zeigen sich als lange, vielfach ausgebuchtete odler verzweigte Schlïuche, in gefïllten Zustande dnrch ihre weisse Farbe und Undurchsichtigkeit leicht auffallend. Der Inhalt besteht aus Dotterzellen und freien Dotterkiirnchen.

Keimstücke und Dotterstücke müuden meist zusammen in einen Canal, weleher in den Raum fülnt, in dem die Eier ontwickelt und nit einer harten Schale ungeben werden sollen. Gleichfalls pllegt die weibliche Samentasche, zur Aufuahme ler Spermatozoiden nach ter Begattmng hestimnt, mit diesen Theiten in Verbinulung zu

1) I. c. pag. 16 .

2) Vergleichende Anatomie pag. 14\%. 
stehen. Ilier kommen manche Verschicdenheiten vor, welehe erst bei dis speciellen lieschreibung der Arten erwïhnt werden sollen.

Ist likeim unl Dottermasse in den liersack (uterns) eingetreten, mul die liefruchtung geschehen, so beginnt lie Bildung einer harten, erst farblosen spüter rothbraun erseheinenden Schale. Bei Vortex truncatus, V. pusillus n. sp., l'rostomum lineare welcher grleichfalls aus der bramen Eischalenmasse besteht. O. Schmidl ${ }^{1}$ ) verunuthet, dass dieser Fortsatz sich in llem Canal bildet, welchen der Dotter passiren musste. um zum uterus zu gelangen.

Die Eier werden, nachdem sie die harte Schale beknmmen hałen, von dem Thicre noch eine Weile herumgetragen. Bei manchen hildet sich niclit eler ein neues, bis das erste entfernt worlen. (Vortex balticus, truncatus, Derostomm Schmidtianum u. A.). Bei Opistomum pallidum künen his b Eier zu gleicher Zeit im uterus liegen. Bei Anderen lü̈ufen sich dieselben in grossen Mengen bis 30 und nehr in einem Raune zwischen Darm und Haut an, in welchen sie rom uterus aus gelangen (bei Vortex viridis mu vielen Mesostomeen).

Eine Entwickelung des Embryo labe ieh im Innern der ron dem Uutterthier noch beherbergten, hartsehaligen Eier mur bej Vortex balticus gesehen. Hier enthält das immer nur einfach vorlandene $\mathrm{Ei}$ ganz constant zwei Keimbläsehen, welche sich zu zwei Embryonen entwickeln, die vollständig ansgebildet nebeneinander im $[E i$ liegend beobachtet wurden. Tab. IV. fig. 2. Bei anderen Rhablocoelen werden die Eier gelegt, elıe lie Eutwickelung des Embrṛo hegonnen hat. Dieselben künnen dann Nonate lang trocken licgen, olme dass ilırer Entwickelungfïhigkeit dadurch ein Schade geschieht. (Vergl. O. Schmidt l. c. pag. 1S).

Eine merkwïrdige Erseheinung ist lie, dass manche Rhabulocorlen hartschalige Eier enthalten zu einer Jahreszeit, in weleher sich die mäumlichen Gesehlechtstheile derselben noch kaum in ilıren ersten Spuren zeigen: nämlich Ende des Winters. Bei noch kaum halberwacbsenen Exemplaren von Derostomum Schmidtianum, Mesostomum tetragonum, rostratum, pratense, welche ich im Februar mol März sanmelte, entwickelten sich nach kurzem Aufbewalıren in der warmen Stube fast constant hartsclalige Eier, wïhrend bei allen diesen Exemplaren noch keine. Spur von Spermatozoen gefunden wurde. Die so gebildeten, und nach dem Legen sorgfiltig aufbewahrten Eier zeigten nach 2 Monaten noch kcine Embryopntwickelung. Auch in Freien habe ieh im ersten Frülyjalı hie und la solehe oflenbar an fiüh entwickelte hartsehalige lier bei den angegebenen Mesostomeen gefunden.

Die harte branne lisschale besteht ans einer Substanz. Welehe dem Chitin in seinem Verhalteı gegen Alcalien und Süuren gleicht. Ieh fand lieselbe vollkommen nuluslich in kochenter concentrirter Ḱalilauge. in Ammoniak mul Lssigsäure. lïslich

1) Die rhabdocoelen Strudelwürmer pag. 2!. 


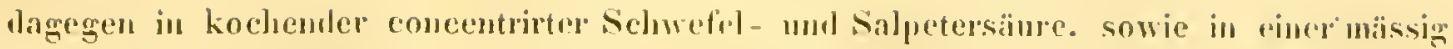

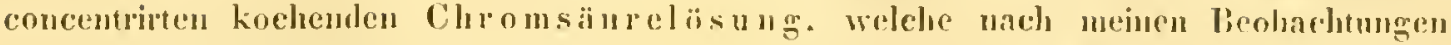

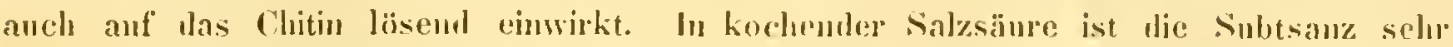
schwer läslich. Ebenso verlicelt sich die harte Srohale der liber ron Planaria lactea.

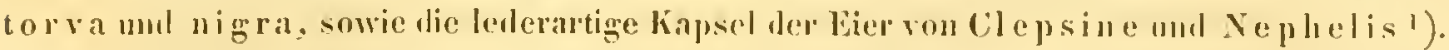

Nieht alle Phabdocoelen logen hartschalige Vier. Einige Mesostome en mud

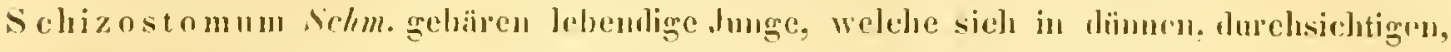

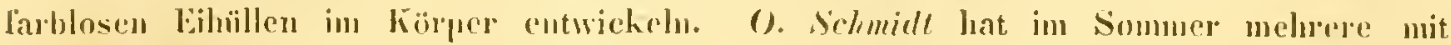
einer grossen Anzahl Inugen angelüllte Arten beobachtet ${ }^{2}$ ). Gegon den Winter lin legten dieselhen Arten jedoch anch hrane hantschalige lier. Eine Ml etamorplose

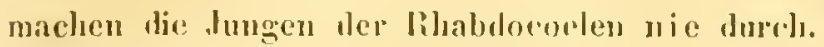

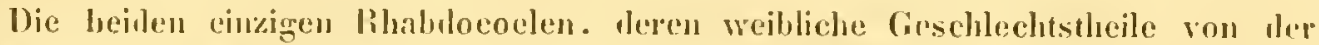
olsen beschriebenen Anordumng wesentich abweichen, sim Macrostomum lıstrix

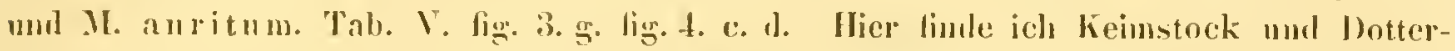
stock in einem schlauch rereinight. in dessen oherem Theile die likeime dielıt gerlringt liegen, willrend sich im muteren die Dottermasse nu dieselbon ablagret. Jic Eier entstehen so. dass sich der unterste Theil dieses Sehlanehes mit einem Keim-

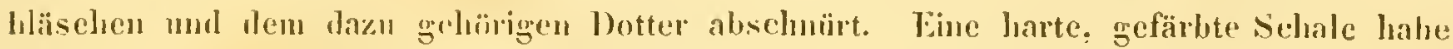
ich nie un das Ei gebililet gesehen.

1) Die Verloreitung des Chitin's bei wirhellosen Thieren zeigt sieh in immer ausgedelunteren Grade. Als wesentlicher Bestandtıeil der Haut der Insecten, Arachuiden, Crustaceen und Borstenwirmern namentlich durch $C$. Schmilt's Arheit (Zor vergleichenden Physiologie der wirlsellosen Thiere 1845) bekannt, ist dasselhe von diesem Forscher neuerdings (Arehiv lïr Naturgeschiehte 1850. pag. 253 in Grube's rortrefllicher Arbeit "die Familien der Anneliden") aveh in der Haut der Ilirudineen, Lumbricinen, Borstenwïmer und deren Riiliren, ferner bei Sipunculus, Gordius und Asearis nachgewiesen, nachdem kurz vorher lh. Leuchart diesen Stoff in der Haut von Pen tast omum gefunden hatte. Auch bei den Polypen finde ich das Chitin. Die Eischale ron Ilydra viridis und der Polypenstock von Campanularia genieulata und Sertulariat abietina (letzere rom Mlittelmeer aus der Sammlung meines Vaters) besteht aus einen Stofl mit allen Eigensehaften des Chitins, wie sie uben angegelsen wurlen, logaht.

2) Mesostomu lingua. Sehizostomum froductum. Nich Focke gebärt auch Mesostom um Ehrenbergi lebendige Junge. 


\title{
II. Specielle Beschreibung der beobachteten Arten.
}

\section{Opistomea.}

Mund im hinteren Theil des Körpers gelegen, Schlund schlauchförmig. Gattungen. Monocelis, Opistomum.

\section{Monocelis. Örsted.}

\author{
(Tab. II.)
}

Schlundröhre frei, ohne seitlich sich an dieselbe ansetzende Iluskeln. Körper cyliudrisch, langgestreckt. Im vorderenzugespitzten Ende ein Otolith, bei einigen Arten noch vor demselben ein Auge.

Ehrenberg stellte für die ron $O$. Fr. Müller ${ }^{1}$ ) heschriebene Planaria rutilaus die Gattung, Mo nocelis auf ${ }^{2}$ ) ansgezeichnet durch das einfache mittlere Auge, unl ordnete dieselbe den Dendrocoelen nnter, gestiitzt auf die Muiller'sche Abbildung, welche einen verzweigten Darmkanal andeutete. Erst Orsted $^{3}$ ) characterisirte die Gattung genauer nach den 3 von ihm bei Kopenhagen beobachteten Arten Mon. unipunctat a identisch mit Planaria unipunctata O. Fubricius, Mon. lineata gleich Plan. lineata O. F. Mïller und Mou. fusca. Monocelis rutilans Ehrbg. wurde seit O. $\mathrm{Fr}$. Mïllev nicht wieder gesehen; nach der oben citirten Abbildung kann dieselbe den 3 Örsted'schen Arten wohl als 4 te beigesellt werden.

Orsted bringt die Gattung Monocelis ans Ende der Dendrocoelen. Den Darm faurl er zwar nicht baumförmig verzweigt, sondern ,:aus lauter kugelfürmigen Blindsäcken bestehend." Die weitere Organisation betreffend crfahren wir von Örsted nur noch die Structur des Auges (Iles späteren Otolithen) und die Form des Zeugungsgliedes. Frey und Leuckrn't ${ }^{4}$ ) beohachteten an der Küste Ilelgolands Monocelis lineata. llire Untersuchungen bezichen sich nur anf die Otolithen. Vergl. pag. 25. O. Schmidt ${ }^{5}$ ) fand

1) Lool Dan. III. pag. 49. Tal. 109 fig. 10. 11.

2) Symbolae plyysicae. Plivtozoa Turbellaria.

3) Entwurf ete. pag. 55.

4) Beiträge etc. pag. 82.

5) Neue Beitrige etc. pag. 18. Anm. 
auf seiner Reise nach den Färür und nach einer mündlichen Mittheilmg anch an der Norvegisehen Küste Mon. fusca. Ueber den Darmkanal sagt derselbe: . Örsted's Angabe ..Der Darmkanal ist nicht baumartig verzweigt, sondern hestelit aus lanter kugelfürmigen Blindsïicken,": ist sehr unggenau. Nicht nur. Jass lev haumartig verzweighte Damkanal vorhanden ist, (womit aber, wie ieh vermuthe, leicht die Dotterstïcke zusammen geworfen werden künnen), tritt ausserdem nie die Nalıung in diese kugelfürmigen. kurzgestielten mul mit einer engen Oeffmmg rersehenen Blindsïckehen. Dass diese aber noch eine ganz andere Beleutung lahen mïssen, wird Jedem cinlenchten, der sich bei sorgffiltiger Prüfung überzeugt, dass jerle Kugel einen garbenfümnigen Biinchel langer Wimpern enthäl, welche vom Stiel ans ihren Ursprung haben, und sich gebogen bis an den auderen Pol der Kügel erstrecken:" Ausserdem faud O. Achmilt noch die voni den Dotterstöcken getremnten beiden Keimstïcke anf. - Soweit die bisherigen Angaben der Schiftsteller.

Ich habe an der Ostseeküste in der Nähe ron Greifswald 3 Arten dieser Gattung beobachtet. Monocelis lineata md unipunctata Örst. und eine neue Species: relche ich Monocelis agilis nenne. Der genauen Beschreibung derselhen werde ich eine Zusammenstellung der Allen gemeinsamen Organisationsverhiltnisse voranschicken.

Zunächst bedarf es einer Erklämng. Ilass Monocelis von mir nicht, wie hisher den Dendrocoelen. somilem den Rhabdocoelen zugerechnet worden ist. Dass sich (Orsted in der Deutung der kugligen 1Blasen als Magenanhänge geirt, hat (). Norhmidt richtig erkannt. Speisereste funden sich in denselben nie, somlem allein Entwjekelungsstufen der Spermatozoiden die .. garbenfürmigen Büschel langer Wimperus: sind als solche aufzufassen. Diese vermeintlichen Darmanhinge sind also Hodrubläschen. Was 0 . Schmidt bei Mon. fus ca als verzweigten Darmkanal ansieht. ist mir aus der Betrachtung der 3 hier vorkommenden Arten nicht ganz klar geworden. Letztere haben einen solchen entschieden nicht. Ueberreste der Nalırung habe ich um bei Monocelis agilis im Imern gesehen. und diese, aus einzelligen Algen bestehend, waren im hinteren Kürpertheil wie in cinem Blindsack angehinft. Die bei frisch gefangenen Thieren überall in Kürper verbreiteten Fettrïpfehen himdern die Erkemmmg der Gestalt und Ausdelnung des Darmkanals. Nach mehrmonatlichem Anfbewahren der There in einem klemeren Gläschen ist es mir jedoeh gelmugen bei II n. a gilis cinen ganz leeren, hellen, graden Schlanch im lnnern zu entdecken, den ich für nichts anteres als den leeren Darmkanal halten kamu. Derselbe wurde an den durch langen IInnger etwas gesehrumpften Thieren, ohne Compression mit einem Deckgläschen anzurenden, coustant aufgefunden. Bei llonocelis lineata mol unipunctata liist sich ler Darm auch an frisch eingelırachten Exrmplaren im vorderen von den Guschlechtstleilen uicht eingenommen hörpertheil crkemen. Fr stellt einen fast gauz mit lettrö̈pfehen erfüllten Schlauch dar, wclcher ron den beiden seitlichen Dotterstioken loirlit zu unterscheiden ist. An seinem Emfange zeigrt er eimelue Ansbuchtungen. welche namentlich in zusammensezogenen Zustande des Thieres stark lepvortreten, und welche denen des Darms 
der Nenertinen ïhulich sind. einen Verghteich mit den Darmverzweignugen der Dendrocoelen jedorl nicht aushalten. Nach längeren Verweilen in der Gefangensehaft sedwinden

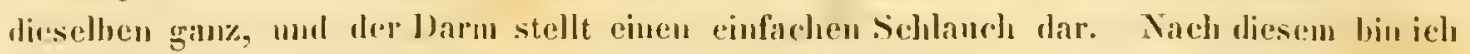

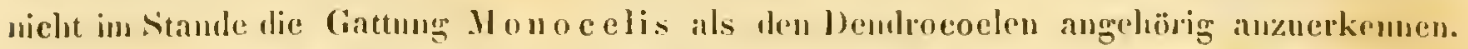

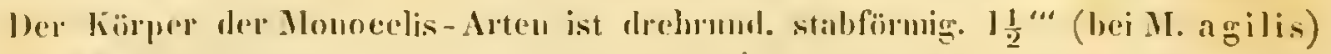

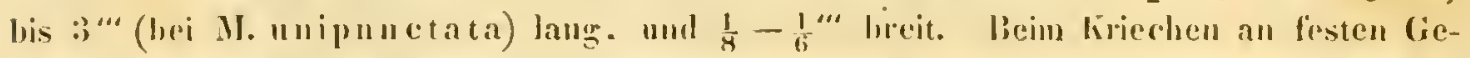

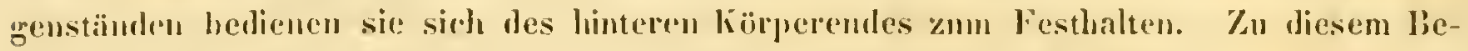
lunfe wirl dassello abgeplattet und breit, und eine Menge kleiner l’apillen treten an der Oberlbible hervor. So bei Howoe elis agilis lig. I. Dielı hinter dem rorderen etwas zugespitzten Kiorperende liegt in Jer Mitte ein Otolith, lessen genauere liessureibung

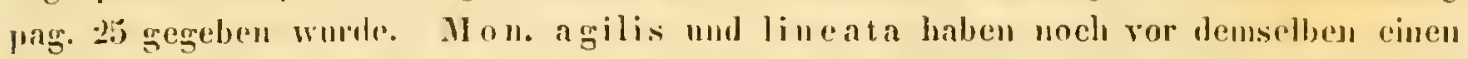
schwarzen ligmentlleck. Welcher als Auge anfzufasson ist. Vuter dem (Jtolithen liegt das Centrahervensytem in Forn rines Ganglion. dessen Cinrisse jedoch trotz den

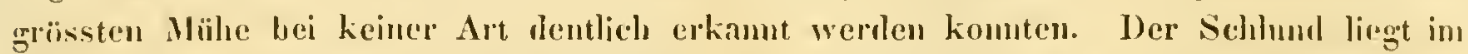
linteren lïrpertheil vor der Mumbiffumg. ist schlanchförmig, vie bei den bendrocoelen. selur beweglich mol bervorstreckbar. Wassergefisse siml als zwei steitliche, vielfach verïstelte Stämme vorhandru. Doeh komuten diesclben mu an den durehsichtigeren Stellen des lïippers. Mümdungen derselben nach aussen aber grar nicht erkannt werden (figg. J.

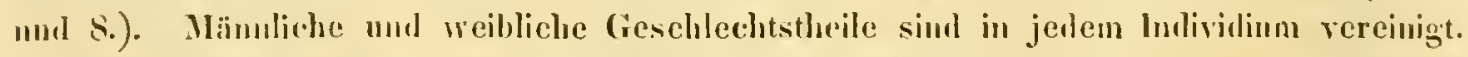
Von diesem nehmen die Hoden den bri weitru grössten Ram ein. Sie bestehen aus lauter einzehnen kughligen Blasen. Welehe: von Örsled für Maggenblasen grehalten wuden. Sie liegen zu $30-40 \mathrm{im}$ mitteren Drittheil des lï̈per's dicht ancinamler, und umgeben dron in der Axe des 'Theres liegenden Darm. Dieselben enthaten Entwickelungsstnfen der spermatozoiden wie sie fig. 3- i abgebildet sind. Im ersten Fribjahr trilit man sie meist noch leer, sic stoblen dann ganz geschlossene, diindüiutige, ovale Zellen mit dentliejı wandständigen lién ilar fig. 2. Der letatere verschwindet bei der begimenden Spermatozoileubildung, welelue auf dic pag. 30 beschriebene Weise vor sich geht, die Waulumg ler grossen Mutterelle, Jenn als solehr glaube ich die Hodenblïschen auftassen \% dürfen, erhält cine Ocfunug. um die reifen Sinmenfüden cutleeren zu kïnnen. Vou April an fand iel bis in den Spätherbst stets die Hoden mit ren hezeichueten Entwirkelungsformen der Spermatozoiden gefiillt. Die sïmmtlichen Ausfïlumugräinge der Ho. denbläschen sammeh sich in zwej zartwandignen vasa deferentia, velehe jedned erst. cine Strecke miterhall, der lloden erkannt verden konnten (ce). Dieselben minubu jeInrseits in rine im hinteren kärpertheil liegende Samenblase (fig. 1. 12. 1. lim. 9. d'). in weleher wihrend der Geschlechtsleife ein dichtes Gewire von spernatozoiden grefunden

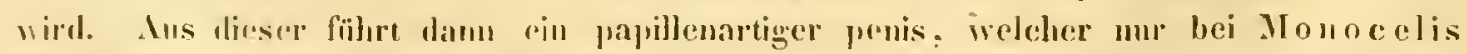

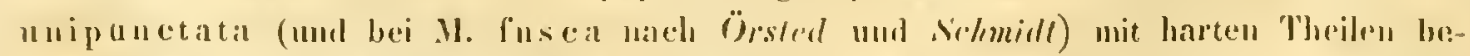
walfuet ist, liach aussen. der fieschlechtsiilfumng (fig. 1. 9. k.) zu.

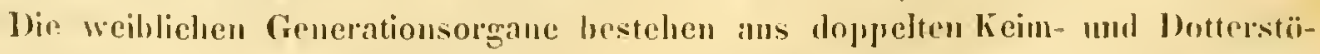

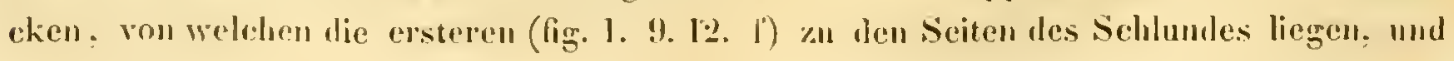


kurze Schlinche darstellen, in welehen eine geringe Anzahl Eikeine mit Kieimblischen und keimlieck enthalten sind, von denen die kleinsten im oberen hlinden bule, die grössten dem unteren Ausfïlurungsgange zu liegen. Die Dotterstöeke, nur bei M. unipunctata und lincata erkamu, stellen grade, vielfach ansgebuchtete Schlinche dar (fig. 9. 12. g.). lïn recejtaculum seminis findet sich bei eben diesen Arten (lig. 9. d. fig. 1.2. h). Jn welcher Weise mol an welcher Stelle die Bihdmg der lier geschicht, ob) diesclben vor dem Legen eine harte Schate erhalten oder nicht. wie die Entwickelung der sungen vor sich geht, konnte bei keiner Art heohachtet werden. Wahrscheinlich ist, dass die Eier sehr selmell nach dem Zusammentritt der Dottermasse mul des Eikejmes gelegt werden. und daher dem Beobachter entgingen.

\section{Monocelis agilis nov. spec.}

Tah. 11 fig. 1.

Kïrper 1 - $\frac{1}{2}$ “" lang, $\frac{1}{8}$ “' breit, vorn zugespitzt, linten abgestumpft, dnreds wenig feinkïrniges l'igment, welches an der vorderen Spitze besonders angehäuft ist, lorïınlich gefärbt. Fin Otolith und darüber ein schwarzbrauner ligmentleck im vorderen Kö̈rerende. Der jenis papillenartig. olune harte Theile.

Diese Art ist die kleinste der bisher benhachteten. Von 1I. fusea, mit releher sie, "as die Färlunng betriflt, am meisten Aelmlichkeit lat, ist sie durch die Grösse und uamentlich durch die Form des Zengungsgliedes unterschieden. Die vordere Spitze ist unit einigen längeren steifen Tasthanren versehen, stäbchenfümuge Körper finden sieh in sehr geringer Anzahl ebenfalls in derselben. Bei einen emzigen unter etwa 50 im (ianzen von mir beobachteten Exemplaren war von dem Gehörapparat kcine spur vorhanden. dabei der Pigmentfleck aber in gewöhnlicher Form.

Die Hodenbläschen e c sind wic bei den übrigen Arten, die vasa deferentia e e münlen in die Sameublase d, und dieser sitzt der papillenartige, weiche, muskuliose penis mmittelbar auf. Die Geschlechtsöffinng $k$ liegt noch hinter demselben. Die Kémstöcke If liegen etwas weiter nach hinten als bei den anderen Arten. Sie vereinigen sich zu einem grmeinschaftlichen Gange, welcher in einzelnen Fällen noch eine strecke weit mach hinten verfolgt werden komnte. Dotterstöcke und reeprtaculum seminis wurden sielst gesehen.

Diese Art ist sehr häufig an der kiniste bei Greifswald, unl wurde roun Fröhjalı bis in den spätherbst beobachtet. Sie hält sieh an den einige Fuss unter der Ober. llärche des Wassers wachsenden Algen anf. und kann durch Abspülen derselben in einem Gilase leicht rhalten werden. doch selhwimnt sie anch gern frei im Wasser, und int selu behend. Slit den inderen IIonocelis-Arten komnt sie nie zusammen vor. 


\section{Monocelis unipunctata Oirsterl.}

T'alb. II fig. $s-10$.

Planaria unipunctata O. Fabricius Kongel. Danske Vidlenskabernes Afhandlinger II. pag. 21. Tab. I. G.

Monocelis unipunctata Oersted Entwurf ei. system. Einth. etc. pag. 56 'Tab. I, fig.

1. 4. Diesing Systema helmintlı. I. pag. 185.

Kürper 2-3" lang, $\frac{1}{6}$ " breit, vorn etwas sehmaler als linten, ganz weiss. Fin Otolith, aber kein Pigmentfleck im vorderen Körperende. Das Begattungsglied im erigirten Zustande mit vielen harten Wilerhacken besetzt.

Durch ilhre bedeutende Länge, sowie Ien Mangel eines Pigmentfleckes üher dem Otolithen ist diese Art von den übrigen leicht zu unterscheiden.

Tasthaare an der vorderen Körperspitze (fig. 8) sowie stïbchenfürmige Kürperehen finden sieh wie bei der vorigen Art. Zellen mit kleinen 0,007" langen Stibchen wurlen auch im hinteren Körperende gesehen (fig. 9). Hinter dem Otolithen liegt ein Ganglion, welehes jerloch nur in seiner oberen, dem Otolithen zugekehrten Begrenzung erkaunt werden konnte. Die Hodenblïschen (fig. 9 cc) sind wie bei ller vorigen Art, ebenso die Keimstöcke ff, welche jedoch etwas höher liegen, neben der Wurzel des Schlundes. Die Dotterstöcke $(\mathrm{g} g)$ stellen zwei lange grade, vielfach ausgebuchtete Schlinche dar, und liegen jederseits einer neben dem Darm. Eigenthümlich sind die ansfiihrenden Theile des Gesehlechtsapparates. Die Samenblase d' liegt am Ende eines Schlauehes p, weleher in seinem lunern eine Menge einwïrts gebogener harter Hïckehen enthailt, welehe bei starkem Drucke des Thieres unter einem Deekgliisehen dureh die Samenblase hindurehgetrieben werden küınen, und dann an der Oberflïche eines ausgestïlpten, prramidenförmigen Fortsatzes der Samenblase erseheinen (fig. 10), weleher als Begattungsgliesl aufgefasst werden muss. Die Ilïekehen sind an der Basis des erigirten penis grösser and 2-3spitzig (in fig. 10. b bei 500 maliger Vergrösserung dargestellt), naeh der Spitze zu werden sie immer kleiner. Der Sehlauch $p$ steht an dem nicht der Samenblase zugekehrten Ende mit einem anderen gleichbreiten Canale hi in Verbindung, weleher von der Gegenrl der kímstöcke herabsteigent walıseheinlieh der Ausführungsgang rer letzteren ist. Im hinteren Kürperende nieht weit von der Geschlechtsüflinung $\mathbf{k}$ endet dieser Kanal ebenfalls in ciner mit Samenfiden angefüllten Blase d, welehe ich für das receptaeulum seminis halte. Dieselbe wurde auch bei vollstindliger Geschlechtsreife oft leer gefunten. Ob von ıer Gesehleehtsüflunng noch ein Canal zu derselben linführt. wurde nicht erkannt. Ein Theil dieses eigenthümlichen Canales nebst den mit Widerhacken besetzten penis ist auch sehon von Örsted. wemgleiel selnr mvollstäulig. ahgebihlet worden (Tab. I fig. 4.) Was er als ,harte muskuliise Scheilec betrachtet. ist mir unklar geblieben.

Diese Art findet sich nicht selten an der llachen Ostsee-Kïste bei Greifswald unter kleinen Steinen mol Holzstiicken. welche nur halb oder hiichstens I Zoll hoch 
vom Wasser bedeckt sind. Tiefer habe ich sie nie gefunden. Sie schwimmt in Glïsern aufbewahrt nicht frei im Wasser, soudern hält sich versteckt anf den Boden des Glases anf. O. Fabricins und Örsted fanden sie bei Kopendagen in Sunde ebenfalls hüufig am thachen Strande.

\section{Monocelis lineata örsted.}

Tab. Il. fig. 12.

Oersted Entwurf ete. pag. 57. Diesing Systema helminth. 1. pag. 185.

Kö̈rper $1 \frac{1}{2}-2 \frac{1}{2}{ }^{\prime \prime \prime}$ lang, $\frac{1}{6}{ }^{\prime \prime \prime}$ breit, vorn zngespitzt, hinten abgestumpft, rein weiss. Vor dem Otolith ein schwarzer l'igmentlleck. Der penis papillenartig ohne harte Theile.

Örsted fülırt als symonym Planaria lineata $O . F$. Mïller verm. terr. et lhuv. hist. I. 2. pag. 60 und Prodrom. Zool. Dan., pag. 222 auf. Die Beschreibung passt jelloch nur in Bezug auf das eine schwarze Ange. Einen weissen Streifen auf grauem Grunde, welcher Veranlassung zu dem Namen gab, finte ich bei meinen Exemplaren nicht, so wenig wie Örsted eines solchen erwïhnt. Ich glaubte desshalb dieses Synonym streichen zu müssen

Diese Species ist ron Monocelis agilis, der sie in Bezug auf den Pigmentlleck über dem Otolithen und die Form des penis gleielıt, dureh ilıre Grösse mud die rein weisse Farbe, sowie auch durch ihre Lebensart unterschieden. Nit M. unipunctata stimmt sie in Grösse, Farbe und Kürpergestalt fast überein.

Örsted bildet auf dem Holzschnitt fig. 10 pag. 57 zwei seitlich zum Otolitheנ herantretende Nerven ab. Diese habe ich nicht gesehen, und glaube auch nicht, dass sie existiren. Der Otolith schien mir auch hier wie bei Mr. unipunctata einem Gangliou unmittelbar aufzuliegen. Hodenblïschen, Keimstöcke und Dotterstöcke stimmen ganz mit denen der vorigen Art überein. Zwei vasa deferentia e e führen zu der Samenblase 1, welche wie bei M. agilis in einen prpillenartigen penis ausmündet. In der Mitte zwischen dem Schlunde mnd der Samenblase fand sich bei vielen Exemplaren eine Anhïufung von sich sehr lebliaft bewegenden Spermatozoiden h, welche wahrscheinlich durch die Begattung hier deponirt wurden. Dieselben waren niclıt in einer Blase (recepta(ulum seminis) eingeschlossen, sondern lagen in $8-10$ kleineren Blïschen, welche um eine mittlere Blase als Centrum gruppirt waren. Manche dieser Bläschen waren ganz leer, andere enthielten mur 2 orler 3 Samenfïden, welche sich in dem verlültnissmässig weiten Behälter lebhaft bewegten. Bei $\mathrm{O}_{\mathrm{p}}$ istomum pallidum werden wir unten etwas Aclunliches finden, inden anch hier die Jurch die Iegattung iibergeführten Samenelemente sich in mehreren kleineren Blïschen vertheilen. Welche oft nuregehnässig zerstreut liegen. Ganz in der Nilhe des hintern Kürperendes unserer Monocelis bei i. wurden enige Male auch solche Blischen mit Spermatozoiden gefunden. 
Diese Art kommt nach Ojrsted's umb meinen Beobachtungen in ganz denselben Verhïlnissen wie die vorige Art: doch bedentend seltener vor. Ich habe sie nur in lıohen Sommer einge Male gelumlen, mod zwar stets gesclilechtsreif.

\section{Opistomum O. srmmidl.}

Sehlundribre durch seitlieh sieh an dieselbe ansetzende Muskelu in iluer lage befestigt. Körper platt. lang gestreckt. Keine Gehör-noch (iesichtsorgane.

\section{Opistomum pallidum (). Sichmill.}

Tab. 111 fig. $1-3$.

Die rhabdocoelen Strudelwürmer etc. pag. 38 Tab. V fig. 14. Diesing Systema helminth. 1. pag. 233 .

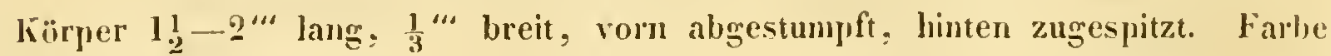
gelblich weiss.

Jie anatomisehen V'erhältnisse dieser Species, welche die einzige ihrer (iattung ist : siml ron $O$. Nhmidt, der nur wenige Exemplare beohachten kounte, zum Theil sehr unzureichend dargestellt. leh lasse daher eine nusfïhrliche, nach einer selır grossen Anzall ron Exemplaren entworfene Beschreibung folgen.

Ueber die feinere Strnetul der Haut vergl. pag. 10. Staibchenfürmige Körperchen finden sich in derselben sowenig wie unter derselben. In dem volderen liüpertheil liegt das Centralnervensystem, ein Doppelganglion nit 3 nach oben, nach der Seite und nach unten jerlerseits abgehenden Nerven (fig. 1. a). Vgl. 1. 22 1. Tab. I. fig. 26.

Der Verdaumgrkanal beginnt in hinteren Kürpertheil nit dev Inuläflumng (fig. 1. b), welche von blassen Ilautmuskehı zum Emeitern um Verengern umgeben ist. Nach vorn zu folgt der Selılınd (fig. l. c), eine stark muskulüse Röhre. mit einem kuopffürnigen, an der Oberllïche wimperuden Mundstïck (fig. 2. c) und einem lïugeren den Magen zugekehrteu Schlundstiick. Die Mluskulatur int in beiden gleich, iussere Ring- und innere Jängsfasern. Zwischen dru letzteren sind Gänge. mit einer feinkörnigen Jlüssiggkeit grefïllt. V'rogl. pag. 28.

Da wo sich lodide Abtheilungen drs Sohlumdes berïlnen. setzen sich ringsum an Jenselben zahlreiche Nlnskelfirden an. welehe an der imeren Oberlhiche Jer Haut in der Nïhe antspringen, mul zur bewegung des ganzen schlundes dienen. Dieser kann hehufs

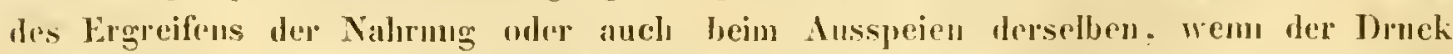

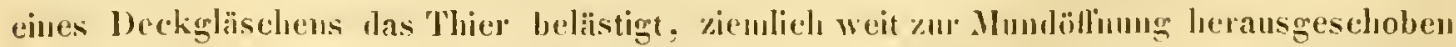
werilen. Nach vorn folgt der Magen. Welcher durelı keine bestimmte II and gegen das 
Parenehrm abgegrenzt erselorint, mit den pag. 2S beschriebenen und Tah. I fig. 35. abgebildeten Zellen unvollständig ansgekleidet. Jir erstreckt sich nie hinter den Schlumd. In seinem Innern triflt man einzellige Algen, Rädlerthiere 11. dergl.

Den Augaben (). Schemidl's, dass der Schlund tonnenförmign, wie bei den Derostomeen sei, unl mit seiner Oeflumg dem Vorderende zu liege, desshall, mit dem Mlagen einen spitzen Winkel bilde, kamn ich nicht beipllichten.

Den rom Verdauungskanal nicht eingenommenen liumm erfüllen fast ganz die Geschlechtstheile. Die Hoden dol sint zwei lange Schläuche, welche mit ilıremblinden Ende his dicht unter das Centrahnervensystem in vorderen Kärpertheil reichen. an dem entgegengesetzten jeder in einen Canal, ras deferens fig. 1. 2. е e, ïbergelıen. Reide münden dicht nebeneinander in ein flaschenföruiges Organ $f$, welches in seinem Banche die SamenJlase, in seinem IJalse den penis enthält. Letzterer fig. 1. 2. g stellt einen langen, gewuntenen, aus der Samenblase ausfïlırenden Canal dar, welcher in Innern melrere Reihen dicht nebeneinander liegender, einwïrts gebogener, kleiner IIäckchen enthailt, und mit einer lutartig aufsitzenden, ebenfalls ans Jauter mit den Spitzen aneinander liegenteu Iläckchen bestehenden Kappe endigt. Von dieser gehen zwei harte Stiibchen nach abwïlts, und schliessen die Contour des Flaschenhalses nach oben ab. Die ganze Flasche liegt in einer dümlı̈utigen Scheide, welche sich über den penis hinaus bis zur Geschlechtsöllhung h rer]ängert. Der Ausführungsgang der Sanenblase wird, un als penis zu fungiren, seiner ganzen Lünge nach umgestïlpt, wodurch die Hïckchen nach anssen treten, und den ans der Geschlechtsöfinung weit hervorstehenden Glierle ein Ansehn wie in Fig. 3 geben. Die vorher an der Spitze befindlichen beilen harten Stäbchen liegen jetzt an der Basis gleich zwei Strebepfeilern. Durch Druck konnte icl den penis immer nur unvollständig zur Umstiilpung bringen. Dagegen sah ieh einmal an einem todten Exemplar, welches mit einem anderen zusammen in einem engen Gläschen längere Zeit gelebt hatte, Jas Beghattungsglied vollstïndig so erjgirt, wie fig. 3 dasselbe zeigt, und in seiner ganzen Länge aus der Geschleclitsüffnung hervorragen. Was die Spermatozoiden betrifit, so vergleiche man über deren Eutwickelung und Gestalt pag. 30.

Die weiblichen Geschlechtsorgane bestehen aus zwei Dotterstïcken. einem Keimstock, Scheide und receptaculum seminis, sowic Eiertasche orler uterus. Erstere mm sind zwei lange. schmale, etwas buelutige Schliuche, welche dicht mit botterkörnchen und Zellen angefültt sind. Mlr blindes Ende liegt in der Nähe aler vorderen Körperspitze. an dem entgegengesetzten münden beide nebeneinanter dicht neben der Mnndoffhung in einen Panm fig. 2. o. welcher vor iler Geschlechtsreife viele kleine gekernte Zellen, später Dottcrkörnchen entbält, und in dessen Mitte das receptaculum seminis fig. 1. 2. k liegt. In dieses gelangt man von der Geschlechtsiiffumng h nus Jurch eine lange ziemlieh starkwandige Scheide i, welche in ilnem Anfangstheil weit und muskulizs. gegen das receptaculum hin eng und selnr blass ist. 
Neben dem Raum, in welehen die Dotterstöcke münden, liegt der Keimstock l, 10-12 Eikeime enthaltend, und ebenfalls neben ihn der Eiersack n, in welchem die Dottermasse unl Keimblischen zusammentreten, und mit ciner harten Eischale umgeben werden. Dieser mündet an ver Geschlechtsöffnung h nach aussen.

Gleich nach der Begattung findet man die weibliche Samentasche gedr:ingt roll Spermatozoiden, wie in fig. $1 \mathrm{k}$. Einige Tage spüter zeigt sie sich jeloch wieler leer (fig. 2. $\mathrm{k}$, wo ihre dieke Wandung und eine nach der Behandlung mit Cluromsäure cinmal deutlich gesehene centrale Oeffunng abgebildet ist). Dagegen liegen einzelne Samenportionen in ler Umgegent derselben in ovalen Bläschen eingeschlossen entweder in dem Raume, in welchen lie Dotterstöcke einüülen, oller auch ausserhalb desselben. So in fig. 2. Wenn diese noch zur Begattung verwandt werden sollen, wie es wahrscheinlich bleibt, da die Spermatozoilen noch die lebhafteste Bewegung zeigten, so müssten sie zusanmen mit Keimbliischen und Dottermasse dureh einen nicht zur Beobachtung gekommenen Canal in den unnittelbar anliegenden uterus übertreten. Nach Analogie der Gesehlechtstheile des unten zu besehreibenden Vortex viridis könnte man auch folgenden Vorgang bei der bildung des Eies annehmen. Wenu eine Communication des Keinstockes unl des Raunes, in welchen die Dotterstöke münlen, mit der Scheide existirt, so dass der luhalt der ersteren in letztere eintreteu kann (eine Annahme, die nach den Benbachtungen an Vortex viridis nicht unwahrscheinlich ist), so kännten Eikeim, Dotternasse und Spermatozoiden durch die Scheide rückwïrts wandernd leiclıt in den uterus, welelıer in der Nähe der Gesehlechtsöffunng mit der Scheide communcirt, gelangen. Hier würde daun die Bildung der harten Schale vor sich gehen.

Die Eier sind braungelb gefürbt, und nielıt ganz vollstïndig oval, sondern, wie die Abbildung in fig. 2 zeigt, gegen die Geschlechtsöffuung hin mit einem stumpfen Fortsatze versehen. Der nterus ist dümwandig, nicht muskulös, aber sehr ansilehubar. Er kanı 5 Eier zn gleicher Zeit enthalten, von denen eins nach dem anderen gebildet wird, und das linterste das jüngste ist.

Von dieser Darstellung der Geschlechtstheile weiehen die Angaben ron O. Sckmidt selır ab. Doch glaube ich, dass er dieselbe Species vor sich gehabt hat. Seine unvoltstindigen Beobachtungen beruhen, wie er selbst sagt, auf Mlangel an linreichendem Material.

Ich fand dieses schïne Turbellarium anerst im December bei Thauwetter in enem seichten Wiesengraben zusammen mit Jungen ron Vortex virilis. Die Gesehlechtstheile waren noch niclit granz entwickelt. Joch zeigten sich nach wenig Tagen Anfentlalt in der warmen Stube die reifen Spermatozoilen in der Samenblase, mul die Entwickelung der Kier begann. Den ganzen Winter hindurch babe ich es sodanu auch unter dem Lise beobachtet, loch war neist eine wenn anch mur kurze Stubenwärme erforderlich, die Geschlechtstheile zur vollstündigen Entwickelung zn bringen. Nie brachten es die Thiere auf meln' als 5 Vier, wahrscheinlich entledigten sie sich damn derselben. Anch cinzehe kaum $\frac{1}{2}$ “ lange Exemplare kamen unter den Erwachscueu vor. Der 
Schlund derselben hatte eine grosse Aehnlichkeit mit dem der Mesostomeen. Doch verrieth die in der Anlage schon vorbandene Haschenfürmige Samenhlase ilhre OpistomumNatur. Im März wurden die Thiere anch im Freien geschlechtsreif angetroffen, wurden jedoch seltener. In Mai habe ich weder an dem ersten noch an mehreren anderen mittlerweile entleckten Fundorten cine Spur von ihnen auffunden kümen. Aus den Eiern, welche ich nach dem Tode der Hutterthiere isolirt aufbewalurte, sind nach mehreren Mouaten noch keine Jungen ausgekrochen.

\section{Derostomea.}

Mundöfnung etwas hinter dem vorderen körperende, Schlund tonnenfürmig.

\section{Guttungen: Vortex, Derostomum.}

Dugès war der Erste, welcher diejenigen Rhabdocoelen, welche wir in oben. stehender Familie begreifen, als zusammengehürig erkannte. Er bildete für sie die Gattung Derostomum ${ }^{1}$ ), ausgezeichnet durch den in der Nïhe des Vorderendes liegenden Mund. Dic Familie der Derostomeen, in dem Sinne wie wir sie hier nehmen, wurde von Örstel ${ }^{2}$ ) aufgestellt, und in zwci Gattngen getheilt, Vortex (von Eilrenberg zuerst gebraucht) mit der Mundöflinung am Ende des Schlundes und Derostomum mit einer spaltförmigen Mundöflinung an der Unterseite des Schlundes. O. Schmidl ${ }^{3}$ ) folgte dieser Eintheilung, bildete jedoch noch eine neue Gattung Hypostomum, welche sich von Vortex dadurch unterscheiden sollte, dass der Mlund (besser Schlund) schräg von unten nach oben verlaufend mit dem Magen einen Winkel bilde, wïlnrend bei Vortex beide in einer horizontalen Ebene liegen. Ich habe mieh durch vielfache Untersuchung von Iypostomum viride Sehm., der einzigen Species dieser Gattung, ïberzengt, dass dieselbe weder in der Anordnung des Verdaumngskanales noch der anderer Theile so wesentlich von Vortex abweicht, dass sie den Typus einer neuen Gattung abgeben künnte. Der Schlund aller Derostomeen bildet, wem scine vordere Oeffunng der an der Bauchseite des Thieres liegenden Mundöfnung genähert wird, einen wenn auch sehr stumpfen Winkel gegen den in der Axe des Thieres liegenden Darm. Dieser Winkel ist nur bci Hypostomum am auffallendsten, weil die Thicre den grössten Querdurch-

1) Ann. d. sc. nat. 1 Ser. Tom. 21. pag. 70.

2) Entwurf etc. pag. 64.

3) Die rhabdoc. Strudclw. pag. 28. 
messer unter allen Derostomeen haben. Somit hahe ich mich veranlasst gesehen, die Gattung IIypostomum zu streichen, und ilue eimzige Species als Vortex riridis aufufü̈hren.

Der Gattungseharaeter von Derostomum ist mach Örsted und Sclemidl eine Lälngsspalte an der Vuterseite Jes schlundes. Örsted fügt noch besonders hinzu, dass der Schlund iorn geschlossen sei. Jch habe Derostomum unipunctatum Öist. Schmidl, welches ich nach Diesing's Vorgange D. Schuidtianum nemne, beobachtet, und fimle den cinzigen Untersehied im liau des Schlundes zwischen jhm und Vortex darin, dass wo bei Letzteren sich die rordere runde Oeffinng findet (Tab. 111. fig. 4. d hei Vortex virilis), bei ersterem ein Querspalt vorhanten ist (Tab. IV. fig. 6. d). Dieser kann jedoch dureh die Action der Muskeln ebenfalls zu einer rnnden Oeflinung werden ('Tab. IV. fig. 9.), worauf kein Unterselied zwischen dem Schlunde vou Vortex uml Derostomum melr obwaltet. Da jedoch die gewöluliche Form des Schlundes die mit einer Querspalte ist, ausserdem die Anordnung der Geschlechtstheile und der ganze Habitus manches von Vortex Abweiclıende zeigt, so habe ich die Gattung Derostomum noch beibchalten, die Characteristik derselben aber dem Obigen gemaiss ungeäindert.

Was die Organisation der Derostomeen im Allgemeinen betrift, so selicke ich Her speciellen Besehreibung der einzeluen Arten Folgendes voraus: Das Nervensystem ist bei allen erkannt, und stellt ein Doppelganglion dar, auf welehem die beiden Angen, wenn solehe vorhanden, entweder unmittelbar ruhen (Vortex balticus Tab. IV. fig. 1. a Derost. Schmidtianum Tab. IV.fig., 6. a), oder von welchen aus ein besonderer nervus opticus zu den Augen linläuft (Vortex viridis Tab. IIl. fig. 4. a). Augen fehlen bei V. pellucidus Tab. IV. fig. 5. Ob Örstedls V. coecus mit unserem V. pellucidus identiseh ist, kann wegen Mangels einer Besehreibung der ersteren Art nielut ausgemittelt werden.

Die Mundäflimug, welche nach der Characteristik uer Familie nicht weit vom Vorderende des Thieres liegt, kam willkührlich durch Verschiebung unmittelbar an die vordere Körperspitze verlegt werder. Dies findet bei manchen Arten: wenn sie sich zun Fressen anschicken, sehr gewöhnlich statt. So bei Vortex balticus Tab. W. fig. 3. 4., wo zugleich das eine Nal eine sehr bedeutende Eweiterung der Hund- und Schlundüfhumg behnfs der Aufnalıne eines grossen Brachionus stattfindet, das andere Ial der Sehlnum fast um seine Ilälfte ans der Mundöfnung vorgestreckt ist. Aehuliches salı ieh bei jungen Exemplaren ron Vortex viridis. Der Schlumb besteht aus Längs - mol líreisfasern, mol ist sehr dickwandigg. Dicht hinter dem rorderen Ende setzen sich an ihn zahleiche. von der innern Oberlliche der Haut in der Nachbarschaft mutspringende Muskelfasern an, welehe wie bei Opistomum zur Bewegung des Schlundes dienen. Von der Stelle an. Wo sich diese DIuskehn ansetzen, bis zur rorderen Oeff-

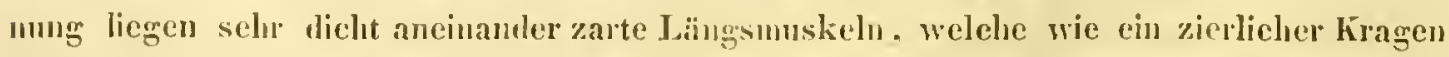
den vorteren Theil des Schlumles bedecken. (Tab. Ill. fig. 4. d. Tab. IV. fig. 9. von 
Vortex viridis und i)crostomum Schmidtanum.) Diese Bildung wurle nach dem Behandeln der 'Thiere mit verdïnnter Chromsinure (rol. p. 19.) leicht erkinnt. Beolachtet man eine der durchsichtigeren Derostomeen bcin schnellen Schwimnen oder Kriechen, so wirl man den Schlunl fast constant eigenthüulich verändert gegen den vorherigen Zustand beim langsamen Fortbewegen des Thieres finden. Er scheint jetzt wie seiner ganzen Länge nach gespalten, eine helle breite Linie zicht sich anf denselben rou Vorder - bis zum Ilinterande hin (Tab. IV. fig. S. vom Derost. Schmidtianum). Setzt sich das Thier in Ruhe, so verschwindet dieser Linngspalt augenblicklich wieder. Dieses eigenthïmliche Phäionen, welches ich bei allen + muten beschriebenen Species, so wie bei mehreren anderen beobachtete, veranlasste mich zuerst zu glauben, dass der Schlund ausser seines vorlerei Ocflung auch noch einen für gewöhulich unsichtbaren Lïngsspalt öfhen köme, ähnlich dem von Örsted als für die Gattung Derostomu nı characteristisch angegebenen .,Längsspalt an der Unterfläche:: Nach der Öj,sted'schen Abbildumg vermuthe ich mit Bestimmtheit, dass er nichts anderes nit rliesem Längsspalt meint, als die ebenbeschriebene Bildıng, welche freilich nicht Deros to mum ansschliesslich, sondern allen I) e os tome en gुleichmäissigg zukonmt. Durch die umständlichsten Beobachtungen glaube ich mich jedoch überzengt zu haben, dass diese Erselıeinung nicht von einem solchen Spalt in der Wandung des Schlumdes herrührt, sondern durch die auseinander weichenden inneren Wandungen des Sehlundes bedingt wird. Diese liegen nämlich in dem Zustande, in welchen wir die Thiere fast allein beolsachten kümnen (auf einem Glastïfclchen in wenig Wasser mol wohl gar unter einem Deckgläschen), und in welchem sie keine Neigung zum Fressen haben, vermöge ilhrer Jicke so dicht aneinander, dass jedes Lumen des Schlundes verseluwuden ist. Sind die Thiere nicht durch ein Deckgläschen gedriickt, und ist der Tropfen Wasser, welcher sie ungiebt, nicht zu niedrig, so beginnen sie bald ihre gewolnten schnellen Bewegungen, und zugleich mit dem Eintritt derselben affnet sich auch der Schlun, un den durch den Wimperstrudel einstrümenden Nahrungsmitteln freien Durchgang zu gestatten. Dieses Ocfinen der Schlundpassage ist es, welches dem tonnenfürmigen Organe das beschriebene Ansehn giebt. als lıabe seine Wandung einen Lïngsspalt erhalten.

Wo Sehluml und Magen zusammenstossen, finden sich die pag. 29 beschriebenen eigenthümlichen Drüsen (Tab. III. fig. 4. c. Tab. IV. fig. 1. 5. 6. e.)

Die männlichen Geschlechtstheile der Derostomeen haben das gemein, dass constant 2 Hoden, eine Samenblase und ein mit harten Theilen bewaffneter penis rorlanden sind. Erstere sind entweder lange cylindrische Schläuche (Vort. viridis Tab. Ill. fig. 4. Derost. Schmidtianm Tab. IV. fig.6. gg.) oder kugelförmige Drüsen, welclıe unmittelbar neben dem Schlunde in vorderen Kï̈rpertheil liegen, unl nit einem langen vas deferens in die Samenblase ausmünden (Vort. balticus Tab. IV. fig. I. V. pelIncidus fig.5. gg g). Letztere Bildung hat $O$. siclemirlt bei Vortex pictus erkannt, wälırend ilnn von den langen cylindrischen Hoden von V. riridis nur einer deutlich erschienen ist. Dic Bewafnnng des penis ist bei den einzelnen Arten sehr verschieden. Am merk- 
würdigsten und anfallendsten zeigt sich dieselbe bei Vort. viridis (Tab. III fig. 4. k. fig. 5.), wo sie auch O. Sichmidt genau beschricb, ihre bedeutung jedoch nicht erkamnte. Zwei harte Leisten unfassen das untere Einde der biruförmigen Samenblase, unl setzen sich, nachdem sie durch eine Brïcke verbmden worlen, jede in eine schmale, biegsame, mit 11-13 langen, harten Hacken besetzte Platte fort. Dieser Apparat liegt für gewöhulich so zusammengefaltet, dass die Hacken nach innen stehen, und sich von beiden Platten aus gegenseitig kreuzen (Tab. III. fig. 4. k), und anf diese Weise leicht in die Geschlechtsöffunng eines anderen Individnunıs eingeschoben werden können. liei der Entfaltung des Organes biegen sich die beilen Platten nach auswïrts (fig. 5), in Folge dessen die gebogenen Ansätze als Widlerlacken wirken müssen. Finen iihnlichen Apparat sah ich, wie $O$. Schmidt, bei V. truncatus. Ferner beobachtete ich ihn bei einer neuen Species, der vorigen älmlich, und Sclmidt beschreibt ihn noch bei V. pictus. Ganz anders ist der penis bei V. balticus (Tab. IV. fig. 1.i.) wo er einem Flasclsenhalse gleicht, bei V. pellucidus (fig. 5. i.), wo er eine lange, feine Riohre darstellt, über deren Nlündung noch eine beinahe elsenso lange solide Borste hinausragt. Bei Derostomum Schmidtianum gleicht das Begattungsglied (Tab.IV. fig. 6.i.) einer conischen Röhre.

Die weiblichen Generationsorgane sind bei allen Derostomeen als 2 Dotterstücke, und 1 oder 2 Keimstöcke erkannt. Bei einzelnen Arten ist die Eiertasche und das receptaculum seminis ebenfalls nachgewiesen. Eigenthunnlich ist es, dass, mïhrend die Dotterstöcke stets paarig vorkommen, die léeinstöcke ebenso oft unpaar wie paarig beobachtet wurden. Ersteres Verhältniss zeigt sich nach Schmilt bei Vortex truncatus, pictus und Derostomum Schmidtianum, nach meinen Untersuchungen noch bei 3 neuen später zu besclireibenden Species, letzteres (das Vorkommen paariger Keimstöcke) finde ich bei V. viridis, balticus und pellucidus. Die Eier sind stets hartschalig.

Während bei allen Vortex-Species die Begattungsorgane im hinteren Körpertheil liegen, finden sich dieselben bei Derostomum Schmidtianum unmittelbar hinter dem Schlunde, noch vor der Mitte des Körpers. Darnach kehrt sich die Lage der IIoden und Dotterstücke auch um, indem deren blindes Ende nach hinten, ilır ausfülırendes nach vorn sieht. 


\section{Vortex. Eilrenbery.}

Vordere Oeffung des Schlnudes kreisrund.

\section{Vortex viridis milhi.}

'T'all. III. fig. 4. 5.

Fasciola Helluo O. F. Miiller. Verm. terr. et flur. historia 1. 2. p. 64.

Planaria Helluo O. F. Mlïller Zool. Dan. III. pag. 39. Tal. CV. tig. 3.

Hypostomum viride O. Sclmirlt d. rhabdocoelen Strudelw. pag. 30. Tals. I. fig. 4.

Diesing Systema Ilehuiuth. J. pag. 2029.

Distigma? Helluo Diesing 1. c. pag. 188 1).

Kürper I-1 $1 \frac{1}{2}$ “' lang, $\frac{1}{3}-\frac{1}{2}$ " hreit, vorn albgestumpft, linten zurgespitzt, fast cylindrisch, schün blattgrün gefïrbt. Zwei schwarze Augen.

Es giebt auch eine ganz weisse Varietit.

O. Schmidt lat diese Art ausfülnlich beschrieben, und ich habe seinen Angaben nur wenig hinzuznfïgen. Dass der grïne Farbstoff unter der Haut Inistologisch und chemisch mit dem Chlorophyll der Pllanzen vollstänlig iibereinstimmt, wurde pag. $16 \mathrm{ff}$. auseinandergesetzt. Ueber die Haut und deren Stäbchen rergl. Tab. I. fig. 1. Das Centralnervensystem Tab. III. fig. 4.a ist dentlich als Doppelganglion mit i jederseits abgelienden Nerven erkannt worden. J)ie Gestalt der Augenllecke fanl ich selten nierenförmig, wie Schmidt als Regel angiebt, meist oval.

Die Lage der Mundöffnnng fig. 4. a ist wie bei allen Derostoneen eine nicht ganz constante. Ieh sah dieselbe namentlich bei jungen Individuen unnittelbar an der vorderen Kürperspitze, meist jedoch dicht vor oder zwischen den Augen, seltener soweit hinter denselben, wie 0 . Schmill auf Tab. I. fig. 4. 0. abbildet. Der Schlund ist sehon oben beschrieben. Die Papillen an seiner vorderen Oeffnung have ich wie schmidt auf Tab. II. fig. 4 b. p. angiebt, ebenfalls gesehen, aber die Vertheilung der sich an iln ansetzenden Muskeln ist eine andere, als die auf dieser Figur dargestellte. Die Anordunug der Wassergefïssstämme habe ich nicht vollständig verfolgen hönnen. Joch sah ich bei jungen durchsichtigen Individuen zwei Stämme im vorderen Kürpertheil und eineı in hinteren reichlich veriistelt.

Die Generationsorgane bestehen aus den beiden Hoden fig. 4. g g g , welche, sich allmählig nach hinten versehmälernd, in die beiden rasa deferentia lı lı übergehen, unn

1) Es ist keinem Zweifel unterworfen, dass die Mäller'sche Planaria Ilelluo mit Iypostomum Schm. identisch, weun auch in der Alhildung die Augen fehlen, in der Beschreilung sind sie erwälut. Dic von Diesing angeführten zahareichen Synonyme zu PI. Helluo habe ich nicht vergleichen könnon, und desshall, weggelassen. Wie die lofusorien-Gattung Distigma bei Diesing unter die dendrocoelen Turbellarien geräth, ist unerklärlich. 
sich in die Sanenblase $\mathrm{i}$ münden. Aus dieser gelangen wir zn den eigenthümlichen Organ k. welches schwerlich anders als ein Begattungsglied wird gedentet werden küunen.

Die Geschlechtsöfmung liegt unnittelbas liuter demselsen, anf dem Rückeu des Thieres. Dureh dieselbe gelangen wir einerseits in eine langre muskuliise Scheide m, andrerseits in cinen dickwandigen weiten, ebenfalls muskulïsen Sack, die Eiertasche p. Erstere führt an ilırem schr zarten Eude in die Samentasche ı: nud nimmt kurz vorher die beiden botterstöcke v v und die Keimstöcke o o mit ihren Ausführmgsgäingen auf.

Von dieser Beschreibung weichen die Angaben Nichmills insofern ab. als er nur einen Jloden und eineı Keimstock sah, und die Scheirle nicht im receptaculını seminis enden soll, somlern sich noch über dassellye in einen die beiden Dottcrstüeke anfuehmenden Canal fortsetzt (Tergl. seine Abbilılung Tal. I. fig. 4 a.)

Die Bildung des Eics beschreibt (). Schmidt richtig so, dass Jottermasse, Eikein und Sane rïckwïrts durch die Scheide in die Ejertasche treten, und lier nun die Bildung der harten brannen Schale beginnt. Sobald ejn Ei fertig ist, tritt es in die Leibeshöhle neben den Verdaungskanal. Wah'scheinlich wird es dureh die Oeffnung 1 ausgeleert, tritt jedoch nun nicht durch die unnittelbar neben derselben liegende Geschlechtsöffnnng in der Hant nach aussen, soudern fällt in die Leibeshöhle. Hier hïufen sich die übrigens nicht runden (wie Schmidt abbildet), sondern länglich ovalen Eier oft bis zu der enormen Zahl von 30 und einigen an (wie mein Freund Dr. $F$. Mïller und ich beobachteten): che Anstalten zum Ausleeren gemachit werden. Wie das Eierlegen geschieht, ist noch nieht erkannt worden, ebenso wenigg ist eine Entwickelung des Embryo in den Eiern gesehen.

Vortex riridis ist in kleinen Wjesengräben und Teichen, welche im Sommer austrocknen: seit mehreren Jahren und immer wieder an denselben Stellen in der Näle vou Greifswald beobachtet. Ganz junge Exemplare fand ich Anfang December. Den ganzen Winter hindurch waren sie reichlich vorhanden, allmählig an Grüsse zunehmend, und wie schon pag. 17 erwähnt wurde, häufig ohne die Chloroplyglkürner, ganz weiss. In der warmen Stube hatte ich schon Aufang Februar geschlechtreife Indivirluen, im Freien fauden sich dieselben erst Ende März. Die Zahl der farblosen Iudividuen nalm inmer mehr ab, und im April konste ich num unter 20 - 30 grünen ein farbloses Individum erhalten. Im Mai fanden sich letztere gar nicht mehr.

Lïngere Zeit in Dunkeln aufbewalırt werden auch die grünen Thiere Anrch Bleichen und Schwindeu des Chlorophylls fast farblos.

\section{Vortex balticus nor. spec.}

$$
\text { Tab. N. fig. } 1-4 .
$$

Körper $\frac{1}{2}-\frac{2}{3}$ ” lang $\frac{1}{d}$ “' breit, vorn abgestumpft, hinten zugespitzt. fast cylin. drisch. liellbrïunlich. Zwei schwarze Angen. 
Diese Art, welehe sehr hïnfig in seiehten Wasser vler Ostseckïste in der Niille von Greifswald gefunden wirl, gelı̈̈rt zu den kleinsten lihabdococlen. In der Gestalt hat sie Aeluliclıkeit mit. Vortex pictus O. Nrhmidl.

Dicht hinter dem rorderen, meist alggestunuften, aber auch zu einer Spitze gestaltbaren Vordermule liogen zwei kleine schwaze: Angen, balıl oval bald mehr nicrenförmig. Sie mhen muntelhar auf den duch einc brïcke mit einander verbundenen Centraluervenganglien (fig. 1. a) auf. Die Munlïlnung (fig. 1. c) ist selır ausdelubar, wie fig. 3. zeigt. Schlund mul Magen bieten nichts Aussergewöhuliehes dar.

Samenbereitende Organe sind zwei zu jerler Seite der hinteren Selulumdüfimmgr liegende kugelfirmige Driisen fig. 1. gg, welehe, mit Spermatozoirlen und deren Entwickelungsstufen gefüllt, sich in zwei lange, enge vasa deferentia fortsetzen, und in hinteren Körpertheil in rlie Samenblase rimüulen. I)ieser sitzt nach hinten gerichtet ıler Flaschenhals-ähnliche harte penis i auf, velcher eine kurze, an der Ansmündung etwas erweiterte hïhre darstellt, nnd von einem lackenartigen soliden Fortsatz ïberragt wirl. Hinter ihm finlet sich die Geschlechtsöffunng $k$.

Die Dotterstücke (fig. 1. mm) sind zwei lange schmale cylindrische Schlinche. ohne Ausbuclıtungen. Jeder derselben nimut an seinem hiuteren Ende rlen Ansfülıungsgang eines der ebenfalls doppelt vorhandenen Keimstöcke n Eikeime liegen. Die vereinigten Ansfïlırungsgïnge der lieim - und Dotterstücke miinlen in Jer Nihlıe des Organes 1, einer zusammengefallenen Blase, welche ich für das receptaculum stminis lıalte, zusanmen, unl stehen mit einem weiten sehr dünuwandigen Sack. ler Eiertasehe, in Verbindung: welche sich ïber die Samenblase mul Kícimstöcke erstreckt. und aus diesem Grumle in der Abbildung weggelassen wurle. In derselben entwickelt sich zur Zeit immer nur ein Ë, welches sich durch seine Grüsse und ladurch auszejehnet, dass dasselbe stets zwei Kiembläsehen enthält, welche sich schon im Eiersacke zu zwei Embryonen ausbilden (fig. 2.). Ob dieselben auch hier ausschlïpfen labe ich nicht beobachtet.

Dieses Turbellarium, welches das häufigste an unserer Kïiste ist, wurde rom April bis in den Spätherbst in geschlechtsieifen Exemplaren beobachtet. Jedoch kamen zu gleicher Zeit auch inmer junge 'I'hiere vol. lm März wurlen letztere ausschliessliclı gefunden.

\section{Vortex pellucidus nov. spec.}

Tab. 1V. fig. 5.

Kïrper 1" lang: $1^{\prime \prime}$ breit. etwas abgeplattet. rorn wie hinten gleichnässig verschmilert, ganz farblos umd durchsichtig. Kieine Augen.

Diese seltene. Wie die vorige an ler Küüste der Ostsee gुefundene Art künnte rielleicht mit Vortex coerus Örsted. l. c. prag. 66 identisch sein. Doch fehlt ilhr das ron (̈)rsted als peuis gedentete, kreuzweis gestreifte Orgau. 
Das Centralnervensystem a ist ilhnlich wie bei opistomnm pallidum. Doch wurden mur zwei Nervenfïlen, einer nacl, vorn, einer nach hinten, jederseits erkaunt. Der Verdauungsapparat bietet nichts Eigenthümliches dar.

Die lloden gg sind wie bei V. balticus kugelfïrmige, neben dem Schlunde liegende Drïsen mit langen vas deferens. Die Samenblase h, von cylindrischer Gestalt und in der Mitte etwas eingeschnïrt, nimut die letzteren an ilıem hinteren Ende auf. Vorn geht sie in einen langen der Geschlechtsöffmung $\mathrm{k}$ zugewandten penis $\mathrm{i}$ über, welcher eine feine Rïhre darstellt, an seiner Oeffnnug von einer langen, biegsamen Borste überragt. Eine eigenthïmliche, einer gelappten Drüse nicht unähnliclıe, feinkiirnige Masse I befindet sich in der Ungegend der Samenblase. Ueber ihre Bedeutung kömnen nur Vermuthungen gehegt werden.

Vou den weiblichen Generationsorganen sind nur die doppelten Dotter - und Keinstöcke beobachtet worden. Erstere mu sind zwei keuleufürmige Schliäuche, letztere nn stellen blinde Auhänge derselben dar, welche nit einer breiten Basis, in welcher sich die grössten Eikeime befinden, den Dotterstücken aufsitzen. Die vereinigten Ausfülı• rungsgänge beider Organe lanfen gegen die Goschleelısüfhung $\mathrm{k}$ hin. Ihr Ende konnte jedoch ebenso wenig wie eine Scheile und ein receptaculum seminis erkamnt werden.

. Das einzige Exemplar dieser ansgezeichneten Art, welehes mir rorgekommen ist, wurde durch Abspïlen von Algen am flachen Strande bei Greifswald im September erhalten.

\section{Derostomum Örst.}

Vordere Oeffung des Schlundes eine enge Spalte.

\section{Derostomum Schmidtianum milhi.}

$$
\text { Tab. IV. fig. } 6-9 \text {, }
$$

Derostommu unipunctatum Örsted Entwurf etc. pag. 66. Tah. Il. fig. 25. O.

Schmidt die rhabdocoelen Strudelwïrmer etc. pag. 36. Tab. Il. fig. 5. 5 a. 5 b.

Turbella unipunetata IJiesing Systema helm. I. pag. 225.

Turbella Schuiltiana Diesing eod. loc.

Körper 1!2-2"“ lang, $\frac{1}{2}-\frac{2}{3}$ "” breit, abgeplattet, vorn abgerundet, nach hinteı breiter werdend und mit einer kurzen Spitze entend. Farbe weissgrau, selten grünlich. Zwei schwarze Augen.

Dies: von Örsted kurz beschriebene Art wurde ron O. Sclmielt einer grenaueren Untersuchung unterworfen. Letzterer behielt den von Ersterem ganz unpassend nach den mufïlligen Vorhandensein eines Jies gewïlten Namen bei. Diesing hïilt die Örsted sehe Art ohe Grund fïr verschieden von der von Schmidt beobachteten, und 
gab letzerer den Namen 'Turbella Schmidtiana. Ich nehme den meinem Freumle zn Ehren gewällten Speciesnanen an Stelle des nupassenden älteren auf. Die Dicsing'sche Cattung 'Turbella. auf eine friiler vou Elreubcrg angewandte begrïnlet, begreift die verschiedenartigsten Thiere in buntem Gemisch, und kann kein Bürgerreeht erhalten.

Was ich der von (). Schmidt gelieferten Beschreibung zuzufïgen bahe, beschrinkt sich anf Weniges. Das Centrahervensystem (fig. 6. a) bestelut aus zrei grossen, dicht ancinanderliegenden Ganglien, von welehen ein Nervenfaden nach hinten ausgehend erkannt wurle. Stäbchenfürmige Körper von 0,004"“ Länge sinn an der vorderen Körperspitze angehïuft, mul begleiten die Nervenfäden eine kur\%e Strecke nach abwärts. Das Augenpigment b b ruht den Ganglien jederseits unmittelbar auf. Nur in seltenen Fïllen fand ich rlasselbe in so scharf unschurebenen Anbïufungen, wic O. Vichmidl es abbildet. Meist bildete lasselbe selır diffuse Pigmentflecke, welche in einzelnen Fïllen die ganze vordere Körperspitze fast gleichmässig schwärzlich färbten. Den Schluud d fuste ich dem Vorderende nälıer als $O$. Schmielt angiebt. Seine vordere dem Munde c zugekehrte Oeffunng wird von einem zierlichen aus strahlenartig divergirenden Muskeln gebildeten Kragen nageben, wie bei Vortex viridis. Beobachtet man das Thier bei starkem Druck unter einem Deckglïschen, so sieht man den Schlund meist mit runder vorkerer Ölfunng wie in fig. 9. Beim schnellen Schwimmen des Thieres, nngehindert durch irgend welchen Druck, nimmt der Schlund die in fig. 8. gezeichnete Gestalt an. Wie dieselbe zu erklïren, wurle oben in der Einleitung zur Familic ter Derostomeen auseinandergesetzt. Beim Ausleeren des Magenimbaltes aus der Mundüfunng; welcher Vorgang ron selır heftigen Muskelanstrengungen begleitet wird, salı ich das Vorderende des Thieres wie in fig. $\%$ gestaltet.

Wie bei allen Derostomeen liegen anch hier seitlich zwei cyliudrische Horlenschläuche g̊g. Da die Samenblase lı sich unmittelbar linter dem Schlunde befundet, so gehen die vasa deferentia abweichend ron dem bisher gesehenen Verhalteı von rlem vorderen Tlıeil der Hodensehläuche aus. Der penis stellt eine einfache harte Rölıre dar, relche nanentlich vor rlel vollständigen Geschlechtsreife mit einer feinkürnigen Masse zienlich dicht angefüllt ist, und dadurch ein Ansehn erhält, als lïge noch ein dunkler Kürper in ihr. Teben dem penis liegen, wie dies U. Schmirlt rirltig abbihlet, noch zwei ungefïhr birnförmige Blasen, welche einen gemeinsamen Ausgang haben, die eine walırschemlich rlas receptaculum seminis, die andere der Keimstock. In letzterem funden sich stets eine grössere Anzahıl Sikeime vor, deren unterste, grösste sich durch die dunklen Körnchen. welche un das Kelmblïsclen hermmliegen, auszeichnen. Spernatozoiden habe ich so wenig wie sirkmielt in dem receptaculum seminis gesehen. Die Dotterstöcke nım sind zwei vielfach verzweigte und in ihren Verzweigungen nit einander anastomosirende Schläuche, Sie nehmen in geschlechtsreifen Zustande einen grossen Theil der hinteren Körperlı̈ilfte eiı. In der Nähe des Keimstoches müssen dieselben einen Ausfülırugsgang haben, welelier die Dottemasse in die hier befmaliche Eiertasche $k$ leitet. In derselben 
entwickelt sieh immer nur ein Ei auf ein Mal, welches, nachdem es eine harte brame Schale erhalten und einige Zeit von der ilutter herumgetragen worden, bevor noeh eine Embryoentwickelung begonnen, ausgeleert wird.

lı den ersten Tagen des Jimuar wurle Derostomum Schmidtianum zuerst in der Lünge von 1 “ in einem kleinen Wiesengraben in ziemlieher Menge beobachtet. Von den Geschlechtstheilen wurde nur der noch mentwickelte penis wahrgenommen. Die meisten der in der warmen Stube aufbewalırten There zeigten nach Verlauf von etwi 14 Tagen ein hartsehaliges Fï, olue dass sic an Grösse zugenommen hatten und obne eine Spur vou Ilorlen mit Spermatozoiden zu zeigen. Am f. Februar wurde in einem kleinen Teiche, welcher viel Opistomum pallidum und Mesostonum tetragoum enthielt, ein vollkommen ausgewachsenes Thier gefunden, welehes nach Verlauf einiger Tage ein hartsehaliges Ei entwickelte, und lasselbe einen Tag nachher ausleerte. Von Spermatozoiden war in der Samenblase noeh keine Spur. Erst Ende März wurden die mämilicluen Gieschlechtstheile in vollstïndiger Entwickelung gefunden.

\section{Mesostomea.}

Mundïffuung in der Mitte oder uahe der Mlitte des Körpers. Schlund ringförmig, .einem Sanguapf ähnlich.

\section{Vinzige Gallung: Mesostomum.}

Die hierher gehörigen Turbellarien wurlen zuerst von Dugis ${ }^{1}$ ) als Untergat. tung der Derostomeen unter dem Namen Mesostomum zusanumengefasst, ron Örsted ${ }^{2}$ ) zur Familic erhoben, md in die genera Nesostoma, Strongylostoma. Typhloplana und Maerostoma vertheilt. Dic drei ersten Gattungen sollen sich sn von einander muterscheiden, dass, während bei Nlesostoma die Mundöffumgg in der Mlitte des Kürpers oder etwas hinter derselben liegt, diese bei Strongylostoma sich vor der Mitte linden soll. Typhloplana ${ }^{3}$ ) ist durch die Abwesenheit der Augen von den beiden vorhergehenten ansgezeichnet.

1) Ann. d. Si. nat. I Ser. Tom. XXI. pag. 76.

2) Entwurl ete. pag. 67.

3) Die Cittung Typhloplana wurde von Eltrenberg in den Symbolis physicis lür die Müller'schen Arten Planaria grisea, fulra und viridata aufgestellt, und, durch den Mangel der Augen characterisirt, fen Dendrocoelen untergeordnet. Später in deı Ab. bandl. der Acad. d. Wissenseh. zu Lerlin 1S33 pag. 243 wurden moch die Dugessehen Derostoma polygastrum, Mesostomum viridatum umel Panaria cocea der Gattung 'Tyluloplana vindicirt, und ihre Stellung bei, den Dendrocoelen bestïtigt. 
Leber die Österlsehe Gatmug Strongylostoma labe ich keine lieobachtungen zu machen Gelegrenheit gehabt. C̈rsted's Angalucn reichen alıer zur licgrimdung dieses genus nicht aus. Stromgylostoma assimile, welches mit l)e rostoma fusiforme Dugès (1. c. T. XXI. pl. Il. fig. I\%.) identisch sein soll, scheint uir ein walnes Nlesostomum, und Strougylostoma radiatum, identisch mit l'lan. ra. diata O. IV Mïller (Zool. Dan. Tab. 106. fig. 1.), mit allerdings etwas vol der Mitte liegemlem Munde, kann, ehe lie übrige Organisation nicht genaner bekannt wird, zur begründung eines neuen genus nicht verwandt werden.

Die Gattung Typhloplana, deren ich zwei Species, T. viridata mul cine neuc beobachtete, unterscheidet sich von Mesostomum nur durch den Mangel del Augen. Verdaumgs- und Geschlechtsapparat, anch die Vertheilung der Wassergelinse sind bej beiden Gattungen werentlich gleich. Es firagt sich un, ob wir auf obigen Unterselicel hiu berechtigt siud, die Gattung T'yphloplana festzuhalten. Ielı muss diese Frage mit nein beantworten. Es würden, wenn wir bei soust gleicher Organisation nach dem Vorhandeusein oder den Mangel uer Augentlecke der Turbellarien Gattungen bilden wolltu, Consequenzen zu ziehen sein, deren Durchfülnugg ich mil nicht gestatten künıte. Der oben beseluriebene Vortex pellucidus, Monocelis mipunctata, Macrostomum a uritum (siehe unten), alle diese species wüıden von den Gattungen, bei welchen sie sehr wohl untergebracht werden komten, abgetrennt werden mïssen. Somit lıabe ich auch dic Gattung Typhloplana fallen lassen, und sind demuach dic beiden durch O. Schmill wohl begrüıdeten Species nebst der von mir beobachteten nenen, welehe ieh II sostomum pratense nenne, und in einer folgenden Abtheilung besehreiben werde, den genus II sostomum unterzuordnen.

Was endlich die vierte der Örstel'schen Mesostome en-Gattungen betriflt, Ma crostoma nämlich, so ist diese der abweichenden Form Jer Mundühnung wegen vou 0. Schmidt natmrgemäss in die Familie der Schizostomeen verwiesen.

Somit bleibt nur die eime Gattung Mesostomum übrig.

Sehon in dem ersten Capitel dieser Leiträge, über die Organisation der Rhabulocoelen in Allgemeinen: ist dasjenge, was die Mesostomeen gemeinsam auszeichnet, mit cingellochten. Eine vollständige Zusanmenstellung der Organisationsvernälnisse dieser Familie verspare ich mir auf eine bald auszugebende zweite Abtheilıng ılieser Beiträge. Wegen Mangels an hinreichendem Material komuten die lieobachungen noch nicht zu Jem gewünselıten Abschlıss gelangen. Ich beschrïnke mich daher jetat auf die Beschreibung zweier in mancher Hinsicht ausgezeichneter neuer speeies.

Örsted erkinnte bei einigen der oben genaunteu Müller'schen Arten den graden, nicht verzweigten Darnkanal, wie ilın schon Dugés für PI. viridala angegeben, und stellte, indenı er die Mundiffnung wie hei Mesostomum gelegen fand, dic Gattung Tỵhloplana z.u den Rhaludocoela M esostomea. Dieselbe Stellung hat diese Gattungr maturgemäss bei () Schmirlt behalten. 


\section{Mesostomum obtusum nor. spec.}

$$
\text { Tab. V. fig. } 1 .
$$

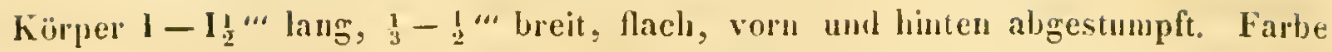
weiss. Drei sehr difluse schwarze Augenflecke an der vorderen spitze.

Das Centrahervensystem ist wegen der grossen Menge von stäbchenfürmigen Körpern, welehe zusammen mit dem dillusen Angenpigment die vordere Spitze des Thieres umhrehsichtig macheu, nicht erkannt worlen. Die Stähchen sind klein, 0,006-0,00\% “. lang, theils frei, theils in Zellen eingeschlossen unter der Haut liegend. Lange, sestielte Stäbchenzellen, ïhnlich den ron Mesostomum tetragonum aut' Tab. I. fig. 25. abgebildeten, stehen mit der vorderen Stäbehenauhäufung in Verbindung. Das Augenpigment zeigte sich bei den beiden von mir beobachteten Exemplaren seh" dillus in der ganzen vorderen Spitze des Thieres verbreitet. Drei diehtere Pigmenthaufen konnten jerloch leicht untersclieden werden, welche bei heiden Exemplaren eine gleiche Lage hatten.

Der Sehlund b liegt hinter der Mitte des Kärpers und bictet sowie der mit grünen und brauen Speiseresten und nit vielen liettröpfehen gefüllte Magen niehts Aussergewöhnliches dar. Von den Geschlechtstheilen ist ein langer eylindriseher Hodensehlauch c, eime Samenblase d, zwei Dotterstöcke $\mathrm{g} g$ und ler Keimstock f erkannt worden. Alle diese Organe münden in hinteren Körpertheil zusanmen. Der Hode enthailt lie Entwikkelungsstufen der Spermatozoiden in ler bei Monocelis beobachteten und pag. 30 beschriebenen Form. Die reifen Spermatozoiden sind fadenförmig, und in der Samenblase d angehäuft, welehe jedoch auch als weibliches receptaculum seminis gedeutet werden kümute. Ein Begattungsglied fehlt merkwïrdigerweise vollständig. Die Dotterstücke, lange cylindrische Schläuche olıe Einschü̈rungen oder Ausbuchtungen, reichen bis in den vorderen Körpertheil hinauf. Wo sie zusammenmünden findet sich der Keimstock, aus einzeln nebeneinander liegenden und nicht ron einer gemeinsamen Haut umselhlossenen Eikeimen bestehend. Eine Eutwickelung von Eiem ist nicht beobachtet worden.

leh faud diese Art in einem bewachsenen Graben im Juli in 2 Exemplaren.

\section{Mesostomum marmoratum nov. spec.}

Tab. V. fig. 2. 2 a. 2 3.

Kürper I“" lang, $\frac{1}{4}$ "breit, vorn abgestumpft, hinten zugespitzt, hellbrann unit sehwarzbrannen Aılern. Zwei mit einer Linse versèhene Augen.

In Iler ansehnlieh dicken, farblosen Hautschicht funlen sich vicle kleine stäbehenfürmige Kürper ('l'ab.l. lig. 16.), und eben solche auch in der vorferen Kürperspitze nuter der Ilaut in bententender Menge abgelagert, ähulich wie bei der vorigen Art. 'Trïger rler dunkeh Farbe des Thieres, namentich ueg schwarzbanen, verzweigten Streifen ist ein feinkörniges Pigment, welches unmittelhar muter der llant liegt. Das Centralnervensystem ist nicht crkant worden. Die Augen sind nierenfümige: srluwarzb Pignentflecke. in 
deren naelı aussen sehender Coneasitï eine stark liehtbrechende Linse liegt. Der Mund und Schlund finden sich etwas hinter Ier Nlitte des Körpers. Der Mlagen liegt mit seiner grösseren Hïlfte vor dem Sclılunde. Yon den mïnulichen (ieselılechtstheilen ist ein Horle c, Samenblase d, und der ron derselben ansgehende, sehr lange gewmene penis gefunden worden. Letzterer, eine enge harte Rühre darstellend, liegt zn!n grössten Theil in einer mmskulösen, quergerunzelten Scheide, dureh deren Contraction er aus der Cieschlechtsölfinung e herans getrieben wird. Das der Letzteren zngekelurte Ende, in fig. $2 \beta$. besonders abgebildet, hat die Oeflumg, zn welcher die Spermatozoiden heranszutreten bestimmt sind, nicht in der verlïngerten Axe, sondern in einer seitlich dicht vor der änssersten Spitze abgehenden, ku'zen Röhre o. Die ganze Länge des penis leträgt beinahe $\frac{2}{3}$ der Kürperlänge. Die weiblichen Generationsorgane bestehen aus dem im linteren Körpertheil gelegenen Keimstock $f$, und zwei Dotterstöcken gg, von welchen der eine bei dem in fig. 2 abgebildeten Thicre etwas verkümmert war. Scheide, receptaculun seminis und Eiertasche sind nicht beobachtet worden.

Diese in fig. $2 a$. in ihrer natïrlichen Farbe bei etwa Gmaliger Vergrösserung albgebildete Art wurde an der Ilachen Küste der Ostsee bei Greifswald an Algen, doch selten,

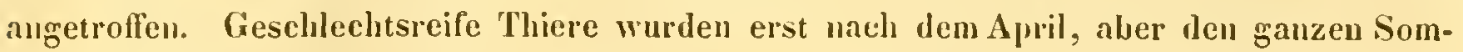
mer hindurch, nie jedoch mit Eiern, gefunden.

\section{Schizostomea.}

Mund eine Längsspalte nahe dem vorderen Körperende. Ein muskulöser sehlund fehlt.

\section{Gallnngen: Schizostomum. Macrostomum.}

(1. Sclmidt 1) stellte für eine neıe Speeies mit vorderer, spaltförmiger Ilundïfhung die Gattung Sehizostomum, und für diese und das genus Macrostomum Örsl., mit gleichgestalteter Mundiofhung, die Familie der Schizostomeen auf. Erstere Gattung, welehe ich bloss ans der Beschreibung bei Sclımidt kemne, hat bis auf die Mundöllnung grosse Aelmlichkeit mit Mesostomum. An Stelle des ringfürmigen Schlundes findet sich ein ganz älnlich gestaltetes saugnapfartiges Organ, welchem jedoch eine zum Darmkanal führende Oefliung fehlen soll. Die Generationsorgane sind, so weit sic erkannt wurden, denen vieler Mesostomeen ganz gleich. Aueh das Gebïren lebenliger Jungen, welches nuter allen Rhabdocoelen bisher nur in letztgenaunter Familie bekannt ist, kommt bei Schizostomum vor.

1) Die rhabdococlen strudelwïrmer ete. pag. 21. 54. 
Die Gatumg Macrostomum: Welche sich ron der vorhergehenden dureh die Lage des Mundes zu den Augen, das Fehlen des Sangnaples mud durch dic Auordumg der Geschlechtstheile unterscheidet, enthält hei Örsted ${ }^{1}$ ) 2 Species, Macrostomum hystrix mo appendiculatum. Letztere: nach der Planaria appendiculata vou O. Fobricius $\stackrel{\circ}{)}$ aufgestellt, ist, wie ich mich aus der betrell(ublen Abbildumg überzengt hahe, identisel, mit Ersterer. Jjese wurde schon von Juges beobachtet: später von Elmenberg, endlich ron O. Schmirlt. Von rler imeren (Organisation ist ansser den selır entwickelten stäbrhenförmigen Körperehen der Ilaut, und der Lage der Angen und

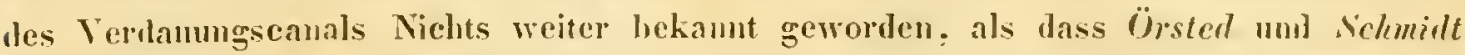
den schon ron Ehrenberg gesehenen harten, hackenartigen penis und letzterer noch zwei im liuteren Körpertheil liegende Eier abbildeten.

lch habe ausser Macrostomum hystrix noch eine nene Species in der Ostsee leobachtet, die ich M. a uritu menne wegen des in Jer vorderen Spitze des Thieres liegenden Otolithen (Tab. V. fig.4. a). Mund und Verdanungskanal sind älnnlich wie bei M. Jystrix. Dic Anordnnng der Geschlechtstheile stimmt bei beiden Species in den merkwïrdigen Verhalten überein, lass Keimstïcke mu Dotterstïcke nieht wie bei ulen übrigen Rhahdocoelen getrennt, sondern in einem und demselben Raum veremigt sind. Sownhl hierdurch als anch durch die bei M. hystrix im Darmkanal rorkommende Flimmerbewegung billet die Gatumg Maerostomm ren Uebergang von den Rhabdocoelen zu der folgenden Abtheilung der Turbellarien, den Proetueha.

\section{Macrostomum Örsted.}

Mundiffung hinter den Augen oder dem Otolithen.

\section{Macrostomum hystrix örst.}

\section{Tab. V. fig. 3.}

Planaria appendiculata O. Falricius. Kongel. Danske Videnskabernes Afhandlinger II. pag. 17. Tab. I. B. I. 2.

Derostoma platurus Duges. Anm. d. sc. nat. 3 Ser. Tom XV. pag. 142. Tab IV.tig. T. 'Turbella platyura Ehreubery Symbolae plyysicae. Phytozoa 'lurbellaria. Abhandl. der Acad. der Wiss. 1835. pag. 254. Diesing Sỵtema helminth. I. jang. 223 .

Macrostonum hystrix Ürsted Entwurf ete. pag. 72. Tab. Il. fig. 28. 29. 34. O. Schmidl die rhabrloc. Strudelw. etc. pag. 54. Tab. V. lig. 15.

Turbella ajpendiculata Diesing I. c. pag. 224.

Turbella lysstrix Diesing l. c. pag. 224.

1) Entwurf etc. pag. 72.

2) Kongel. Wanske Videnskabernes Afhandlinger II. pag. 17. Tah.1. B. 1. 2. 
Kürper l "'lang, 1 '“ lneit, fast cylindrisch, vorn ahgerundet, hinten in eimen platten, zun Anheften dienenden Schwanz ansgehend. Farbe weiss. Zwei kleine scluwarze Augen.

Die IJant dieser Art int ansgezeichnet durch die viden stibehenfïmigen Körper, welche in ihr liegen, und zum 'Theil ans ihr herrorragen, unl den kïrper ein stacheliches Anseln goben. Schon Örsted hat dieselben richtig hesidrieben und alrgebildet. Es sind meist zu dreien mit einamler verhumlene, $0,00.)^{\prime \prime \prime}-0,005^{\prime \prime}$ lange, pfriemenförmige Kïperelen, welehe mit dem gencinsamen breiteren Ende oft cine Strecke weit über die Oberfliche der Hant hervorragen. Hhe Menge ist bei verschiedenen Individnen sehr verschicden. Bei den in fig. 3 abgehildeten Thiere waren sie nur in geringer Anzalul rorhanden. ${ }^{1}$ ) Einzelne lïngere, sehr zarte, steifr. Borsten sitzen in weclisehuler Henge zwischen den Wimpero. Dieselben gleichen den anf der Ilaut der Denchocoelen unl Nemertinen rorkommenden liorstenhaaren.

Das Centralnervensystem gleicht dem von Vortex balticus anf Tab. IV. fig. 1.a abgebilileten, nmt bestelt ans zw ei durch eine brücke verbundenen (ianglicn, welchen die klejnen schwarzen. runden Angenflecke unmittelbar aufsitzen. Der Mund a stellt einen Lingsspalt in uler Jaut dar, von strahlig livergirenden blassen Nuskelfasern nmgeben. Dieser und der hinter ilm beginnemle, gegen das Kürperparenehym nicht scharl" abgesetzte Magen sind ciner bedeutenden Erwciterung fïhig. Ids sah ein Individuum, welches 20 und mehr Brachionen in seinem Magen beherbergte, und zu ciner unfürmlichen Dicke ausgedelmt war. Aul den Objectrïger gebracht gab es balıl cinen grossen Theil der meist noch lebenten liitlerthiere durch den Mtund ron sich. In Grunde der Mund-nnd der Magenhädle (bei b) ist lebhafte Wimperbewegung, rlurch wclche an letzterem Orte die Speisereste in steter Rotation erhalten werden.

Zur Seite des Mlagens, nicht weit von der Mundüfnung, liegt auf jeler Scite ein ovaler Horle ce, mit Spermatozoiden in den bei Monocelis geschilderten Entwickelungsstufen gefüllt. Der obere Theil her vasa deferentia wird von den weiblichen Geschlechtstheilen verdeckt. Im hinteren Körpertheil wurde ein ziemlich breiter, blasser Canal il aufgefunden, welcher sich bei $e$ in eine mit Spermatozoilen gefüllte, gestielte Blase erweiterte, und desshalh als vas leferens angesprochen wurde. Nie komuten zwei solche Canäle aufgefunden werden. Hinter der Samenblase geht dieser Canal in einen erst muskulösen, dann harten, liakenartigr gekrümuten penis f über, welcher seiner ganzen Länge nach durchbolırt ist. Eine Geschlechtsöfhung wurle bei h geselıen. Dieselbe ist von vielen strahlenartig angeordueten, runden, sehr blassen Körnchen umgelıen, welche in der Ilant liegen, und vielleicht P'apillen sind. Ob rler penis zn dieser ziemlich entfernt

1) Leiler sind au dieser Albildung die Stäbchen des hinteren Körpertheils in ungekehrter lage gezeiehnet worlew. Dieselben ragen nicht mit der Spitze, sondern wie im vorderen Kirpertheil mit der Basis aus der llant hervor. 
liegenden Oeffunng ausgestossen werden kamm, müchte bezweifelt werden. Fine zweite, dem penis nähere Oeffunug ist aber nicht erkannt worden.

Die Eierstiocke sind zwei zur Seite des Magengrundes hinter den Hoden befundliche kegclfürmige Schläuche gog, in deren vorderem enggeren Theile einzehe Keimblïschen, nur von wenig Dottermasse umgeben, liegen. Nach hinten hïuft sich letztere immer mehr an, Einschnürungen treten am Eierstocke auf, die küuftige lsolirung der Eier andeutend, enc. lich schnürt sieh der unterste Theil mit einem Keimblïschen und der dazu gehı̈rigen Dottermasse $a b$, mul liegt jetzt frei, von einer farblosen Membran umgeben, neben der Geschlechtsüfnung. Eine harte Schale scheinen die Eier nicht zu bekommen. sondernbalı, che noch eine Embryoentwiekelung lsegonnen, gelegt zu werrlen. Selbst ein Anfang zum Furchungsprocess war an diesen Eiern nie sichtbar.

Ich habe wie (). Fabricins diese von anderen Forsehern nur im süssen Wasser beobachtete Art sehr häufig in ler Ostsee am llachen Strande und in einer Tiefe von einigen Fussen zusammen mit Monocelis agilis, Microstomum lineare und Vortex balticus angetrolien, und zwar von Anfang Sommer bis in den Herbst geschlechtsreif.

\section{Macrostomum auritum mili.}

Planaria excavata O. Fabricius I. c. pag. 26. Tab. II. M.

Monocelis excarata Diesing. Systema helminth. I. pag. 187.

Körper ${ }_{4}^{3}-1^{\prime \prime \prime}$ lang, ${ }_{3}^{1}$ “' breit, platt, vorn etwas verschmälert, in der Mlitte meist eingesclmürt, hinten abgestumpft. Farbe weiss. Keine Augen, aber ein Otolith in der Nähe der vorderen Körperspitze.

Es ist kanm zweifelhaft, dass schon O. lolbricins dieses schöne. Uurchsichtige Turbellarimm beobachtete. Seine Abbildung giebt zwar nur die Kïrpergestalt und die Lage des Otolithen dureh einen hellen P'unkt an.

In der Haut finden sich nirgends stäbchenfürmnige Körperchen. Das Centralıervensystem ist nicht erkannt worden. Der in der Nähe des vorderen Endes liegende Gehörapparat a besteht aus einer durchsichtigen Blase mit eigenthümlich lichtbrechender Flïssigkeit und einem kugeligen Otolithen, und ist von dem entsprechenden Organ bei Monocelis nur dadurch unterschieden, dass die beiden kleinen seitlichen Gehörsteinchen fehlen. Der IInnd b ist eine weite, sehr ansolehubare Hautspalte, deren strahlenfürmige - Muskeln jodoch so blass sind, dass die ganze Sjpalte sehr leicht überschen wird Der Magen wurde mit einzelligen $\Lambda$ Igen gefüllt gefunden Wimperbewegung, wie bei II acrostomum hystrix, konnte in demselben nicht wahrgenommen werden.

Im hinteren Kürperende liegt eine mit faulenförmigen Spermatozoiden gefültte Blase I, und unuittelbar auf lieser eine musknlöse Papille mit centraler Oeflnung e. das Begattungsglied. Die den Samen bereitenden Organe liegen wahrsehcinlich melar im rorderen Kïrpertheil, von den grnssen Eierstïcken bedeckt. In dem sehr durchsichtigen Parenchym der unnittelbaren C'mgegend der Samenblase fanden sich melurere untereinander 


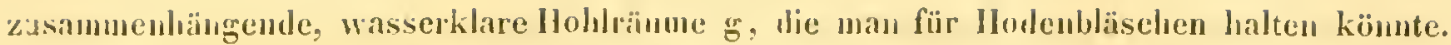
Doch nurden keine Spermatozoilen in denselhen gasehen. Die Eierstöcke stellen lange kenlentiomige Schlänche dar, in deren oberem nehen der Mlundïfnumg liegenden Ende ce Keimbläschen in grosser Menge dicht nebencinander liegen, wïlrend in den unteren Theile sich Dottemasse zwiseben denselbcn insinmelt. Viuschutirungen, eine spätere Ablïsng von Eicrn audentend, furlen sich wic an den Eierstücken von Macrostomum liystux.

Ich fand diese Art im seichten Stranlwasser der Ostsec bei Greifswald ju wenigen Exemplaren in Sommer und Herbst ules Jahres 1849. Später ist sie nicht wieder gefum. Jen worden, und es komnten die damals in der Beobachtung gebliebenen Lücken nieht ergainzt Werlen. O. Fubricius salı sic in Meerwasser bei Kunenlageu.

\section{Einiges über Nemertinen.}

Nemertinen sind diejenigen Turbellaxjen, welche einen geraden Darm mit After mo einen luervolstreckbalen oft bewaffueten Rissel habeu. Sic wmden in der pag. 3 gegebenen Eintheilnng als 4te Ordmung der Turbellarien überhaupt, als 2te der 2teu Unterklasse derselben, Jer Turbellaria proctucha. aufgefülut.

Meine Beobaehtungen über die Nemertinen beschrïnken sich auf die ejuer Art aus der Ostsee und eimer aus Jem siissen Wasser. Beide Species sind neu. Erstere gab erwïnschte Gelegenlseit zur Verfolgnng der Entwickelungsgesehichte, welehe bislıer noch von keiner Nemertine bekanut geworden was. Letztese ist durch ilıre Organisation nieht weniger wie durch ihr Vorkommen in süssem Wassed interessant.

Es wurle schon in der Eimleitung pag. 6 u. F crwihnt, dass einem Organ bei den Nemertinen von verschiedenen Beobachteru die versehiculenste Bedeutmg untergelegt worden. Von Manchen als Begattumgsglied anfgefasst, silsen Andere in diesem Organ deı Darm, noch Andere einen rom Darm gauz isolirten. seluststïuligen Rïssel.

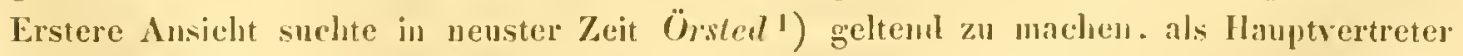

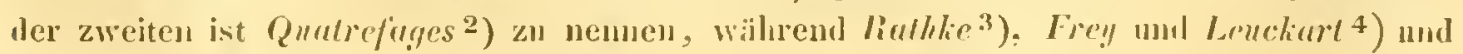

1) Entwurf rtc. pag. 2...

2) Aun. d Sc. nat. 3. Ser. Tom. V1. pag. 173.

3) Neuste Schriften der naturforsehenden Gesellschaft in Ianzig. 1S42 13d. 3. Heft 4. p. 9S.

1) lecitrïge ete. pag. 76 . 
v. Siebold ${ }^{1}$ ) der letzten Ansicht sich anschlossen. Ich habe nich schon an einem anderen Orte ${ }^{2}$ ) fiir die letztgenannte Deutung ausgesprochen, und glaube jetzt dureh die Beschreibung der neuen Süsswassernenertine, zn welcher ieh zuniichst iihergehe, vleu vollstïndigsten Beweis für die liichtigkeit dieser Ansielıt beibringen zu künnen.

\section{Prorhynchus stagnalis nor. gen. nov. spec.}

Tab. VI. fig. I.

Körper $1 \frac{1}{2}-2$ "“ lang, $\frac{1}{6}$ “" breit, cylindrisch, rorn schntäler wie hinten, weiss. Augen felılen, der Rüssel ist kurz, nicht zum Umstïlpen sondern zum Vorstossen; desshalb liegt die Bewaffunug desselben unnittelbar hinter der vorderen Oeffunng. Aufenthalt in süssen Wasser.

Unter allen hisher bekamnten Nemertinen ist keine, deren Rüsselwaffe so nahe dem Vorlerende des Thieres liegt, unl in der Gestalt sich mit der unseres Thieres vergleichen liesse. Daher war ich genöthigt, eine neue Gattung zu bilden.

Das Centralnervensystem der Nenertinen besteht nach Quatrefages und Frey und Lenckart aus zwei dureh eiue doppelte Brïcke miteinander verbundenen Ganglien. So erkannte iel dasselbe auch bei Tetrastenma obscurnm fig. 2. aa. Das Nervensystem von Prorhynehus stagualis besteht auch aus zwei, aber auffallend blassen Ganglien fig. 1. a a, zwischen welehen nur eine Brïcke gesehen wurde.

Von den Ganglien geltt jederseits ein Nerve nach vorn zu den Wimpergribchen b.b. Die Bedeutung dieser eigenthümlichen, bei den grössten Theil der Nemertimen nachgewiesenen, mit lïngeren Wimpern besetzten Hantgruben ist noch unklar. Der starke Nerv, welcher in vielen Fïllen zu denselben hin verfolgt ist, macht die Vermuthung wahrseheinlich, dass eine eigenthümliche Sinnesfunction denselben ime wolne. Angen fehlen gäızlich. Nach hinten geht ebenfalts ein starker Nerv von jeden Ganglion atus, uıd konnte bis in den hinteren Körpertheil verfolgt werden.

Der Riissel besteht aus einem vorleren, bewaftneten Theil d, und einen linteren muskılösen e. Letzterer enthält in Innerı einen Canal. welcher sich am hinteren Ende in eine Blase erweitert. Es ist wahrscheinlieh, dass diese eine Flüssiggkeit enthält, welehe bei Jer Verwurlung mit lem Stilet als Gift wirkt. Die Oeffunng an rler vorderen Kiirperspitze c dient den Rïssel zun Austritt. Das Stilet bestelıt aus einer mittleren nagelartigen, seharfen Spitze, zwei aceessorischen Stäbchen, welehe etwa halb so lang als die Spitze sind, mit ihrem vorderen Theil Jerselben fest anliegen, mit den hinteren etwas ahstehen, und aus einer cylindrischen, vorm verschnailerten und an der Spitze durchbohrten Kapsel fïr das Stilet. Letztere besteht in ihrem vorderen Ende aus derselben Substanz wie die Spitze, hinten geht sie in eine membranöse, schliesslich erwei-

I) Lehrbuch d. vergl. Auatomie pag. 5\%:

2) Arehiv fïr Naturgesehichte. 1849. pas. 289. 
terte Röhre über, in weleher der muskulöse, quergerunzelte Thıil des Riüssels mit seiner Endblase liegt. Ganz getrenut vou diesem Organ ist der Verdaunugskanal. Derselhe beginnt mit dem schlauclffürnigen Schlund $e$, weleher neben dem liüssel gelegen ist, und eine Strecke weit, vielleicht bis zur vorderen Oefhnugg des Thieres, vorgeschoben werden kamm. Diesem folgt der. Darn gr, in gerader lichtung his an das Hinterende des Thieres verlaufend, mnd bei h mit dem After endend. Derselbe ist im anrefïllten Zustande etwas buchtig, und lïsst nur wenig Raum neben sich ührig fïr die Geschlechtstleile. In seinem lunern fanden sich vicle lettröppehen und dieselben dunkelkernigen Zellen, welche wir im Darm der Rhabrlocoelen kemen gelernt haben. Gefiissverïstelungen von ausserordentlicher Zartheit, olne contractile Wandungen und mit einer zitternden Bewegungr in Innern, also wahrselıeinlich Wassergefïsse, komnten in dem vorderen durchsichtigeren Theile des Thieres erkannt werlen.

Die wenigen von mir aufgefundenen Exemplare waren alle Weibchen. Ein schlauchförmiger Ëierstock lag neben dem Darm in der linteren Körperhilfte. Der schmalste Theil desselben k, in der Nïhe des Afters gelegen, enthielt Eikeime in ziemlicher Menge. Nach vorn fanl sich um dieselben Dottermasse abgelagert, und einzelne Ausbuchtungen im Umfange des Schlauches sehienen eine Neigung zum Abschnüren der vorteren Theile des Eierstockes anzulenten, gerade so wie bei Macrostomum. Ein isolirtes Ei i, ohne harte Schale mit Ḱeimbliischen und gekernten Dotterzellen sah ich einige Mlale vor dem Eierstocke liegen. Eine Geschlechtsöflumng wurle nicht wahrgenommen.

Prorhynchus stagnalis kommt bei Greifswald in einem grossen T'eich mit'Torfgrumd am Wege nach dem Dorfe Wackerow, doch selten, vor. Anfang April fand ich junge, noch keine Andeutung der Gesehlechtstheile enthaltende Exemplare. Ende April und August wurden einige geschlechtsreife Weibchen beobachtet.

Die zahlreichen bisher bekannt gewordenen Nemertinen-Arten stammen alle aus (lem Meere. Zwei von Dugès ${ }^{1}$ ) beschriebene Turbellarien scheinen jedoch eine Ausnahme zu machen; es sind dies die in Bächen im lmnern Frankreichs gefundenen Prostona lumbricoideum uml P. clepsinoideum. Ersteres von Ehrenberg in den Abhamtl. der Acad. d. Wissensch. zu Berlin 1835 pag. 244 als Tetrastemma lumbricoideum aufgefïhrt. Körpergestalt und Augenzahl dieser beiden Arten sowie das Vorhandensein eines Afters berechtigten zu der Vermuthung, dlass es Nemertinen gewesen seien, welche Dngès beobachtete. Für letztere Art ist diese Annalme durch Beobachtungen meines Fremdes $n_{r}$ : $F$. Mïller, mündlichen Mittheilungen zufolge, vollständig gerechtfertigt. Dieser fand bei Tetrastemma lumbricoideum, in der Näbe von Berlin gesammelt, den für die Nemertinen characteristischen Rüssel mit Stilet und Reservespitzentaschen. Zn dieser einzigen sicheren Süsswassememertine kommt nun als zweite Prorly yohus st agnalis. Eine dritte Art beobachtete $\boldsymbol{F}$. Mïller bei Greifswald in einem Torfinoor-Graben.

1) Ann. d. sc. vat. I Ser. T. XXI. pag. 73. 74. 
Jirselle war etwa 3 "' lang, weiss, und hatte im lunem des libirpers das stilet mit ten lieservespitzen erkennen lassen. Leider war von dem einen dinzigen zu lieobachtunng gekounenen lisemplar keine Zcichnumg angefertigt. Später koumte sie nieht wieder aufgefinden werden.

\section{Tetrastemma obscurum nov. spec.}

Tab. VI. tig. $2-10$.

Körper 1" lang I"“ breit, cylindriseh, vom cin wenig verschmilert, an beiden Ludeu alggestumpft, dunkel olivengrün: 4 Augen. Rïssel mit einem Stilet und zwei Reservespitzentasehen. Aufenthalt an flachen Strande der Ostsee bei Greifswald unter Tang und Holzstücken, welehe kamm ron Wasser bedeckt sint.

Eine ansfïhliche Beschreibung aller einzehen Theile des erwachsenen Thieres behalte ich mir fïr eine spätere Arbeit vor. Das in lig. 2. alugebildete lunge gielot ein vorläufiges Bild der Organisation des Erwachsenen. Der Beschreibung desselben füge ich einige Beobachtmngen über friilsere Entwickelungszustände bei, welche trotz ihrer Unrollstandigkeit von Interesse sein müchten, da sie die ersten über die Entwickelung. der Nemertinen überhaupt sind.

Örsted ${ }^{1}$ ) und Desor ${ }^{2}$ ) beobachteten an zwei Nemertinen-Arten, dass sie Eier legten. welche dem Sehmeekenlaiche nicht unähnlich waren. Letzterer Forseher verfolgte auch die Vorgänge des Furchungsprocesses nach der Befruchtung his zum ersten Aultreten des Embryo im Ei. Nach diesem musste es mich nieht wenig Wunder nehmen, als ich bei der Lntersuchung ron erwaelsenen Exemplaren unseres Tetrastemma, an 1sten April gesanmelt, die ganze Leibeshöhle mit lebendigen Inugen angefüllt fant. Dieselben waren in einem Individunm fast alle anf ziemlich derselben, in verschicdenen jedoch anf sehr versehiedenen Entwickelungsstufen. Eier worden leider nirgends meh* gefimmlen, dagegen dunge von $\frac{1}{11}{ }^{\prime \prime}-1 \frac{1}{2}{ }^{\prime \prime}$ Länge.

Ich schicke die Beschreibung des ans dem Mutterleibe entnommenen in fig. 2. abgebildeten Jungen von $1 \frac{1}{2}$ “ Länge voraus. Die ganze Oberlläche desselben ist gleichmässig ınit Wimpern bedeckt. Zwischen denselben stehen an der vorderen Körperspitze einige lingere. mulewegliche, feine IJärchen. Die Haut ist als eine durehsichtigere Schicht scharf von dem Parenchym abosesetzt. Dirselbe gleicht ganz der der grösseren Rihabdocoelen. In einer leinkïrnigen Grundiage linden sieh zahlreiche wasserhelle Hohlräume. die als Zellen desswegen nicht angesprochen werden kömnen, weil sich keine eigenthümlidhe Wandung und kein Kern an ihnen nachweisen liisst (fig. 4.). Beim Zerdrücken sowohl wie beim lielandeln mit verlünter Essigsäure und Ammoniak zerfüllt dic ganze

1) Eotwurf etc. pag. 25.

2) Miillers Archiv 1Sis. pag. 51:2. 


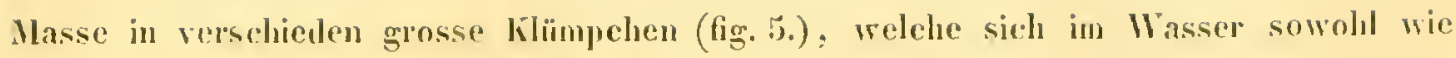
in den genanıten lieagentien balı aulläsen.

ln der vorderen lïrperspitze liegen zwei ziemlich soharf contonsirte, kuglige

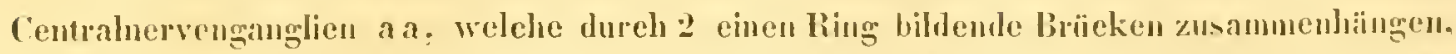
und jedes nach hinten einen starken Nerven $a_{1} a_{1}$ ansisenden. welele sich, olue an Dicke sehr ahzunehmeu, fast bis an das hintere lï̈perende verfolgen Iassen. Vum deu

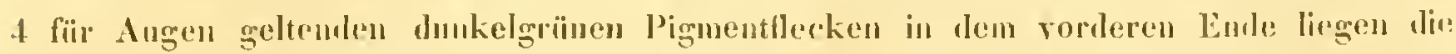
beiden unteren, grösseren, unmittelbar nuf den Centralganglien, dir oheran ctwas entlerut ron ihnen. Seitlich finden sich an Koplende die lïr die Vemertinen chararori-

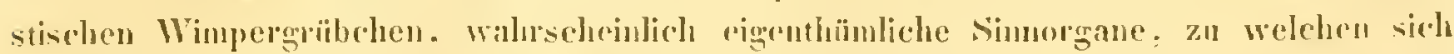
hei unseren Thicren jednch keine Nerven verfolgen liessen.

Am vorderen Ende des 'Thieres befundet sich eine Ocflumg c : der Eingang in cinen in der Axe ales Thiures liegenden Soblauch. Aessen Aufangstheil durch den Nervenriug hindurchlinft. Es ist dies daspenige Organ, weldhes ich nach dem Torgauge Auderel

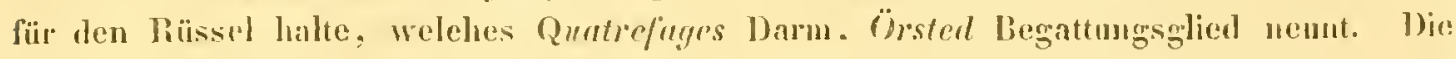
Wandung ler ersten Hälfte dieses Schlanches ol ist selu dick, muskulis, und imwendim mit Papillen besetzt. Welche das Lmmen desselben fast ganz ausfïllen. Der mittlere. solide Theil e besteht aus dicken Mnskelfaserlagen, und enthilt in seinem lunern ein Stilet mit dunkelköruigem, in Säuren nieht verïuderlichem Ilandgriff und einer wahrscheinlich aus Kalksalzen bestehenden spitze. (Vergl. fig. 10. h.). Ersterer liegt unerrïckbas in den Gund des liusscls eingehettet, innerhalb einer durelısichtigen tseitigen Masse, die Spitze ragt frei in die Höhle des Rïssels hinein. Seitlich von diesem Stilet liegt juderseits eine helle. farblose, ovale Blase, welehe im lmmem melnere dergleielıen nagelfümige Spritzen, wie cine anf dem llandgriff des Stilets festsitzt, muregelmissig Jurcheinander liegend und anf versehientenen Stufen der Ausbildung befindlieh, enthïlt. Auf diesen mittleren. soliden Theil des Rïssels, welcher nach linten durch eine lualhkugelig-muskuluse Masse ganz abgesehlossen wiod, folgt der selıwächere, hintere Theil, weleher von e bis zu seiner Anheftung an die imere Oberflache der Haut $f$ in mehrachen Windmigen verhiuft, und ganz frei in der lïrperhühle liegt, denshalb bei den Bewegnngen des Thieres seine Lagre manughaltig indert. Dieser ist ebenfalls, wenigstens in seineu vorleren Theil, hohl, hesteht aus stark nuskulösen Waulungen. welehe inwendig mit kleinen Papillen besetzt sind, mol ein verschwindend Keines Lmmen einselsliessen. und befestigt sich, nachdem er sich allmählig verschmälert hat, und zu cinen soliden Strange geworlen. nicht weit vom hinteren Kí̈rperente bei $f$ an die innere Oberloäehe del Haut.

Un sich dieses Riissels zur. Verwundung und zum Ergreifen der Bente zu bedienen, wird derselbe mit Blitzessclunclle ungestülpt, und bis an das Stilet, also ungefäln auf lialbe Kürperlänge. vorgestossen. So sah ich es boi erwachsenen Thicren hïufig: weun ihnen z. B. ein Gammans in die Nähe kam. Bei dieser Tustiilpung ninnt aler mit dem Sillet versehene Theil des liüssels die in fig. 3. gezeichnete Gestalt an. Die P’apillen. 
vorher in lumern des liussels gelegen, sind dabei alle nach aussen getreten, und ragen als conische Fortsitze in diehter Menge über die Oberdäche hervor. Ist das zu ergreifente Thier angespiesst, so wirı Aer Rüissel allmählig wieder zuriekgebracht, olıte jedochı seine Bente loszulassen, und nu kriecht dic ganze Nemertine dureh die rernittelst des Riissels gemachte Oeflum, in das verwundete Thier hinein. um dassellue ausunfessen. Vou Crustaceen bleibt un das hohle Clitinskelett zurück. Nicht selten versammelı sich um ein so gespiesstes grösseres Thier mehrere Nemertinen. welche von versehiedeneı Seiten ihren Angriff mit dem Rïssel ausfïlıren, und sich dann in die liente theilen. Sehr geschickt wissen sie zur Einbohrung des Stilets die weichere Banchseite des Theres zu willen.

Neben dem Rïssel liegt Aer Darm gg, ein grerader Canal. Welcher den grössten Theil des Körpers ausfïllt. Derselbe wimpert an der inneren Oherflälse, und enthält in seiner Waudung zalılreiche der dunkelkernigen Zelleu. Welche auf Tah. 1. fig. 3a. aus dem Darm ron Rhabdocoelen abgebildet sind. Es i.ji nit vielen Jettröpfehen angefiilt, welehe ihn ein dunkles Ansehn geben. De Itundïffunng fällt mit der Riisseliffimmg c nicht zusammen, sondern liegt eine kurze Streche hinter derselben. So sah ich es bei den erwachsınen Thieren, wihrenel ich bei den Jungen die Mundöfnung nicht erkennen kounte. An deu hinteren Ende liegt ser After lı, dureh keine besondere Muskulatur ausgezeichnet, mul desshalb nur beim Austritt des Darminhaltes dentlich.

Zwei Arten von Gefüssen habe ich an unserem jungen Tetrastemma gefunden. contraetile Blutgefässe und Wassergefïs e. Nur erstere sind bisher bei Nemertinen gesehen worle». Die schönen Abbildungen des Gefässsystems, welehe Quatrefages gegeben. siml von solehen Arten entworfen, welche sich bei grosser Durelısichtigkeit res kïrpers lureh rothes Blut fülırende Gefässe auszeichneten. Lnser Tetrastemma hat farbloses Blut unel selbst in den jugendlichen Exemplaren nicht die Jinreichende Durchsichtigkeit, un die Verheilung der sehr zartwandigen Blutgefïsse verfolgen zu kümın. So habe ich dem, tıotz lem dass audere Forscher constant 3 Lïngsgefisse angeben, nur 2 und diese nur in der Mlite des Kï̈pers, nicht aber in ihreı Endigung am Kopf unl Sehwanzende erkennen kïmen. Es sind die fig. 2. kk abgebildeten Gefissstiumme. Verästelungen scheinen sie nicht zu haben. eine Eigenthiimlichkeit. auf welche anch sehon bei anderen Nemertinen aufmerksam gemacht ist. Die Pulsationen Ichnen sich wie bei den Gefässen der Annelinlen wellenfürnig anf die ganze Jïnge derselben aus, mul wielerholen sich etwa alle $4-6$ Secumben.

Viel leichter zu erkennen sind die bisher bei Nemertinen noch nicht beobachteten Wassergefäisstïmme nit ihren Veristelungen. Dieselben stellen zwei ziemlich dickwandige, vollstündig bewegungslose Längsgefäisse dar (fig. 2. ii), welche sowohl' durch die eigenthümliche Lichthrechung ihres farblosen Inhaltes, die den Wassergefïssen der Rhabdocoelen eigenthümlich ist. ansge\%eichnet sint. als anch namentlich in ihren Veristelungen dentlich eine bewegung schwingenter. Wimpern erkennen lassen. welche der in den glrichwerthigen Gefissen der Lumbricinen und Naillnen gleicht. Jiuzehn stelıende Winperläpuchen. wie 
bei den Rhabdocoelen, scheinen nicht vorlanden zu sein. Oeffinngen dieser Gefïsse nach aussen wurden vergeblich gesucht. Ich vermuthe, dass dieselben an vorderen orler hinteren Ende des Thieres liegen; hier kounten die Wasserefefisse aber wegen grösserer Unulurehsichtigkeit des Kïrpers überhaupt nicht crkinnt werden.

Es bleibt kinftigen Beobachtungen durclsichtiger Nemertinen anderer Meere vorbehalten, zu entscheiden, wie weit die Wassergefïsse allgemein bei dieser ()rdmung der Turbellarien verheitet sind. Auffallend ist es, dass ihrer bisher gar nielht erwïuht worden.

Was die früheren Entwickelungsstufen dieser Nemertine Jetrifft, so luabe ich dieselben vou $\frac{1}{10} "$ Jänge an beobachtet. Vine der jüngsten ist in fig. 6 . alıgebildet. Der Körper ist eifürnig gestaltet, mit Wimperı gleichmässig bedeckt. Die Ilaut liess sich als eine gesonderte, durehsichtigere Schicht schon erkennen. Spuren der beiden Ganglien a waren in Vorderende sichtbar, doch fehlten die Augen noclı rollstïndig. Der Riussel war als blasser Canal b, aber ohne Bewaftunng, in lmuern vorlunden. Fettröpfchen theils frei, theils als Kerue von Zellen lagen in der Darmhöhle. Aus der geringen Grösse des Thieres lässt sich schliessen, dass es das Ei noch nieht lange verlassen haben komnte.

Die nächste Veränlerung: welehe sich bei der weiteren Entwickelung zeigte. war die, dass die Augenllecke auftraten, und dass sich die Bewaffinung im mitleren Theil des Rüssels ausbildete. Auf die Beobachtmmg der letzteren wandte ich mich mit besonderer Aufnerksankeit, weil ich durch sie Aufsehluss ibber die Function der sogerenaunten Reservespitzen zu erhalten loffte. Thiere von $\frac{1}{8}$ "' Lïnge zeigten die Spitzentaschen in der in fig. ₹. abgebildeten Weise. An der Stelle des Stilets lag eine Zelle mit kleinem, granulirten kíerne a. Die Länge der Spitzen, deren 3 oder 4 in jeder Tasche lagen, betıug $0,006^{\prime \prime}$. Bei Thieren von $\frac{1}{6}$ "“ hatte die Länge der Spitzen bis zu 0,009" zugenommen. Zwei der Spitzen hatten die Taschen verlassen, und lagen fiej vor ler die Stelle des spaiteren Stilets einnehmenlen Zelle nit granulirten Keru. Noch eine Stufe weiter, bei Jungen von $\frac{1}{4}$ “ Länge hatte die zu dem jetzt bedentend vergrüsserten Kern gehörige Zellmembran die 4 seitige Gestalt angenommen, welehe wir an dem das fertige Stilet ungebenden hellen Ramm kcmen lernten. Der lien zeiggte dieselbe gelbgrüne Farbe, wie der Handgriff des fertigen Stilets. Die beiden Spitzen lagen, ohne unterdess gewachsen zn sein, noch genau 0,009"“ lang; an derselben Stelle wie vorher vor der Zelle, der vollstämligen Ausbildung des Handgriffes, wie es scheint, wartend, um sich solann zum Verwachsen mit Letzterem zur Disposition zu stellen. Innerhalb der vierseitigen Zelle ist keine Spur der Bildung einer Spitze zu erkennen. Viele Thiere vou $\frac{1}{4}$ " Länge hatten ein schon vollständig ausgebildetes Stilet, und es ist nir niclit gelungen, eine Entwickelungsstufe aus dem Zeitraum, wo der Handgriff fertig, die Spitze aber noch isolirt liegt, aufzufinden. Doch bin ich nicht in Zweifel, dass eine solehe exis. tirt, und dass die Bildung des Stilets also auf die W' 
griff isolirt als Zellenkern entsteht, und dass eine der Spitzen aus den schon vorher gebildeten Reservespitzentaschen dazu bestimmt ist, nit dem Handgriff zu verwachsen.

Ist diese Darstellung der Entwickelung des Stilets der Nemertinen die richtige, so ist die bisher mur vermuthungsweise ansgesprochene und andererseits angefochtene Ansiclıt, dass die Spitzen, welche in den Tasehen seitlich vom Stilet liegen, dazu bestimmt seien, bei etwaigem Verlust der Stiletspitze, dieselbe zu ersetzen, gestützt. Denn so gnt bei der ersten Entwickelung das Stilet seine Spitze aus den seitlich liegenden Taschen bezieht, wird dasselbe auch bei späterem Verluste auf demselben Wege einen Lisatz erhalten kömnen. Ieh habe mich benuiht, eine Abnutzung des Stilets bei erwachsenen Thieren direet nachzuweisen, doch ohne Erfolg. Ich fand bei solehen Thieren, welche ihre Waffe eben gegen einen hartgepanzerten Gamnarus angewandt hatten, stets das Stilet unverselırt. Es wïrle somit ein Abbrechen desselben nur zı den selteneren Ausnalımen gerechnet werden kömnen. Dass jedoch ein Verbrauch der Spitzen auch bei erwachsenen Thieren stattfindet, müchte daraus nit Sicherheit gefolgert werden künnen, dass bei diesen immer nene Spitzen in den seitlichen Taselıen entstehen, während die Zahl der alten nieht zuzunehmen seheint. Es muss also entsprechend dem Zuwachs eiu Verbrauch stattfinden. luteressant ist in dieser beziehung, dass, wälıend bei friseh gesammelten Thieren die Zahl der vollständig entwickelten Spitzen in jeder der seitlichen Taschen nicht leicht 5 iilbersteigt, bei einem Thiere, welehes isolirt und mit sehr spärlicher Nahrung o MIonate in einem kleinen Gläschen aufbewahrt worden, nud welehes sein Stilet zu gebrauchen keine Veranlassung gehabt hatte, in einer Tasche 24 normal entwickelte Spitzen gefunden wurden, und neben denselben einige abnorm gestaltete von Navicula-Form. Die andere Spitzentasche enthielt eine etwas geringere aber auch sehr bedentende Anzahl. Dabei hatte die Stiletspitze die ilır sonst eigentlümliche Durchsichtigkeit verloren, und eine branne Farbe angenommen.

Was endlich die Bildung der Spitzen selbst anbetrifft, so entstehen dieselben in ganz durclısichtigen, kernlosen, ovalen Bläschen im Inuern der Spitzentasclıe. Vergl. fig. 10. a. In der Axe der ersteren tritt ein kleiner Kalkstift auf, welcher sich allmählig vergrössert, und, wenn er mit seinen beiden Enden die Wand des Blïschens erreicht hat. diese so vor sich hertreibt, dass die Blïschenwand sich den vorrleren, zugespitzten Fude des Kalkstiftes fest anlegt. An der Basis rlagegen bleibt die Blïsehenwand noch in einiger Entfermmg ron dem Stift, bis sich der Knopf ausgebildet hat. Nach der vollstïnligen Entrickelung ist als Ueberrest dieser Bildung nur noch eine feine Linie, wolche von tem Ramle des Knopfes nach der Basis der Spitze himüberläuft, zu erkennen. 


\section{Ueber Entozoen von Turbellarien.}

Örsted sagt pag. 14 seines lntwurfes etc.: „Eingewcidewürmer hahc ich bei den lihabdocoela oft vorgefunden, sie haben die grösste Aehnlichkeit mit den Leucophren unter den Infusionstlieren, und sind besonders dadurch merkwürdig, dass sie immer zu 3-4, mitmuter zu $8-10$ zusammengekettet oler gehäuft sind." Der beigefügte Holzschnitt bestätigt die Achulichkeit derselben nit gewissen Infusorien, und lïsst rermuthen, dass es Opalinen gewesen.

Ich habe bei Rhabdocoelen nie Entozoen gesehen ausser einmal im Darm eines neuen II esostom um aus der Ostsee zwei bewegungslose, kleine Gregarinen von etwa birnförniger Gestalt, mit dunkelkörnigem Inhalt und grossem Kern und Kernkö̈rperchen. Dagegen fand ich im Darm von Dendrocoelen hïufig Opahinen und Gregarinen, welche ich lier kurz beschreiben will. Erstere hat auch schon $r$. Siebold ${ }^{1}$ ) erwähnt, und $\mathrm{O}_{\mathrm{p}}$ alina $\mathrm{Planariar}$ m genanut, giebt jedoch nicht lie Planarienspecies an, aus welchen dieselben entnommen wurden.

Die Gattung Opalina wurde von Purkinje und Vuleutin ${ }^{2}$ ) für lie im Dickdarm der Frösche lebenden, Infusorien ähnlichen Thiere aufgestellt, welche schon Leeuweuloeck ${ }^{3}$ ) kannte und $O . F$. Müller ${ }^{4}$ ) Leucophra globulifera naunte. Dieselben gleichen in Bezug auf Körpersubstanz und Bewegung durch Wimpern ganz den grösseren Infusorien, wesshalb dieselben von Elwenberg ${ }^{5}$ ) mit in das in Bezug auf die Körpergestalt am nächsten stehende Genus Bursaria aufgenommen wurden. Von diesen unterscheiden sie sich jedoch, wie ich mit $v$. Siebold ammehmen muss, durch den Mangel einer Mundöffiung. Die bisher beschriebenen Arten sind, so viel mir bekamnt geworden: 1) Opaliua ranarum Purk. et Vulent. l. c., 2) O. lumbrici Dujurdin (Histoire natur. d. infusoires 184l. pag. 461), 3) O. naidos Duj. 1. c. O. Sclmidt (Müll. Arch. 1516 pag. 419), 4) 0. planariarum v. Siebolld 1 . c.

Ich habe in Dendrocoelen 2 Opalinen-Species beobachtet, deren eine aus Plauaria torva wahrscheinlich mit der $v$. Sieboll'schen übereinstimnt, ich neme sie Opalina polymorpha. Die andere ist ans einer Ostsee Planarie Pl. ulvae, und wurde wegen der sie auszeichnenden Haken Opalina uncinata grenanut. Die erste auf Tab. VIl. fig. 1-5 dargestellte hat eine Länge von $\frac{1}{10}-\frac{1}{3}{ }^{\prime \prime}$. Ënem scheiben- orler

1) Lehrbuch der vergleichenden Anatomie pag. 15. Anm.

2) De motu vibratorio 1835. pag. 49.53.

3) Ontledingen en Ontdekkingen 1653. pag. 13. fjg. 3.A.

4) Aninalc. infusor, pag. 149.

5) Die Infusionsthierchen als vollkommne Orgauismen. 1838. pag. 327 . 
halbkugelfürmigen Vorderende sitzt ein langer eylindrischer Körper an, welcher entweder in seiner ganzen Lünge denselhen Durchmesser hat, so bei fig. 2. und 4., oder Verengerungen und Erweiterungen zeigt. Welche in mannigfacher $A$ bwechsehng zahlreiche verschiedene Gestalten hervorbringen wie in fig. 1. uml 3. Die Körpersubstanz ist selır durehsichtitig, feiuk̈̈rnig und enthält viele blasse, kuglige Hohlräume wie das Parenehym der Infusorien. Auf der ganzen Oberllïche stehen zienlich lange, langsan schwingende Wimpern umregelmissig vertheilt, nicht in längssreilsen. Einen Mund haben die Thiere nicht, aber einen hellen contractilen Schlauch, weleher von einem Ende des Kö̈pers bis zum auler'n reieht. Diesen sah auch r. Siebold (1. c. pag. 21.). Er contrahirt sich rhythuniseh in Zwiselnenrïumen von einigen Minuten, meist so, dass die Zusammenziehnng in der Mitte beginnt, und nach den Enden zu fortschreitet. Für kurze Zeit scheint der Canal ganz versehwunden. Bahl erseheint er jedoch an lerselben Stelle wie vorher wieIler, dehnt sich gleichmissig in seiner ganzen Lünge aus, um sich nach einiger \%eit wieder zu contrahiren. Es ist sehr wahrscheinlich, dass der Sehlauch an beiden Eunlen eime feine Oeffunng nach anssen lat, und dass derselbe somit ein Wassergefïss darstellt. Seit O. Sclmeirl die äussere Oeffunng an der contractilem Blase der Infusorien aufgefunden, lïsst sich an dem muzweifelhaft gleichwerthigen Canal unserer Opalinen rine solehe mit Gewissheit vermuthen.

Es scheint mir sehr wahrseheinlich dass die 0 palinen keine selbststindlige Thiergattung bilden, sondern mur Entwickelungsstufen oder Anmen anderer Thiere darstellen. Die Vorbereitmgen zu einer weiteren Entwickehung labe ich an Opalina polymorpha wahrgenommen. Es bilden sieh nïmlich im Imem derselben eifürmige Blasen (fig. 1. 2. a), welehe erst hell und durchsichtigg, später nit dunkeln Kürnchen angefüllt mcist in hinteren Theil des Körpers angetroffen werden; und in der in fig. 4.a abgebildeten Form ganz den Eimlruek eines keimkörnerhanfens machen, ans welchem anf lem Wege les (icnerationswechsels ein neues, molers als das Mutterthicr gestaltetes W'esen licrvorgehen wird. Einmal fand ich 2 solehe dunkele Kerne in einer Opaline (fig. 5.). Zungleieh hatte sich diese zn einer Absehnïrmg rorbereitet, llureh welehe lie lierne mit einem Theil des Mnttertlieres entfernt werden sollten. Vielleicht dass eine Opaline Jurch ifferes Alschnüren des jedesmaligen Hinterendes nach der Bildung eines Keimkürnerhau fens in demselben eine Reihe ron neuen Thieren zu produciren im Stande ist.

Wïhrend die Opalinen der fig. 1. 2. 3. zu allen Jahreszeiten in Planarial torva sowohl aus dem sïssen Wasser wie dem Meere häufig gefunden wurden. kanen die der fig. 4. 5. nur eimmal im August in einer Planarie ans dem süssen Wasser vor. In derselhen fanden sich noch 2 Cysten von $\underset{\ddagger}{\ddagger}$ "Durchmesser, dieht mit Tausenden der in

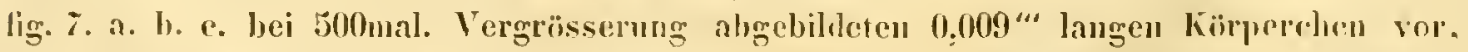
unl gleichfalls das in fig. 6. abgebildete. unbewegliche, vielleicht als junge Opaline zu Jeutende Wesen von 0,02"“ Lïnge.

Eine andere Planarien-Opaline ist dic in PI. ulva he hüulig gefundene $O_{1}$. II" 
cinata (fig. 8. 9.). Dieselbe ist $\frac{1}{1 \pi}$ “' lang platt, oval, und ansgezeicluet dureh die im Vorderende liegenden beiden larten Haken, von denen der eine stets etwas kïrzer als der andere ist. Kö̈perparenclyym mul contractiles Gefïss sind ganz wie bei der vorigen Art. Ehenso der in einzelnen Fällen vorhandene helle Fleck a. Fig. 9. stellt ein in der Theilung begriffenes Thier ror.

Merkwürdiger Weise fanden sich bei Planaria lactea und uigra (Polycelis) niemals (Opalinen vor ${ }^{1}$ ).

1) Die Organisation anderer Opalinen weicht von der elsen beschriehenen varzugsweise darin ab, dass sich in ersteren keine Spur eines contractilen Gelildes, weder blase noch laingsgeläss findet. Ich habe O. ranarum, lumbrici mol naidos untersucht. In Nais littoralis der Ostsee, in weleher schou $O$. F. Mliller einc Iseucophra, die er nodulat a nennt, fand, und in der Zoolog. Dan. II. Tab. 80 . fig. a-e ahbildete, lebt eine Opaline, welelse von der von Dujardin und $O$. Schmidt beschriebenen wohl abweicht. Ich nenne sie (Opalina li neata. Dieselbe ist Tab. VII. lig. 10. u. 11., in letzterer Figur ganz. ansgewachsen und in der Theilung begriffen, abgebildet. Fig. 12., gleichfalls aus $\mathrm{N}_{\mathrm{a}} \mathrm{is}$ littoralis, ist vielteicht eine linfwickelungsstufe. Isetztere stimmt mit (Op. naidos (). Schmidt üherein. Diese Opraline ist ausgezeichnet durch die feinen Längsstreifen, welche ilır ein :iusserst zierliches Ansehn gelsen. Dieselhen sind nieht der Ausdruck reihenweis gestellter Wimprern, wie man glauben mïhte, sondern liegen unter der Haut. unl scheinen einer mittleren Höhle oder einem im Inneru liegenden Kïrper anzugehören, weleher namentlich in fig. Il. deutlich umgrenzt erkannt wird. Die Laingsstreilen sind auch nicht ïber die ganze Opaline sichtbar, wie es der Fall sein müsste, wenn die Wimperstellung ihre Ursache. Sie sind nur in dem angeschwollenen Theil des Thieres ganz scharl, and verlieren sich allmahlig dem diüneren Ende zu. Junge Exemplare hesitzen die Streifen noch nicht, wie has zum Abschnüren bestimnte der lig. IJ zeigt. Doch ist die centrale Hühle auch hier schon sichthar.

In dem Darm derselben Naide fundet sich ein eigenthïmliches Entozoon, der Rotatorien-Gattung Albertia Dujardin angehïrg. Dasselhe ist rerschieden von der vn Dujardin in der Leibeshihle yon Regenwürmern und dem Darm von Limacinen entsleckten Alhertia rermiculus (Ann. A. se. nat. 2 Ser. IS3S. 'Tou. X. pag. 175. Tab. Il. fig. I. ‥ 3. Histoire nat. des infusoires 184I. pag. (0.j3), der einzigen bisluer bekanten Species. Ich neme dasselhe Albertia erystallina. Aul Tab. VH. fig. 13. ist hei 300mal. Vergrüsserung ein Thicr abgebildet, welches in lebluafer Bewegung im Darm der Naide begrifien war. Der Kürper ist eylindrisch, vorn etwas versehmälert md mit einem diehten besatz von Wimpern verselsen, hinten elienfalls verschmälert, und in einen scharf abgesetzten, spitzen, lieweglichen Schwanz ausgehend, weleher, wie fig. 14. zeigt, nicht in der Axe des Thieres, sondern seitlich von derselluen liegt. Die Mnodoffunng ist bei a; sie führt in einen kurzen Canal, in dessen Grunde der Greifapparat, wie eine Zange gestaltet, liegt. Dieser kann bis au die Mund̈̈fnung vorgeschohen werden. Einige drüsige Gebilde umgeben den Anfang des Darmes b, welcher im hinteren Kiirperende mit dem After e endet. Der neben dem Darm liegende Schlanch d ist der Eierstock. Er enthïlt viele Eikeime, um welche sich nach unten allmählig Dottermasse ansammelt. Ein vollständiges Ej fand sich fast constant im hinteren Ende. Dasselbe liess stets das Kicim. bäschen noch deutlich erkennen. linzelne Eier ron derselben Gestalt wurden hic und 
Endlich bleibt uns noch die Gregarinenform zu beschreiben äbrig, welche in Planaria torva des süssen wie See-Wassers micht selten ist. Dieselbe, in fig. 18. iu den vollstindig ausgebildeten Zustande dargestellt, gehört den Monocystideen nach stein ${ }^{1}$ ) an, d. h. der inncre, von der Aurchsichtigen Haut unschlossene liaum stellt eine einzige, nieht durch Querwände abgetheilte Höhle dar. Die feinkürnige dunkle Masse im Innern ist an dem vorderen Ende wie an dem hinteren in geringerer Nenge enthatten wie in der Nitte. Ilier liegt der für die Gregarinen characteristische Kern mit Kernkörperchen. Jüngere Formen sind in fig. 19. und 20. dargestellt. Eine Copulation zweier Individuen behufs der Bihung von Navicellen habe ich nicht benbaclitet. Dagegen landen sich häufig ganz kuglige Formen, wie fig. 21., mit deutlichem Kern. Navicellenhehïlter, welche ich mit diesen Gregarinen in Verbindung hringen zu müssen glaube, sind in einzelnen Fällen vorgekounmen. Der Inhalt derselben bestand aus Tausenden der fig. 22. dargestellen 0,002 "“ langen liörperchen.

Das Vorkommen von Gregarinen in Turbellarien ist hier übrigens nicht zum ersten Male besehrieben. Kölliker ${ }^{2}$ ) und Frey unl Leuckart ${ }^{3}$ ) beobachteten dergleichen in Nemertinen. Aus Dendrocoelen waren jedoch noch keine bekant geworlen.

da frei im Darm der Naide angetroffen. Von Gefässen mit schwingenden Wimplerläppchen, wie dieselben Dujardin bei seinen Speeies sah, babe ich nic eine Spur erkennen künnen.

Diese Art untersebeidet sich von A. vermiculus durch ilhe geringere Grisse, welche zwar nicht durelı directe Messungen wachgewiesen ist, da bei Dujarlin derartige Angaben fehlen, und auch ich die Grissenhestimmung rersäumt bahe, welehe sich aber Jurch Vergleichung der Ablildungen in den Annales des sciences naturelles und den meinigen (beide hei 300maliger Vergrüsserung angefertigt) ergiebt. Ferner fehlt der A. vermieulus der abgesetzte Sehwanz, letztere ist lebendiggebärend, während A. erystallina nur Lier zu legen scheint.

Eine eigenthümliche Entwickelungsstufe mnserer Albertia ist die kleine lig. 17. abgebildete Form mit deutlich gegliedertem llinterleibe, und obne Spur eines Verdaungsund Geschlechtsapparates. Nur das Greiforgan liegt vollständig entwickelt im Vordertheil. Dieselhe wurde frei im larm und in lehhafter bewegung angetroffen. Ganz unerkliirlich sind mir die in fig. 15. und 16. ahgebildeten, hehaarten Thiere geblieben, welche neben den normalen häulig rorkamen. Weiche, liegsame, unmessbar feine llaare hedeckten den ganzen Körper nit Ausnahme des Vorderendes. Dabei war die lieweglichkeit des Thieres nicht heeintrạchtigt. Nur die fig. 16. dargestellte behaarte Entwickelungsform schien alıgestorhen zu sein.

1) Müller's Archiv. 1848 pag. 187.

2) Zeitschr. für wissensch. Zoologie von $x$. Siebolıl u. Kölliker. lid. I. pag. I.

3) Beiträge etc. jag. 76. Dass Örsted Gregarinen aus Turbellarien beschreilıe, wie Frey und Leucliart behaupten, kann ich nielst finden. 


\section{Resultate ${ }^{1}$.}

1. Die Haut der rhabdocoelen Turhellarien besteht aus einer weichen, homogenen, lcinkürnigen Grundsubstanz, welehe die Cilicn trägt und in ilırem lnnern viele wasserklare Hohlrämme enthält. Sie grleicht hierin der Kürpersubstane der Infusorien und Hydren (der Sarcode Dujurdin, der ungeformten contractilen Substanz niederer Thiere Ecker), unterscheidet sich von derselben jerloch dadurch, dass sie heim Behandeln mit gewissen Reagentieı namentlich, verdünntem Ammoniak, in regelmässige Stïeke zerlegt werden kam, von denen ein jedes aus einem Complex von Hohlräumen und der dazu gehörigen Grundsubstanz besteht. Eime Erklärung dieses Zerfallens komıte nur in der Amnahme gefunden werden, dass jedes der regehmässigen IIautstiicke aus einer Zelle entstanden sei. Wandung und Inhalt der ursprünglichen Zellen sind gleichmässig zu ter eigenthünlichen, der Sarcode ähnlichen Substauz metamorphosirt, deren Eutstehung aus Zellen bisher noch nicht naclıgewiesen war. Untereinander siud dic chemaligen Zellen jedoch noch nicht so weit verschmolzen, dass nicht durch chemische Hülfsmittel eine Trenmung noch möglich wäre.

2. Die stïbchenförmigen Kürperchen der Rhabdococlen nnd Süsswasser-Dendrocoelen bestehen aus einer eigenthümlichen Substanz, ausgezciehuet durch Schwerlüslichkeit in Alcalien und Zerfliesslichkeit in Wasser und verdümnten Säuren. Von den Nessclorganen der Acalephen und Polypen sind sie sehr verschieden. Sie stehen bei vielen Arten in einer eigenthümlichen Beziehung zum Nerrenșstem, und wurden als wahrscheinlich das feinere Gefühl der Haut erhöhende Gebilde angesehen.

3. Der grïne Farbstoff von Vortex viridis nnd II esostomum viridatum wurde als identisch mit dem Chlorophyll der Pflanzen erwiesen. Ebenso der von Ilydra viridis mol Stentor polymorphus.

4. Das Muskelsystem der Rhabdocoelen ist sehr entwickelt und besteht aus einem Hautmuskelnetz, Huskẹln zur Bewegung des ganzen Körpers und solchen zur Bewegung imnerer Organe. Das Parenclymm zwisehen den Mtuskeln gleicht der „ungefornten contractilen Substanz niederer Thicrc."

5. Das Nervensystem ist in allen Familien der Rhabdocoelen nachogewiesen,

1) In diese Zusammenstellung kounten nur die vorzüglichsten histologischen, histologisch-chemischen, rergleicluent-physiologischen und einige der zoologiselı-systematisehen Resultate aufgenommen werden, da die anatomischen Darstellungen und die Beschreibungen neuer oder wenig gekannter Species keinen Anszug gestatten. 
unl besteht aus zwei durch eine Brücke verbundenen (Ganglien orler einem Doppelganglion nebst von diesen ansgehenden Nervenfïden.

(i. Simuesologane kommen bei den Rhabulocoelen als Augen mit und ohne linse und als Gehörolgane vor.

7. Die harten Theile des Begattungsgliedes bestchen aus einer dem Chitin ähnlichen, von diesem jedoch dureh die Lïslichkeit in kochenter Kalilange unterseliedenen Sulstanz.

8. Die harte Schale der Rhabdocoelen uml Dendrocoelen-Eier besteht aus Chitin, ebenso die von Clepsine, Nepluelis uml von Hydra viridis.

9. Der Polypenstock der Sertularinen und Campanularien besteht chenfalls aus Chitin.

10. Die Gattung Monocelis Örsted gehört den Rhabdocoelen und nicht, wie bisher angenommen wurde, den Dendrocoelen an. Sie bildet zusammen mit der Gattung Opistomm Schmidt die Familie ler Opistomea.

11. Die Fanilie der Derostomea umfasst die Gattungen Vortex Elrenberg und Derostomum Örsted. Hypostomum Schmidt ist mit Vortex zu rereinigen.

12. Die Familie der Mesostomea enthilt nur eine Gattung Nles ostomum. Typhloplana Örsted und Strongylostoma Örsted sind mit Mesostomum zu vereimgen.

13. Bei Tetrastemma obscurum nov. spec., einer Nemertine ans ler Ostsee, wurden lebendige Junge in der Leibeshïhle der erwachsenen Weibchen beobachtet, während man bisher bei Nemertinen nur die Fortpflanzung dureh Eier kamte. Die Entwickelung derselben geschicht olme Metamorphose.

14. Jie Bildung des Stilets dieser Nemertine geht so vor sich, dass der Handgriff gesondert als Kern einer Zelle entsteht, die Spitze dagegen aus den sclon vorher gebildeten seitlichen Spitzentaschen entnommen wird. Hieraus wurde gefolgert, dass die Spitzen der seitlichen Taschen auch spiter als wahre Reservespitzen anzusehen sind.

15. Bei derselben Nemertine, sowie bei Prorhynchus stagnalis, einer neuen Art aus dem süssen Wasser, findet sich ein Wassergefässsystem, lessen Anwesenleit bei Nemertinen bisher nicht bekannt war. 


\title{
Erklïrung der Tafeln.
}

\begin{abstract}
'T a b. I.
(1)ie Vergrösserung sänmtlicher Figuren, bei welchen dieselbe nicht besonders angegehen wurde, ist $350 \mathrm{Mal}$ im Durchmesser.)
\end{abstract}

lig. 1. llant ron Vortex viridis. In derselben stäbchenfürnige lïrper, unter derselben Chlorophyllblïsehen.

2. Chloroplyyllbläsehen von Vortex viridis bei 600 mal. Vergrïsserung. Dieselben sind durch Aneinanderlegen eckig geworden. 2 a. Chlorophyllbläschen, welehe llureh langen Aufenthalt des Thieres im Dunkeln geschrumpft und entfïrbt sind.

- 3. Dureh Ammoniak isolirte Bläsehen aus ıler Haut von Hydra viridis.

4. Hant von Mesostomum tetragonum. Unter derselben braune Farbstoffbläschen, in derselben stäbehenförmige Körper.

5. Haut desselben Thieres nach der Behandlung mit Ammoniak.

6. Abgerissenes Hautstïck desselben, vermöge der aufsitzenden Wimpern in lebhafter Bewegung.

6a. Algerissenes Parenchymstückehen von Vortex viridis, welehes selbststïndige Contractionen zeigte. In demselben Chlorophyllbäschen und Fettröpfehen.

- 7. Haut von einem jungen Derostomum Schmidtianum.

- 8. Durch Ammoniak isolirte Hautschïppchen eines erwachsenen Derostomum Sehmidtianum.

9. Haut von Prostomum lineare dureh Imbibition mit Wasser theilweise verindert.

10. Haut ron Mesostomum rostratum mit Ammoniak behandelt, unter derselben das gleichmässig rothgefürbte Parenchym.

11. Ahgelïste Stücken der Hant von Mesostomum rostratum.

- 12. Ansicht der llaut eines lebenden Mesostomm rostratum von oben.

- 13. Hautsehuppen ron Opistomum pallidum dnreh Ammoniak abgelöst.

- 14. Oberhautschïppehen von $O_{p}$ is to m u m palli du m ohne Cilien, dureh Druck ahgelöst.

15. Haut ron Macrostomum hystrix.

- 16. Haut von Mesostom nm marmoratum. Unter derselben rerzweigte ligmentablagemugen.

- 17. Stäbchenförmige Körperehen aus der llant von Vortex viridis bei 500 mal. Vergrisscrung. Ebenso sind die ron Mesostomum marmoratum.

15. Stäbchen aus der Haut von Nesostomum tetragonum. 
Fïg. 19. Stiibchen ron einer gemeinsamen Membran umschlossen, unter der Haut von Mesostomum tetragoun.

- 20. Stäbehen in Zellen liegend, ebendaher.

- 21. Stabchen ans der Ilant von Planaria lactea.

- 22. Dieselben nach anhaltendem Kochen mit Kalilauge.

- 23. Vorderer Körpertheil von Mesostomum rostratum, um das Verhältniss der stibchenförmigen Körper zu len Centralnervenganglien darzustellen, bei 180mal. Vergrösseruıg.

- 24. a. b. Reihenweis georduete Stäbehen aus dem Parenchym von Mesostomum tetragonum. c. Stibehen in Begleitung einer mehrere Anschwellungen zeigenden Faser, wahrscheinlich Nervenfaser, ebendaher. d. Zwei Anschwellungen aus dem Verlaufe einer Nervenfaser, ebendaher.

- 25. Zelle mit Stäbchen, welche sich in eine Stïbchenkette fortsetzen, ebendaher.

- 26. Centralnervensystem von 0 p is tomum pallidum. Bei a endigen die Fasern mit kleinen Anschwellungen in der Haut.

- 27. Centralnervensystem von Prostomum lineare. Eigenthünliche gramulirte Zellen bedecken die Nervenmasse.

- 28. a. Auge von llesostomum marmoratum mit einer Linse. b. Auge ron Vortex balticus.

29. Auge von Hesostomum tetragonum bei 180 mal. Vergrösserung.

- 30. Hautınuskelnetz von Vortex viridis.

- 31. Parenchymmuskeh von Mlesostomum tetragonum. Die Umbiegungen entsprechen lem freien Rande einer der 4 llügelförmigen Fortsätze.

- 32. Abgerissene Mluskelfüden ebendaher.

- 33. Verzweigte Muskelfaser von MLes ost omum tetragonum.

- 34. Wassergefässe mit schwingenden Wimperlappen von Mesostomum tetrag $011 \mathrm{um}$.

- 35. Zellen der Magenwandmg von Vortex viridis, bei 500mal. Vergrösserung.

- 36. Dotterstock eines jungen Vortex viridis.

- 3ĩ. a. Mntterzellen aus dem Hoden eines jungen Vortex viridis. b. Tochterzellen ebendaher. c. Dieselben in die Länge gezogen, daneben reife Spermatozoiden.

- 3S. Spermatozoiden von Derostomnm Schmidtianum in Bläsehen eingeschlossen.

- 39. Spermatozoiden von Opistomum pallidnm auf verschiedenen Entwickelungsstufen, a. aus dem Hoden, b. aus der Samenblase, c. aus dem receptaculum seminis.

- 40. Spermatozoiden von Prostomum lineare, a. aus dem Hoden, b aus der Samenblase. 


\section{'I'a b. II.}

Fig. 1. Monocelis agilis nov. spee, a. Otolith, darüber ein selwwarzer Augenpigmentlleck. b. Schlund. ec. Ilodenblisehen. d. Samenblase. ee. vasa deferentia. ff. Keimstöeke. k. Geschlechtsöllinung.

- 2. Hodenblisehen einer jungen Monocelis agilis.

3-7. Eitwickehungsstufen der Spermatozoiden.

- S. Vorderende ron Nonocelis unipunctata Örsted a. Otolith, darunter die obere Begrenzung des Centralganglions.

- 9. Hinteres Ende von Monocelis unipunetata. b. Schlund. ce. Hoden. d: Samenblase. p. penis. ff. Keimstöeke. gg gotterstïeke. hi. Ausführungsgangु der Keimstöeke (?). d. receptaculım seminis (?). k. Geschleehtsöflıung.

- 10. Samenblase mit dem ausgestiilpten Begattungsglied ron Monocelis unipunctata. b. Widerhaken des letzteren, 500 Mal vergrössert.

- 11. Samenblase und begattungsglied einer Monocelis-Species, welche sich ron $\mathbf{~} 10$ noe elis unipunctata in der übrigen Organisation nicht zn unterscheiden schien.

- 12. Hlinteres Ende von Mo nocelis Jineata Örsted. b. Schlunl. ec. Hodenblïschen. d. Samenblase mit einem papillenartigen penis. e e. vasa deferentia. ff. Keimstöeke. gg. Dotterstöeke. l. receptaculum seminis (?). i. Spermatozoiden in Bhischen liegend, wahrscheinlich vom reeptaculum seminis aus hierher gelangt.

\section{Tab. III.}

1. Opistomum pallidum O. Schmidt. a. Centralnervensystem, neben demselben Wassergefïssverästelungen. b. Mundüffnung. c. Selhlund, dd. Hoden. e e. vasa deferentia. f. Samenblase. g. penis. h. Gesehlechtsüffuung. i. Seheide. h. receptaculum seminis. 1. Keinstoek. mn. Dotterstöcke. n. Eiersack (uterus) mit zwei hartschaligen Eiern. Das mutere ist jünger, lund die Schale noch heller gefürbt. - Wassergefüsse verïsteh sieh zahlleieh in hinteren Kürpertheil. Drei grössere Oeffhungen derselben liegen in der Nähe der Gesehlechtsüflumng.

2. Ilinteres Ende von Opistomum pallidum bei stärkerer Vergrössermng. Die liuchstaben bedenten dasselbe wie bei Fïg. 1. Die Wassergefïssrerïstelungen sind noeh zahıreicher. Zwei kleine Hüıdungen derselben liegen unnittelbar unter der Samenblase.

- 3. Der penis von 0 pistomum pallidum vollständig ausgestïlpt bei 360 faeleer Vergrösserung.

4. Vortex riridis milhi (Hypostomum schm.). Die grïnen Kürnchen sind Chlorophỵllkïgclchen. a. Centraherrensystem. b. Auge. c. Mnndüflinung. d. Sehlund. e. Drïsenzcllen zun Verdaunngsapparat gehürig. gg. Hoden. hl h. vasa deferentia. i. Samenblase. k. penis. I. Imere Gesehlechtsüffnung. Dicht darmuter 
die äussere. Im. Scheide. n. receptaculum seminis. oo. Keimstöcke. p. uterus. ๆ. eiı Ei in der Leibeshöhle liegend. vr. Dotterstüeke.

Fig. 5. Samenblase und liegattmingsolied im ausgebreiteten Zustande von Vortex viridis bei $360 \mathrm{mal}$. Vergrösserung. a. Samenblase, in welche die beiden vasa deferentia eimminnden. b. ductus ejaculatorius.

\section{'Tab. IV.}

1. Vortex balticus nov. sp. a. Centraherrensystem. b. Auge. c. Mundöfhung. d. Schlund. e. Driisenzellen. f. Magen. gg. Hoden. h. Samenblase. i. penis. k. Geschlechtsöffnung. l, receptaculum seminis (?). mm. Dotterstöcke. nn. Keimstöcke.

- 2. Ei von Vortex balticus aus der Eiertasche. 2 Embryonen sind in demselben fast vollstïnlig entwickelt.

- 3. Vorderende von Vortex balticus mit sehr ausgedehuter Hund-und Schlundöffinung.

- 4. Vorderende von Vortex balticus. Der Sehlund zur IJälfte aus der Ilundöffnmg hervorgestreckt behufs der Anfnahme von Nahrung.

- 5. Vortex pellueidus nov. spec. Bedeutung der Buchstaben wie bei lïg. I.

- 6. Derostomum Schmidtianum mihi. Bedeutung der Buchstaben wie bei Fig. 1. k. ein hartschaliges Ei.

- 7. Vorderende eines jungen Derostomum Schmidtianum. Der Schlund zur Ausleerung des Mageninhaltes erweitert und hervorgetrieben.

- S. Schlund von D. Schmidtianum, in der Form, wie er beim schnellen Schwimmen des Thieres erscheint. Der enge Canal, welcher durch Auseinanderweicheu der imneren Schlundwandungen ron der vorderen Oeffnung zur hinteren führt, gleicht einem Lïngsspalt des Schlundes.

- 9. Schlund desselben Thieres, unter einem Deckglïschen einem mïssigen Drucke ausgesetzt. Die gewöhnlich eine Spalte darstellende vordere Oeffinung ist rund wie bei Vortex.

'Tab. V.

- 1. Mesostomum obtusum nov. sp. An der vorderen Spitze drei difuse Augenllecke und vicle stäbchenförmige Körper. b. Schlund. c. Hode. d. Samenblase. f. Keimstock, gg. Dotterstöcke.

-2. Hesostomum marnoratum nov. spec. a. Auge mit einer Linse. b. Schilund. c. Hode. d. Samenblase. An derselben der lange röhrenförnige penis, zur Iẗ̈lfte in einer musknlösen Scheide liegend e. Geschlechtsöffnung. f. Keimstock. g g. Dotterstöcke.

- 2.a. Mesostomum marmoratum bei Gmaliger Vergrösserung. 
Fig. 2. $\beta$. Das der Geschlechtsöfnung zugekelırte Ënde des penis bei 30t)mal. Vergrösserung. o. Ueftiung desselben.

3. Macrostomum hystrix Ürsted. a. Mlundöfmung: über derselben die beiden kleinen schwarzen Augen. b. Magengrund, in welchem Wimperbewegung. cc. IIoden. d. vas deferens. c. Samenblase. f. penis. gg. Eicrstöcke. I. Geschlechtsöffiuung.

4. Macrostomum auritum nor. spec. a. Otolith. b. Mundöfnumg. ce. Obere Enden der Eierstïcke, mit Keimblïschen gefïllt. d d. Untere Enden derselben, in welchen sich die Dottermasse un die Keimblïschen anhäuft. e. Papillenartiger penis f. Samenblase. g. durchsichtige Hohlräume in der Ungegenl der Samenblase deren Bedeutung unklar gebliehen ist.

\section{rab. VI.}

- 1. Prorhynchus stagnalis nov. gen. nor. spec, eine Süsswasser-Nemertine. a a. die beiden Centralganglien des Nerversystems. b b. Wimpergrübehen. c. Oeffinng zum Vorstrecken des Rüssels, vielleicht auch Mundöllinung. d. Vorderev bewafheter Theil des hiissels. e. Hinterer, muskulöser Theil desselhen. f. Schlauchfürmiger, muskulöser Schlund. g. Darm. h. Afteröffnung. i. Ein Ei mit Keimbläschen und Dotterzellen. k. Der untere mit Eikeimen angefïlte 'Theil des Eierstockes.

- 2. Iunges ron Tetrastemma obscurum nor. spec. 11?" lang, ans der Leibeshöhle eines erwaclısenen weiblichen Exemplares genommen. a a. die beiden Centralnervenganglien durch zwei Bräcken nit einander verbunden, zwischen welchen der Riissel hindurchlïuft. a.a. die beiden Hauptnervenstïmme. bb. Wimpergrïbchen. c. Rïsselöfung. d. Vorderer, imwendign mit Papillen besetzter Theil des Rïssels. e. mittlerer, sulider Theil desselben mit dem Stilet und den Reservespitzentaschen. f. Hinteres Ende des Rïssels. gg. Darm. h. After. ii. Wassergefüsse. kk. lihythmisch sich contrahirende Blutgefïssstïme.

- 3. Vorderer Theil des ausgestülpten Rüssels mit dem Stilet an der Sptize und Papillen an der ganzen Oberfliche.

- 1. Haut eines jurgen 'Tetrast emma obscurum bei 500 mal. Vergr. In ilerselben viele wasserhelle llohlrïme u. Pigmentkömchen. Unter derselben feine Ilautmuskelfasern.

- 5. Dläschen, in welche die Haut bei Ammouiakzusatz zerfaillt.

- 6. Jüngste der bcobachteten Tetrastemmen; aıs der Leibeshöhle der Mntter genommen, $\frac{1}{T_{1}}$ "' lang. a. Centrahervensystem. Von Augenllecken ist noch keine Sur da. b. der Rïssel ohne Stilet orler Reservespitzen.

- 7. Mittlerer Theil des Riïssels eines jungen Tetrastemma obscurum von $\frac{1}{8}$ “ Länge aus dem Mntterleibe. Die lieservespitzentaschen haben sich gebildet. An der Stelle des kïnftigen Stilets findet siclı eine Zelle mit granulirtem Kern a.

S. Derselbe Theil eines jungen Tetrastemma obscnrum ron $\frac{1}{6}$ " Liinge ans den Mutterleibe. Der granulirte Kern der Zelle a, welcher später zmm Handgrifi des 
Stilets wird, hat sich rergrössert. Zwei Spitzen sind aus den Reservespitzentaschen ausgewandert, mul liegen in der Mitte vor der Zelle.

Fig. 9. Derselbe Theil eines Tetrastemma obscurum von $l_{4}^{\prime \prime \prime ~ L a ̈ n g e ~ a u s ~ d e m ~ M u t t e r-~}$ leibe. Die Zellenwand un den granulirten Kern hat die 4 seitige Gestalt angenom. men, wie die durchsichtige Stelle im Umkreise des Stilethandgriffes grö̈sserer Thiere. Vergl. fig. 2.3. Zwei Spitzen liegen vor diesen Urgan, wie in der vorigen Figur.

- 10. a. Reservespitzentasclse eines erwachsenen 'Tetrastemma obscurum.

- 10. b. Stilet desselben Thieres.

\section{Tab. VII.}

(Die V'ergrïsserung sämmtlicher Figuren, bei welchen dieselbe nicht liesouclers angegeben, ist $300 \mathrm{Mlal}$.)

- 1.-5. Opalina polymorpha aus dem Darm von Planaria torva. Der helle Streif in Lmem der Thiere ist ein contractiles Gefïss ïhnlieh der contractilen Blase der lufusorien. Fig. 1. 2. a. helle, scharf mmschriebene Stellen im Hinterende, welche walırscheinlich zu der bei Fig. 4. 5, a. befundlichen Ablagerung einer feinkürıigen Masse in Beziehung stelıen. Fig. : 5. in der Theilung begrillen.

- 6. Junge, noch unbewegliehe, mbewimperte Opaline aus Planaria torva.

- 7. a. b.c. Navieellen älnliche Körperchen ans einer Cyste, in weleher viele lundert derselben beisammen lagen. Aus Planaria torva.

- 8. 9. Opalima uncinata ans dem Darm von Planaria Ulvae. a. Wie bei Opalina polymorpha. Fig. 9. in der Theilung begriften.

- 10.11. 12. Opalina lineata aus dem Darm von Nais littoralis. Fig. 12. Junges . Exemplar. Fig. 11. In der Theilung begriffen.

- 13-17. Albertia erystalliua nov. spec. aus dem Darm von Nais littoralis.

- 13. Vollständig ausgebildetes Exemplar. a. Vorderende mit Wimpern luesetzt mit der Mundöfnung. llinter derselben der zangenartige Kau- oder Greifapparat. b. Darm. c. After. d. Eierstock, an dessen hinteren Ende ein reifes Ei.

- 14. Hinterende desselben Thieres von der Seite geselıen. Das bewegliche, spitze Schwanzente an den Körper geschlagen.

- 15. Eine vollständig ausgebildete Albertia erystallina, auf der ganzen Oberllïche mit feinen, weiehen Hïrchen bedeckt.

- 16. Eine noch unentwickelte Albertia, bewegungslos und ebenfalls mit feinen Härchen iiberzogen. Vom Darm und den Geschlechtstheilen keine Spur zu sehen.

- 17. Eine noch unentwickelte Albertia, beweglich.

- 18 1:1 20 21. (iregarinen aus dem Darm von Planaria torva.

- 22. Navicellen aus einer Cyste, welche walıscheinlich durch Modification von Giregarinen hervorgegangen war, bei 500mal. Vergrösserung, aus Planaria torva. 


\section{Verbesserungen.}

Pag. 5 Zeile 11 von unten - Nemertinen lies Nemertinea.

- 15 - 13 von unten - pallidus lies pallida.

- 16 - 12 von ohen - versehiedener lies verschiedenen.

- 18 - 13 - - - Wasclien lies Waehsen.

- 35 - 22 - - - hinter Spermatozoiden felılt ein ;

- 38 - 3 - $\quad$ - hinter Videnskabernes einzuselialten: Selskabs naturvil. og mathem.

Kibenso pag. 56 Zeile 1 und 12 von unten. 





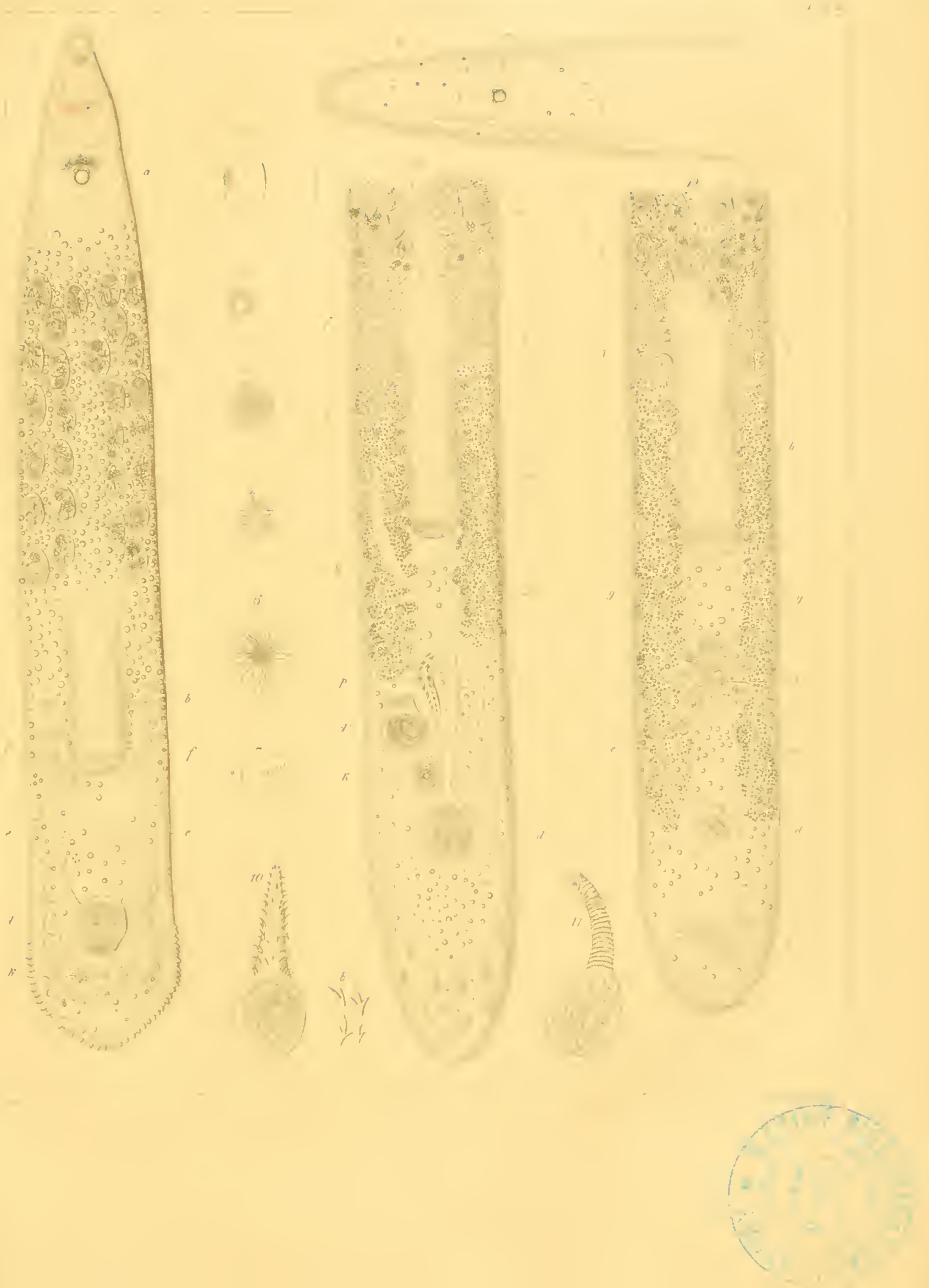





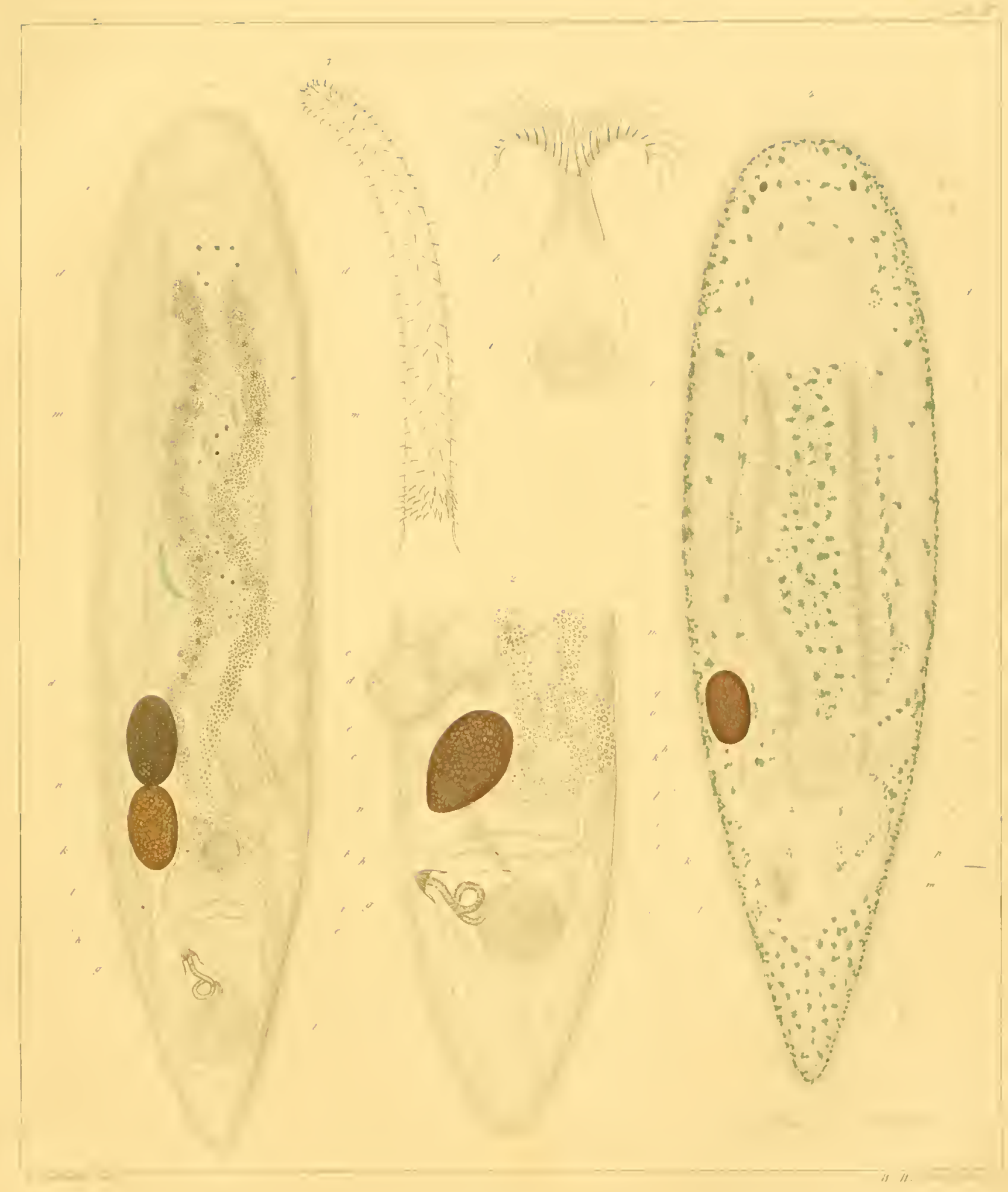





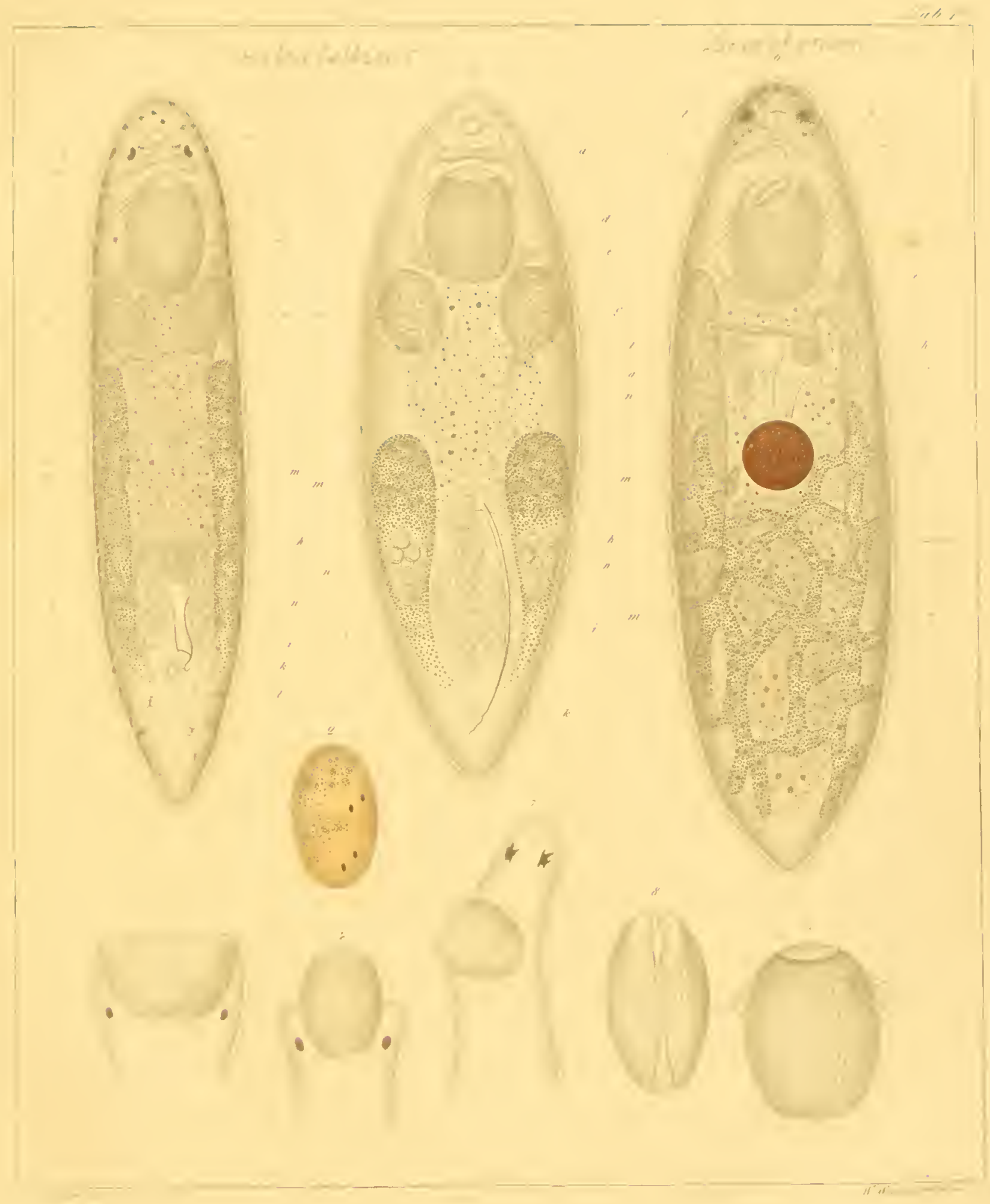




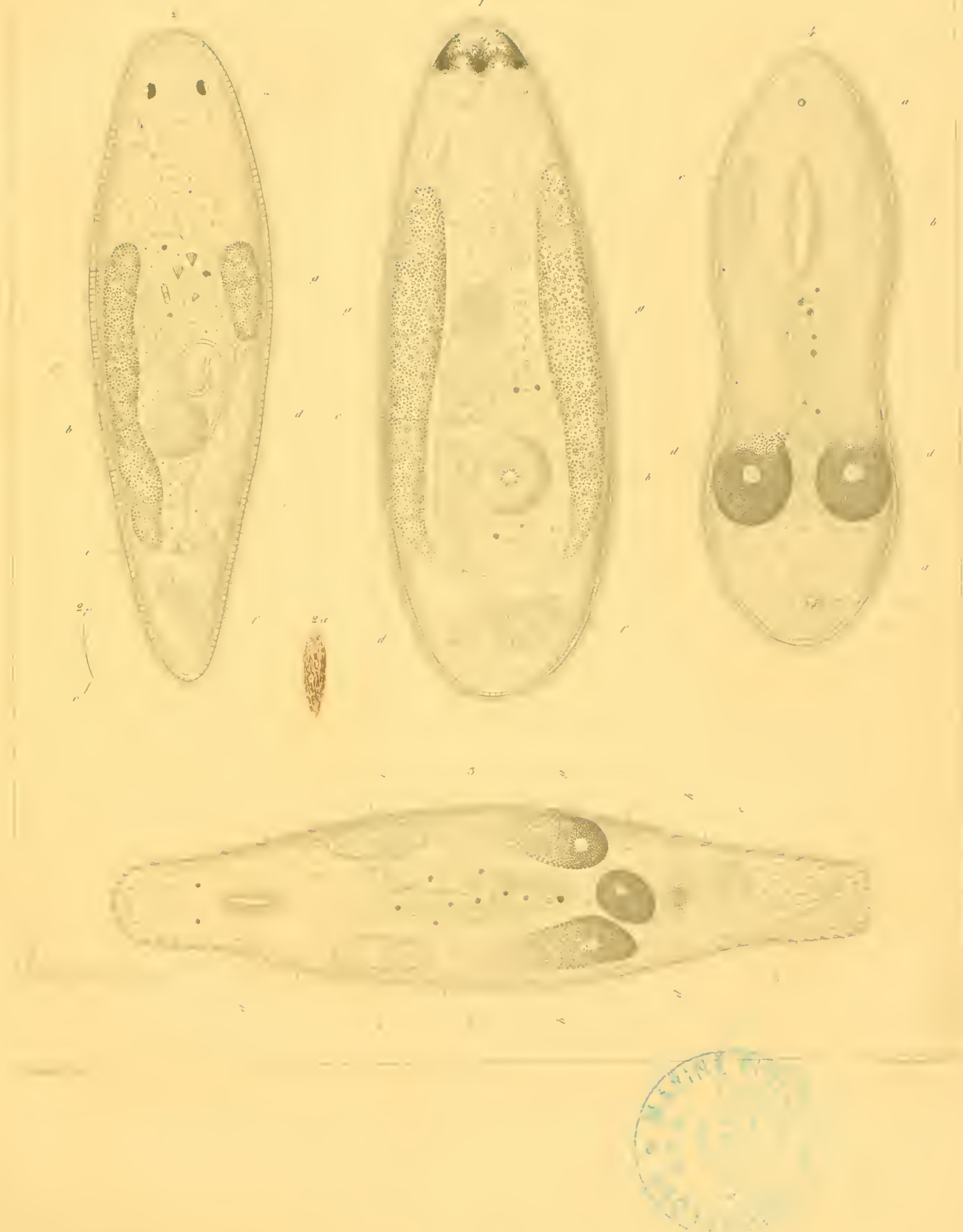
.

4.

\section{1}




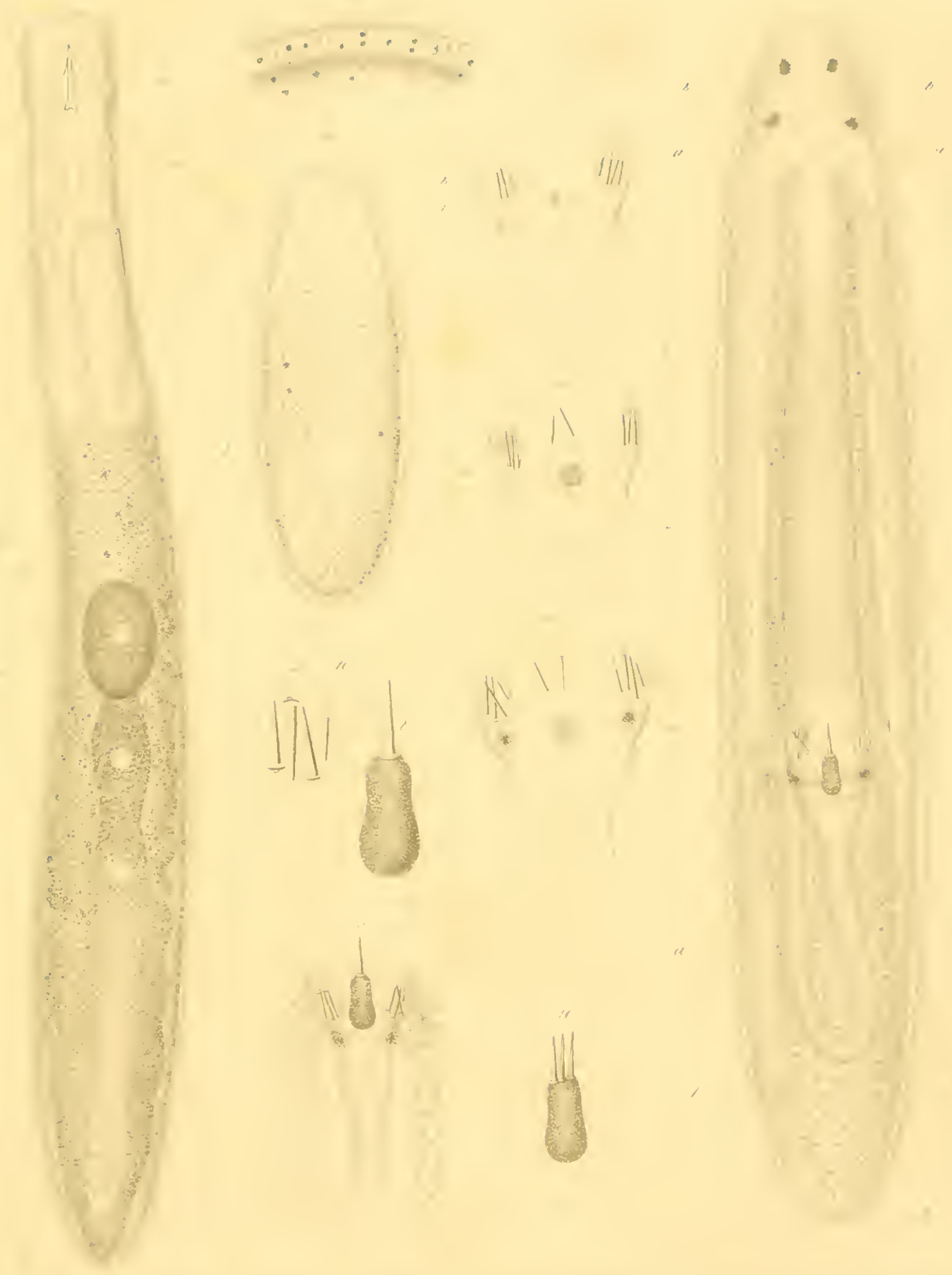







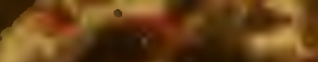 \\ $x=000$}

$69 \pi$

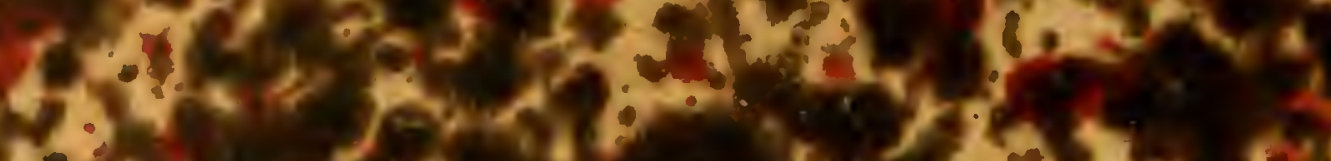

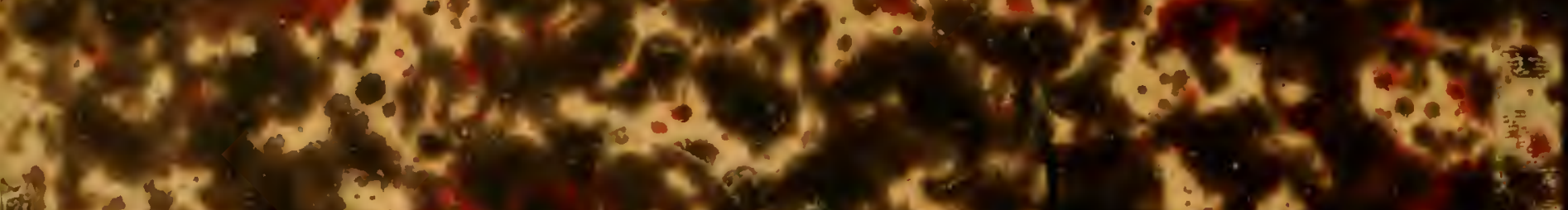

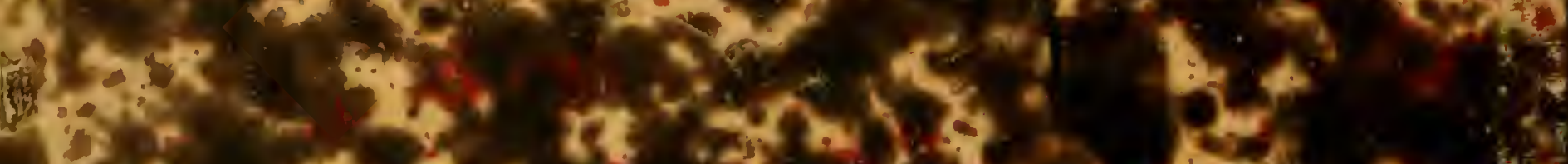
N: $-2 ; x<12$

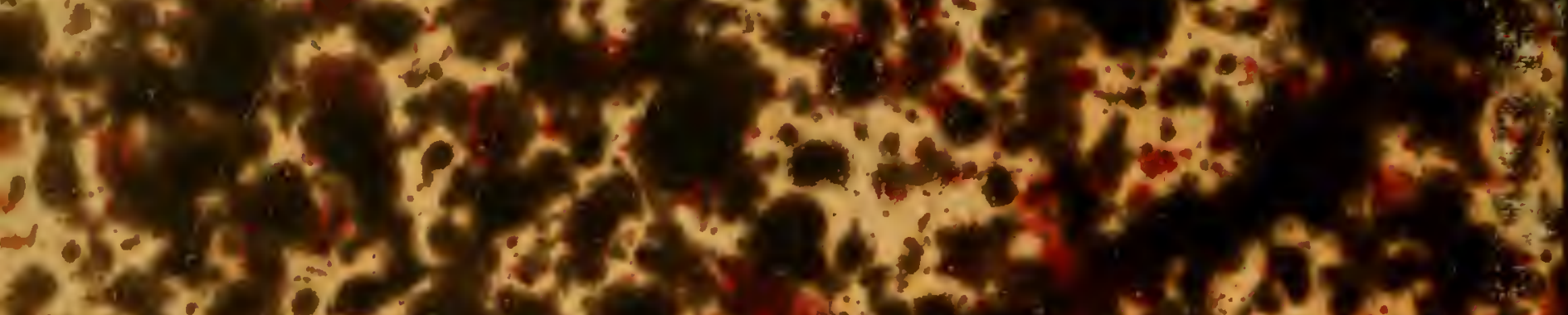

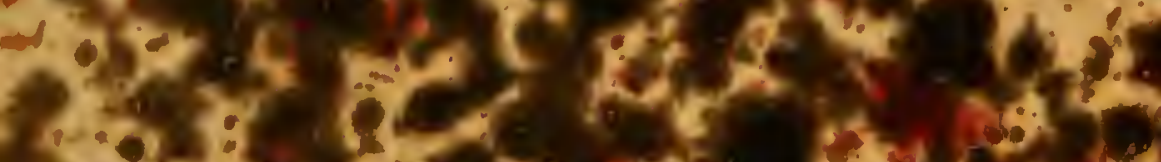

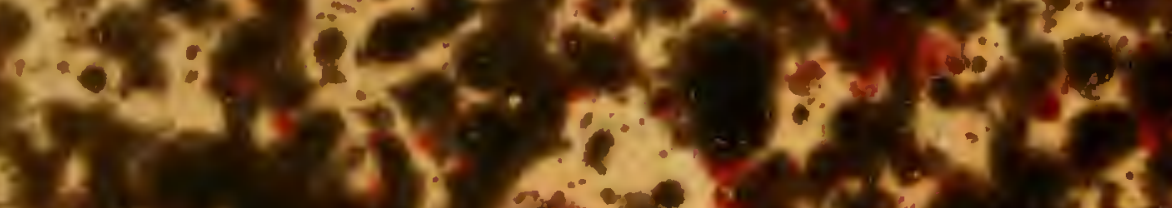

$\sin x$

18.

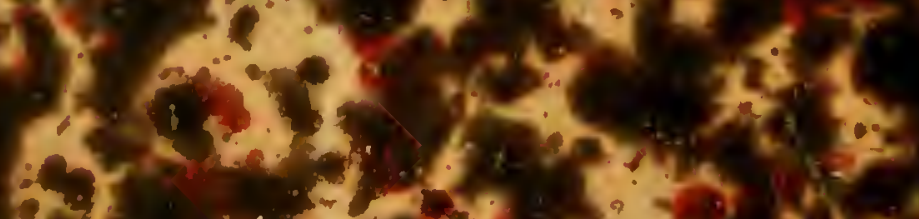

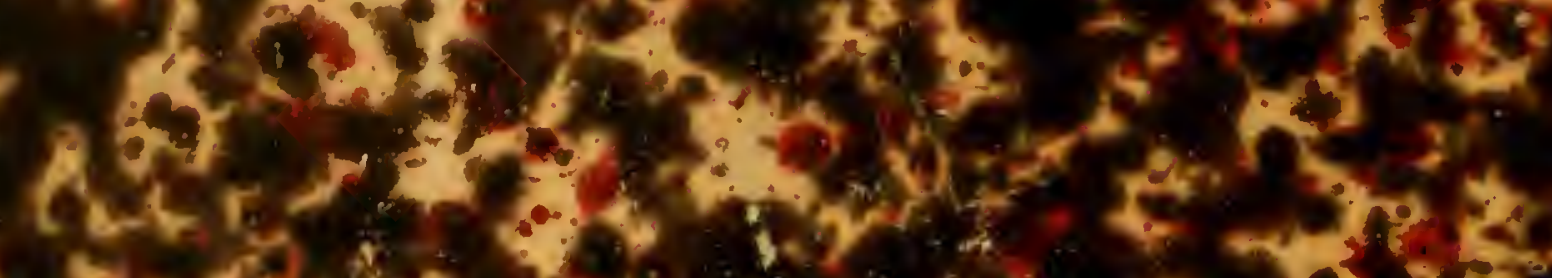
20.

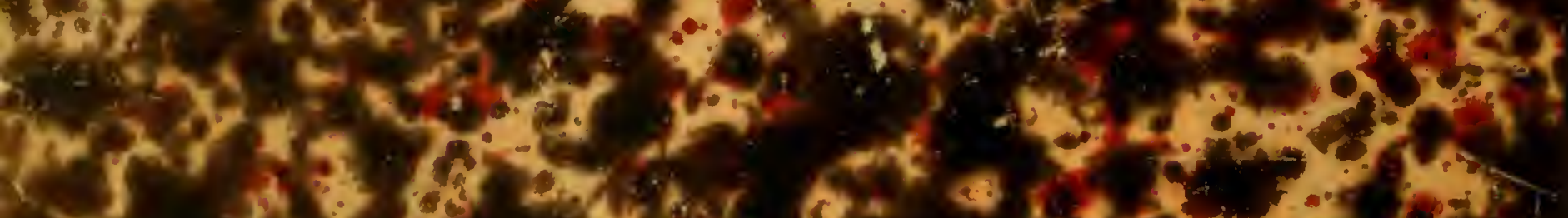
2 .

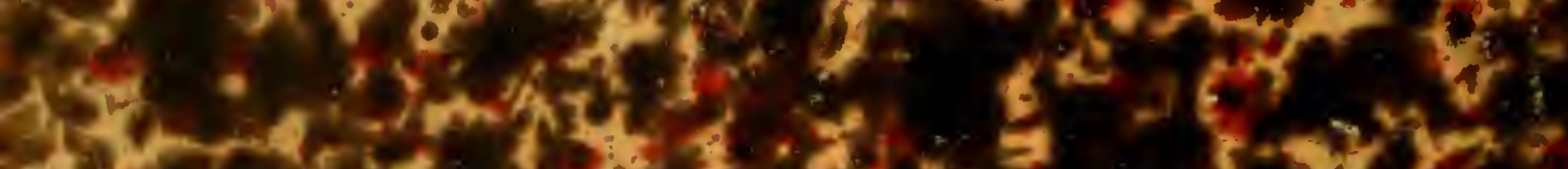

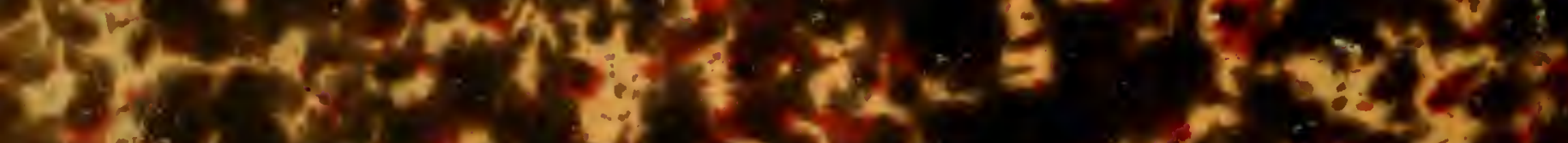

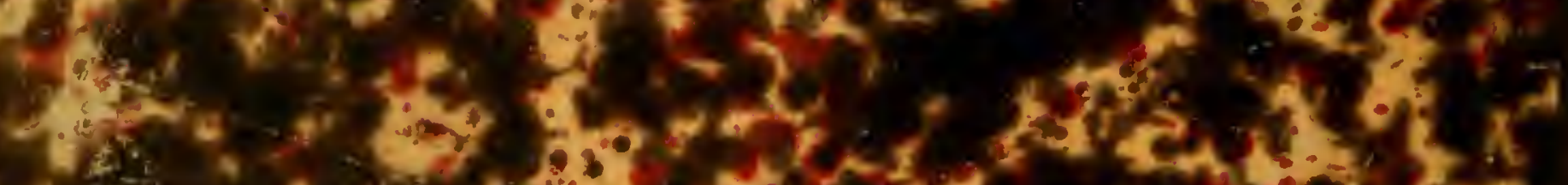

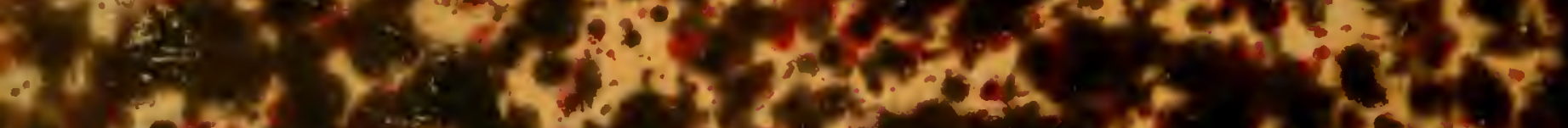

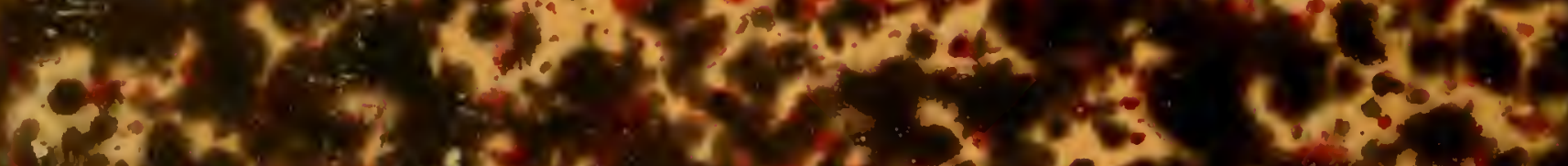

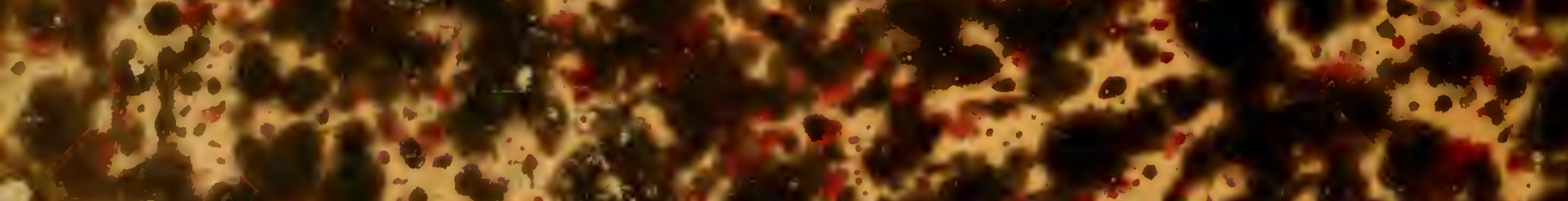

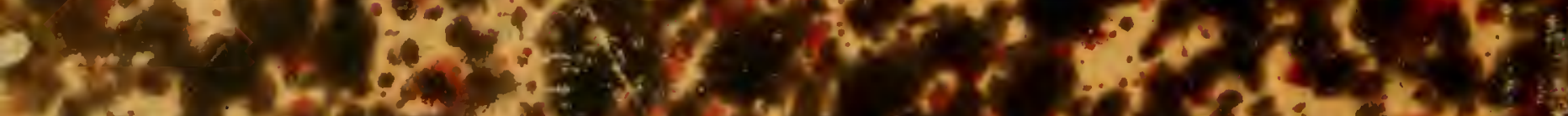

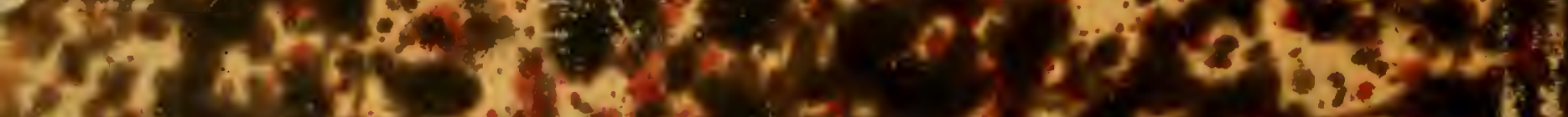

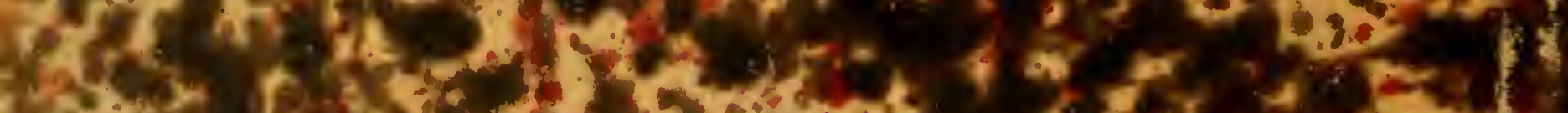

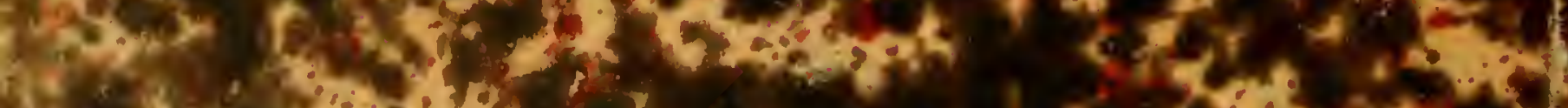

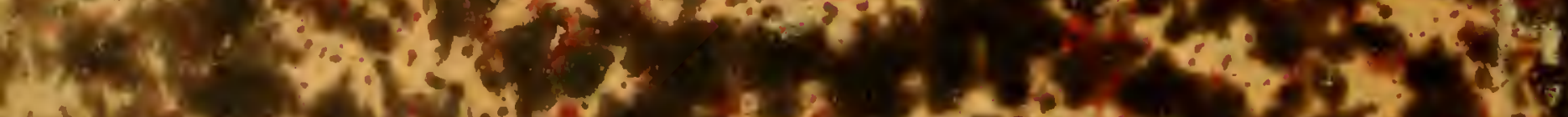

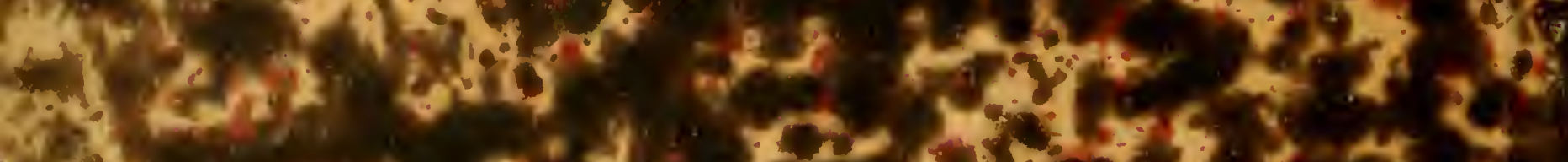

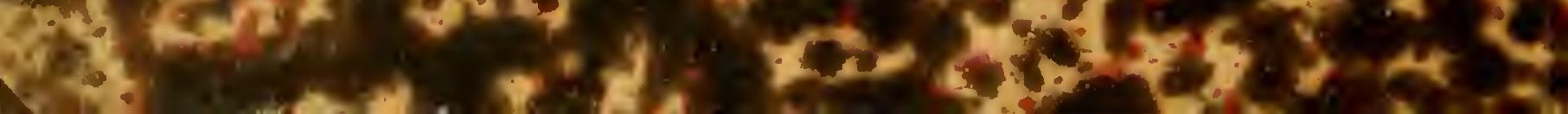

